Review

\title{
Database Survey of Anti-Inflammatory Plants in South America: A Review
}

\author{
Gedson Rodrigues de Morais Lima, Camila de Albuquerque Montenegro, \\ Cynthia Layse Ferreira de Almeida, Petrônio Filgueiras de Athayde-Filho, \\ José Maria Barbosa-Filho and Leônia Maria Batista *
}

Laboratory of Pharmaceutical Technology, Department of Pharmaceutical Sciences, Federal University of Paraiba, 58051-970, João Pessoa, PB, Brazil; E-Mails: gedson@1tf.ufpb.br (G.R.M.L.); camila_montenegro@ltf.ufpb.br (C.A.M.); cynthialayse@gmail.com (C.L.F.A.); athayde-filho@quimica.ufpb.br (P.F.A.-F.); jbarbosa@ltf.ufpb.br (J.M.B.-F.)

* Author to whom correspondence should be addressed; E-Mail: leoniab@uol.com.br; Tel.: +55-83-32167003; Fax: +55-83-32167502.

Received: 1 April 2011; in revised form: 8 April 2011 / Accepted: 11 April 2011 / Published: 21 April 2011

\begin{abstract}
Inflammation is a complex event linked to tissue damage whether by bacteria, physical trauma, chemical, heat or any other phenomenon. This physiological response is coordinated largely by a variety of chemical mediators that are released from the epithelium, the immunocytes and nerves of the lamina propria. However, if the factor that triggers the inflammation persists, the inflammation can become relentless, leading to an intensification of the lesion. The present work is a literature survey of plant extracts from the South American continent that have been reported to show anti-inflammatory activity. This review refers to 63 bacterial families of which the following stood out: Asteraceae, Fabaceae, Euphorbiaceae, Apocynaceae and Celastraceae, with their countries, parts used, types of extract used, model bioassays, organisms tested and their activity.
\end{abstract}

Keywords: anti-inflammatory activity; leukocytes; medicinal plants; natural products; South American; review 


\section{Introduction}

Inflammation is the response of body to injury and danger. It is the central communication network and regulatory process that senses and controls threat, damage, containment, and healing, which are all critical aspects in the maintenance of the integrity of an organism [1].

This process occurs as a defensive response, which induces profound physiological adaptions triggered in an attempt to limit tissue damage and remove the pathogenic insult. Such mechanisms involve a complex series of events including dilatation of arterioles, venules and capillaries with increased vascular permeability, exudation of fluids, including plasma proteins, and leukocyte migration into the inflammatory area [2].

In response to injury or infection, the specialized cells of the first line, leukocytes (neutrophils and eosinophils polymorphonuclear-PMNs) migrate to the damaged regions with the aim of neutralizing and eliminating these harmful stimuli [3]. The mechanism of inflammation is attributed, in part, to release of reactive oxygen species (ROS) from activated neutrophils and macrophages [4]. ROS propagate inflammation by stimulating release of cytokines, such as interleukin-1, tumor necrosis factor- $\alpha$, and interferon- $\gamma$, which stimulate recruitment of additional neutrophils and macrophages. Thus free radicals are important mediators that provoke or sustain inflammatory processes and, consequently, their neutralization by antioxidants and radical scavengers can attenuate inflammation $[5,6]$.

A complex network of mediators, including cytokines and lipids, produced by endothelial cells, epithelial cells and tissue infiltrating leukocytes, characterizes the early phases of inflammation [7].

The clinical features of inflammation were described some 2000 years ago listed as the cardinal signs of inflammation: rubor (redness), tumor (swelling), heat (hyperthermia) and pain [8].

The combined action of the molecules attracts and activates leukocytes to the reactive site, promotes angiogenesis and tissue remodeling [7]. If this sequence of steps is rigorously followed, the acute inflammation will resolve without causing excessive damage to tissue, returning to homeostasis [3].

However, there are several clinical conditions where inflammation becomes chronic with excessive production of macrophage-derived mediators may lead to collateral damage to normal cells, which results in diseases, including atherosclerosis, bowel disease, rheumatoid arthritis glomerulonephritis, and septic shock [9].

Therefore, the classical anti-inflammatory agents glucocorticoids and non-steroidal anti-inflammatory drugs (NSAIDs) can only alleviate symptoms without, however, altering the course of the disease [3].

The current anti-inflammatory therapy aims to control the cardinal signs of inflammation, antagonizing or blocking key pro-inflammatory mediators that are released at the beginning of an acute inflammatory response [3]. NSAIDs typically relieve inflammation and associated pain by inhibiting cyclooxygenase enzymes involved in the production of prostaglandins. These enzymes exist in two isoforms (COX-1 and COX-2) coded by distinct genes on different chromosomes [10]. Compounds that inhibit COX enzymes could therefore be considered to be potential anti-inflammatory drugs. However, many of the commonly used anti-inflammatory agents are becoming less acceptable due to serious adverse reactions such as gastric intolerance, bone marrow depression and water and salt retention, resulting from prolonged use [11].

Within this context, it is of fundamental importance to search for substances that can promote the resolution of inflammation, thus, homeostatic and modulatory, efficient and tolerated by the body [3]. 
Plants are an important source of biologically active natural products and are considered a promising avenue for the discovery of new drugs due to easy access and relatively low cost, since they naturally grow in relative abundance $[12,13]$. The development of standardized herbal medicines with proven efficacy and safety of use is an important source for increasing the access of people to medicines and to offer new therapeutic options [14].

So, can cite examples of plants with scientifically proven anti-inflammatory activity: Annona muricata, Glycine max, Orthosiphon stamineus, Caulerpa racemosa and Oenothera speciosa used in folk medicine [15-19].

Therefore, extracts or isolated compounds from natural products seems to be a promising strategy for developing anti-inflammatory drugs in search of a better therapeutic and quality of life for the patient [20].

In the course of our continuing search for bioactive natural products from plants, we have published reviews of extracts and compounds derived from plants with the following potential activities: inhibitors of mammary, uterine cervical and ovarian neoplasia [21-23]; inhibitors of HMG CoA reductase, angiotensina-converting enzyme and the enzyme acetylcholinesterase [24-26]; with central analgesic activity [27]; employed in prevention of osteoporosis [28]; for the treatment of Parkinson's disease [29]; anticonvulsant and anxiety disorders [30,31]; with antileishmanial [32]; giardicidal [33]; antileprotic [34]; hypoglycemic [35] and antiinflammatory activities [36,37]; for the treatment of malaria [38]; with antiulcer activity [39-41] and effects of plant extracts on HIV-1 Protease [42]. Our group has also reviewed the medicinal and poisonous plants of the Northeastern region of Brazil [43,44], among other review articles [45-54]. So in this work, we reviewed the literature related to anti-inflammatory activity of the plants from South American countries.

\section{Results and Discussion}

It was possible in this review to list 175 species of medicinal plants with anti-inflammatory activity. Those species are distributed in 63 families of which the following stood out: Asteraceae, Fabaceae, Euphorbiaceae, Apocynaceae and Celastraceae with 37, 17, 11, 6 and 6 species, respectively, studied so far (Table 1).

The effectiveness of the plant extracts was dependent on the type of extract used, the model of inflammation induction and the organism tested. Thus, it was possible to classify the extracts as strongly active, active, weakly active, inactive and equivocal.

Different species of Proustia genus have been frequently used as antiinflammatory and analgesic to treat gout and rheumatic illnesses, however, there is little information about their efficacy and acute toxicity [55]. This genus accumulates sesquiterpene $\alpha$-isocedrene derivatives that are typical for the subtribus Nassauviinae of the family Asteraceae [56], and a guaianolide $\beta$-D-glucopyranoside has been previously isolated from Proustia ilicifolia [57].

According to Delporte et al. (2005) [55] in the assays carried out per os crude methanol extract (GME), hexane extract (HE) and methanol extract (ME) exhibited the strongest analgesic activities similar to the reference drug (SN). In relation to the results obtained in per os anti-inflammatory studies, ME showed the strongest effect, and was similar to the reference drug (SN); HE did not present significant antiinflammatory activity. The antiinflammatory activity have been attributed the presence of compounds with a similar mechanism for both activities, as for example inhibition of the synthesis of prostaglandin $\mathrm{E}_{2}\left(\mathrm{PGE}_{2}\right)$. By the activation of the cyclo-oxygenase enzyme, the level of 
$\mathrm{PGE}_{2}$ increases markedly, and its production provokes inflammation and pain [58]. Therefore, we assume that some active metabolites of these extracts could inhibit cyclooxygenase activity.

For arachidonic acid (AA) and phorbol 12-myristate 13-acetate (TPA) induced oedema, GME showed significant effect only against AA assay and on the contrary, HE and ME presented important activities only against TPA and dichloromethane extract (DCE) was active in both AA and TPA models. The action's mechanism of the GME can be explained by inhibition of cyclooxygenase enzymes while the HE and ME may act by inhibiting the synthesis of leukotrienes. Since the DCE in addition to inhibiting the synthesis of leukotrienes may act by blocking production of $\mathrm{PGE}_{2}[59]$.

GME did not show acute toxicity per os up to the maxim dose of $2 \mathrm{~g} / \mathrm{kg}$ and the weight of the mice had a normal variation after the seven days of observation. Common side effects such as, mild diarrhea, loss of weight and depression were not recorded. It is important to carry out toxicological studies in other animal species in order to demonstrate its lack of toxicity [59].

Ageratum conyzoides (Asteraceae), known commonly as "mentrasto", has been used in Brazillian folk medicine to treat various ailments (metrorrhagia, fevers, dermatitis, inflammation, rheumatism, diarrhea and diuretics). A large number of pharmacological activities (anti-inflammatory, antipyretic, analgesic) have been attributed to the essential oil of Ageratum conyzoides [60]. The flowers and leaves are used in the form of an infusion for their analgesic and antiinflammatory properties. Literature data indicate its efficacy in alleviating pain caused by human arthritis [61] or induced experimentally [62].

The hydroalcoholic extract (HAE) of the leaves from A. conyzoides was active in both the on subacute (cotton pellet-induced granuloma) and chronic (formaldehyde-induced arthritis) models of inflammation in rats. The weights of cotton pellets were significantly reduced in (38\%) after treatment with crude extract of $A$. conyzoides $(250 \mathrm{mg} / \mathrm{kg}$, p. o.) and possibly this effect is related to inhibition of neutrophil migration. Exame macroscopic gastric mucosa did not reveal any tissue damage associated with treatment, which is a collateral effect of many antiinflammatory drugs, including aspirin and related compounds $[63,64]$, this result would be explained by an inhibition of the biosynthesis of prostanoids by cyclooxygenase [65].

Literature review reports indicate the presence of pyrrolizidine alkaloids in A. conyzoides plants $[66,67]$. These are known to be hepatotoxic, and to cause lung cancer and variety of other ailments [68]. There was investigated possible hematological and biochemical alteration in animal blood samples following after sub-acute and chronic treatment with the HAE of the plant. To evaluate liver function, serum glutamic oxaloacetic transaminase (SGOT) and serum glutamic pyruvic transaminase (SGPT) levels of plasma were measured. It was observed that during the sub-acute treatment, no significant alteration in serum levels of SGOT and SGPT, however during the chronic treatment with HAE $(500 \mathrm{mg} / \mathrm{kg}$ body wt.) the value of SGPT (108.5726.6 U/l) showed a statistically significant difference $(p<0,05)$ to control group (155.6739.6 U/l), reduced significantly [65].

Artemisia copa Phil. (Compositae), commonly known as "copa-copa", is a small and much branched bush with a height of 30-60 cm that grows in the northwest of Argentina and in the north of Chile. The plant is regularly sold in local markets and herb health stores and the infusion of the aerial parts are used in popular medicine as antitussive, digestive, for lowering fever, for pulmonary diseases, and hypertension [69]. The leaves, macerated in alcohol, are also used locally to rub on rheumatic pains [70]. 
Anti-inflammatory activity of ethanol and dichloromethane extracts were analyzed in models of carrageenan-induced paw edema in rats and the ear edema induced by 12 - $O$-tetradecanoylphorbol-13 acetate (TPA) and arachidonic acid (AA) in mice. Antiinflammatory activity was observed in both extracts that showed antiinflammatory activity in the TPA (88 and 54\%), and the ethanolic extract showed a $37 \%$ inhibition in AA test. The results suggested that A. copa was able to prevent the production of proinflammatory mediators specially those related with cyclooxygenase (CO) and Lipoxygenase (LO) pathway. A. copa has no analgesic effect on the central nervous system that would contribute to its peripheral analgesic effect [71].

Bauhinia tarapotensis Benth. (Leguminosae) is a small tree growing in Ecuador (South America), where it is commonly known as "pata de vaca". The plant leaves are traditionally used for their anti-inflammatory and decongestant properties [72], whereas the bark is employed as antidiarrhoeal remedy [73]. Previous study on the methanol extract of B. tarapotensis leaves revealed antioxidant and radical scavenger properties, due to the presence of different antioxidant principles, such as cyclohexenone, lignans, and phenylethanoids derivatives [74].

The topical anti-inflammatory activity was evaluated as inhibition of the croton oil-induced ear edema in mice [75]. Five extracts of the leaves significantly inhibited the croton oil-induced ear edema in mice, among which the chloroform extract was the most active. The main anti-inflammatory principles of $B$. tarapotensis leaves are triterpenic acids of ursane and oleanane series. The antiphlogistic activity of mixtures constituted of two ursane and oleanane isomers with different hydroxylation pattern, in the ratio $2: 1$, is comparable to that of indomethacin [76].

Croton pullei (Euphorbiaceae) is a liana that grows above other trees, distributed in tropical areas with vast distribution in the Amazon forest [77]. In the folk medicine, several plants of the Croton genus have been used with therapeutic purposes in pathologies that involve painful and inflammatory diseases which justify this work [78].

Anti-inflammatory activity was tested in two models that assess inflammatory processes such as edema and leukocyte migration. The crude methanol extract significantly reduced by $72 \%$ the ear edema by croton-oil induced, as also was a dose-dependent reduction of leukocyte migration to the peritoneum after induction with carrageenan. The mechanism of action has not yet elucidated [78].

Maytenus ilicifolia Mart. ex. Reiss (Celastraceae), popularly called "espinheira-santa" due to the appearance of its leaves and its therapeutic properties, is utilized in popular medicine in cases of inflammation and gastric ulcer [79-81].

This study evaluated the anti-inflammatory activity, antinociceptive and antiulcer of ethyl acetate and hexane extracts of Maytenus ilicifolia [82].

In the model of paw edema induced by carrageenan was observed that there was no significant difference in inflammatory response between indomethacin and the extracts evaluated. The result of hexane extract showed the anti-inflammatory potential of terpenes whereas for ethylacetate extract the anti-inflammatory response has been attributed to flavonoids, which act by reducing the formation of pro-inflammatory mediators as prostaglandins, leukotrienes, reactive oxygen species and nitric oxide [82]. According to Oliveira et al. (1991) [83], both acute and chronic administration of this species did not induce any apparent toxicity. 
Table 1. Extracts of plants with anti-inflammatory activity studied in South America.

\begin{tabular}{|c|c|c|c|c|c|c|c|}
\hline Family and Botanical name & Country & Part used & Type of extract & Model assay/way of route & $\begin{array}{l}\text { Organism } \\
\text { tested }\end{array}$ & Activity & Ref. \\
\hline \multicolumn{8}{|l|}{ Acanthaceae } \\
\hline \multirow[t]{2}{*}{$\begin{array}{l}\text { Justicia pectoralis var. } \\
\text { stenophylla }\end{array}$} & Brazil & Dried leaf & $\begin{array}{l}\text { Hydro-alcoholic } \\
\text { ext }\end{array}$ & $\begin{array}{l}\text { Carrageenan-induced pedal } \\
\text { edema/Intragastric }\end{array}$ & Rat & Active & [84] \\
\hline & Brazil & Dried leaf & Hexane-acetone & $\begin{array}{l}\text { Dextran-induced pedal } \\
\text { edema/Intragastric }\end{array}$ & Rat & Inactive & [84] \\
\hline \multicolumn{8}{|l|}{ Agavaceae } \\
\hline Cordyline dracaenoides & Brazil & Dried rhizome & $\begin{array}{l}\text { EtOH- } \mathrm{H}_{2} \mathrm{O}(50 \%) \\
\text { ext }\end{array}$ & $\begin{array}{l}\text { Carrageenan-induced pedal } \\
\text { edema/IP }\end{array}$ & Rat & Active & {$[85]$} \\
\hline \multicolumn{8}{|l|}{ Alismataceae } \\
\hline \multirow[t]{2}{*}{ Echinodorus grandiflorus } & Brazil & Dried rhizome & $\mathrm{MeOH}$ ext & $\begin{array}{l}\text { Carrageenan-induced pedal } \\
\text { edema/Intragastric }\end{array}$ & Mouse & Active & [86] \\
\hline & Brazil & Dried rhizome & $\mathrm{MeOH}$ ext & $\begin{array}{l}\text { Carrageenan-induced pedal } \\
\text { edema/Intragastric }\end{array}$ & Rat & Active & {$[86]$} \\
\hline \multicolumn{8}{|l|}{ Amaranthaceae } \\
\hline Alternanthera brasiliana & Brazil & Dried leaf & $\mathrm{H}_{2} \mathrm{O}$ ext & $\begin{array}{l}\text { Carrageenan-induced pedal } \\
\text { edema/Route not given }\end{array}$ & Rat & Inactive & [87] \\
\hline \multirow[t]{2}{*}{ Pfaffia glomerata } & Brazil & Dried root & $\mathrm{EtOH}(60 \%)$ ext & $\begin{array}{l}\text { Acetic acid-induced pedal } \\
\text { edema/Intragastric }\end{array}$ & Mouse & Active & [88] \\
\hline & Brazil & Dried root & $\mathrm{EtOH}(60 \%)$ ext & $\begin{array}{l}\text { Acetic acid-induced pedal } \\
\text { edema/IP }\end{array}$ & Mouse & Active & {$[88]$} \\
\hline \multirow[t]{4}{*}{ Pfaffia iresinoides } & Brazil & Dried root & Saponin fraction & $\begin{array}{l}\text { Carrageenan-induced } \\
\text { pleurisy/Intragastric }\end{array}$ & Rat & Active & [89] \\
\hline & Brazil & Dried root & $\mathrm{H}_{2} \mathrm{O}$ ext & $\begin{array}{l}\text { Carrageenan-induced pleurisy } \\
\text { /Intragastric }\end{array}$ & Rat & Active & [89] \\
\hline & Brazil & Dried root & $\mathrm{H}_{2} \mathrm{O}$ ext & $\begin{array}{l}\text { Cotton pellet granuloma } \\
\text { /Intragastric }\end{array}$ & Rat & Inactive & [89] \\
\hline & Brazil & Dried root & Saponin fraction & $\begin{array}{l}\text { Cotton pellet granuloma } \\
\text { /Intragastric }\end{array}$ & Rat & Active & [89] \\
\hline
\end{tabular}


Table 1. Cont.

\begin{tabular}{|c|c|c|c|c|c|c|c|}
\hline \multirow[t]{2}{*}{ Pfaffia paniculata } & Brazil & Dried root & $\mathrm{EtOH}(20 \%)$ ext & $\begin{array}{l}\text { Carrageenan-induced pedal } \\
\text { edema/IP }\end{array}$ & Mouse & Active & [90] \\
\hline & Brazil & Dried root & $\mathrm{EtOH}(60 \%)$ ext & $\begin{array}{l}\text { Carrageenan-induced pedal } \\
\text { edema/IP }\end{array}$ & Rat & Active & [91] \\
\hline Pfaffia stenophylla & Brazil & Dried root & $\mathrm{EtOH}(20 \%)$ ext & $\begin{array}{l}\text { Carrageenan-induced pedal } \\
\text { edema/IP }\end{array}$ & Mouse & Active & [90] \\
\hline \multicolumn{8}{|l|}{ Anacardiaceae } \\
\hline \multirow[t]{7}{*}{ Anacardium occidentale } & Brazil & Dried bark & Shell & $\begin{array}{l}\text { Carrageenan-induced pedal } \\
\text { edema/Gastric intubation }\end{array}$ & Rat & Active & [92] \\
\hline & Brazil & Dried bark & Shell & $\begin{array}{l}\text { Dextran-induced pedal } \\
\text { edema/Gastric intubation }\end{array}$ & Rat & Inactive & [92] \\
\hline & Brazil & Dried bark & Shell & Cotton pellet granuloma/IP & Rat & Active & [92] \\
\hline & Brazil & Dried bark & Shell & $\begin{array}{l}\text { Dextran-induced pedal } \\
\text { edema/IP }\end{array}$ & Rat & Active & [92] \\
\hline & Brazil & Dried bark & Shell & $\begin{array}{l}\text { Carrageenan-induced pedal } \\
\text { edema/IP }\end{array}$ & Rat & Active & [92] \\
\hline & Brazil & Dried bark & $\begin{array}{l}\text { Isopropanol- } \mathrm{H}_{2} \mathrm{O} \\
\text { (1:1) ext }\end{array}$ & $\begin{array}{l}\text { Carrageenan-induced pedal } \\
\text { edema/IP }\end{array}$ & Rat & Active & [92] \\
\hline & Brazil & Dried bark & Shell & $\begin{array}{l}\text { Number of leukocytes in } \\
\text { exudate/IP }\end{array}$ & Rat & Active & [92] \\
\hline \multirow[t]{4}{*}{ Astronium urundeuva } & Brazil & Stembark & EtoAc ext & $\begin{array}{l}\text { Carrageenan-induced pedal } \\
\text { edema/Intragastric }\end{array}$ & Mouse & Active & [93] \\
\hline & Brazil & Dried bark & Tannin fraction & $\begin{array}{l}\text { Dextran-induced pedal } \\
\text { edema/IP }\end{array}$ & Rat & Active & [93] \\
\hline & Brazil & Dried bark & Tannin fraction & $\begin{array}{l}\text { Carrageenan-induced pedal } \\
\text { edema/IP }\end{array}$ & Mouse & Active & [93] \\
\hline & Brazil & Dried bark & Tannin fraction & $\begin{array}{l}\text { Cyclophosphamide-induced } \\
\text { hemorrhagic cystitis/IP }\end{array}$ & Rat & Active & [93] \\
\hline
\end{tabular}


Table 1. Cont.

\begin{tabular}{|c|c|c|c|c|c|c|c|}
\hline & Brazil & Stembark & EtoAc ext & $\begin{array}{l}\text { Carrageenan-induced pedal } \\
\text { edema/IP }\end{array}$ & Mouse & Active & [93] \\
\hline Spondias mombin & Venezuela & Dried bark & $\mathrm{EtOH}(100 \%)$ ext & $\begin{array}{l}\text { Carrageenan-induced pedal } \\
\text { edema/Intragastric }\end{array}$ & Rat & Active & [94] \\
\hline \multicolumn{8}{|l|}{ Apocynaceae } \\
\hline \multirow[t]{4}{*}{ Bonafousia longituba } & Ecuador & $\begin{array}{l}\text { Dried part not } \\
\text { specified }\end{array}$ & $\mathrm{EtOH}(100 \%)$ ext & $\begin{array}{l}\text { Carrageenan-induced pedal } \\
\text { edema/Intragastric }\end{array}$ & Mouse & Active & [95] \\
\hline & Ecuador & $\begin{array}{l}\text { Dried entire } \\
\text { plant }\end{array}$ & $\mathrm{EtOH}(100 \%)$ ext & $\begin{array}{l}\text { Carrageenan-induced pedal } \\
\text { edema/Intragastric }\end{array}$ & Mouse & $\begin{array}{l}\text { Weak } \\
\text { activity }\end{array}$ & [95] \\
\hline & Ecuador & $\begin{array}{l}\text { Dried part not } \\
\text { specified }\end{array}$ & $\mathrm{CH}_{2} \mathrm{Cl}_{2}$ ext & $\begin{array}{l}\text { Carrageenan-induced pedal } \\
\text { edema/Intragastric }\end{array}$ & Mouse & Active & [96] \\
\hline & Ecuador & $\begin{array}{l}\text { Dried part not } \\
\text { specified }\end{array}$ & $\mathrm{CH}_{2} \mathrm{Cl}_{2}$ ext & $\begin{array}{l}\text { Carrageenan-induced pedal } \\
\text { edema/Intragastric }\end{array}$ & Mouse & Active & [96] \\
\hline \multirow[t]{3}{*}{ Ervatamia coronaria } & Brazil & Dried stem & $\mathrm{EtOH}(95 \%)$ ext & $\begin{array}{l}\text { Carrageenan-induced pedal } \\
\text { edema/IP }\end{array}$ & Rat & Active & [97] \\
\hline & Brazil & Dried stem & $\mathrm{EtOH}(95 \%)$ ext & $\begin{array}{l}\text { Carrageenan-induced pedal } \\
\text { edema/Intragastric }\end{array}$ & Rat & Active & [97] \\
\hline & Brazil & Dried stem & $\mathrm{H}_{2} \mathrm{O}$ ext & $\begin{array}{l}\text { Carrageenan-induced pedal } \\
\text { edema/IP }\end{array}$ & Rat & Active & [97] \\
\hline Himatanthus sucuuba & Brazil & $\begin{array}{l}\text { Latex (unspec } \\
\text { part) }\end{array}$ & Hexane ext & $\begin{array}{l}\text { Carrageenan-induced pedal } \\
\text { edema/Intragastric }\end{array}$ & Rat & Active & [98] \\
\hline \multirow[t]{4}{*}{ Mandevilla velutina } & Brazil & Dried rhizome & $\begin{array}{l}\text { Aqueous- } \\
\text { alcoholic ext }\end{array}$ & $\begin{array}{l}\text { Carrageenan-induced pedal } \\
\text { edema/Intragastric }\end{array}$ & Mouse & Active & [99] \\
\hline & Brazil & Dried rhizome & $\begin{array}{l}\text { Aqueous- } \\
\text { alcoholic ext }\end{array}$ & $\begin{array}{l}\text { Carrageenan-induced pedal } \\
\text { edema/Intragastric }\end{array}$ & Rat & Active & [99] \\
\hline & Brazil & Dried rhizome & $\begin{array}{l}\text { Aqueous- } \\
\text { alcoholic ext }\end{array}$ & $\begin{array}{l}\text { 5-HT-induced pedal } \\
\text { edema/Intragastric }\end{array}$ & Rat & Inactive & [99] \\
\hline & Brazil & Dried rhizome & $\begin{array}{l}\text { Aqueous- } \\
\text { alcoholic ext }\end{array}$ & $\begin{array}{l}\text { Carrageenan-induced pedal } \\
\text { edema/IP }\end{array}$ & Rat & Active & [99] \\
\hline
\end{tabular}


Table 1. Cont.

\begin{tabular}{|c|c|c|c|c|c|c|c|}
\hline & Brazil & Dried rhizome & $\begin{array}{l}\text { Aqueous- } \\
\text { alcoholic ext }\end{array}$ & $\begin{array}{l}\text { Snake venom-induced pedal } \\
\text { edema/Intragastric }\end{array}$ & Rat & Inactive & [99] \\
\hline & Brazil & Dried rhizome & $\begin{array}{l}\text { Aqueous- } \\
\text { alcoholic ext }\end{array}$ & $\begin{array}{l}\text { Platelet aggregating factor- } \\
\text { acether induced pedal } \\
\text { edema/Intragastric }\end{array}$ & Rat & Inactive & [99] \\
\hline & Brazil & $\begin{array}{l}\text { Dried entire } \\
\text { plant }\end{array}$ & $\mathrm{EtOH}(95 \%)$ ext & $\begin{array}{l}\text { Arachidonic-acid induced ear } \\
\text { edema/Intragastric }\end{array}$ & Mouse & Active & [100] \\
\hline & Brazil & $\begin{array}{l}\text { Frozen } \\
\text { rhizome }\end{array}$ & $\begin{array}{l}\mathrm{EtOH} \mathrm{H}_{2} \mathrm{O}(50 \%) \\
\text { ext }\end{array}$ & $\begin{array}{l}\text { Bradykinin-induced pedal } \\
\text { edema/Intragastric }\end{array}$ & Rat & Active & [101] \\
\hline & Brazil & $\begin{array}{l}\text { Frozen } \\
\text { rhizome }\end{array}$ & $\begin{array}{l}\mathrm{EtOH} \mathrm{H}_{2} \mathrm{O}(50 \%) \\
\text { ext }\end{array}$ & $\begin{array}{l}\text { Carrageenan-induced pedal } \\
\text { edema/5-HT-induced pedal } \\
\text { edema/Intragastric }\end{array}$ & Rat & Active & [101] \\
\hline & Brazil & $\begin{array}{l}\text { Frozen } \\
\text { rhizome }\end{array}$ & $\begin{array}{l}\mathrm{EtOH} \mathrm{H}_{2} \mathrm{O}(50 \%) \\
\text { ext }\end{array}$ & $\begin{array}{l}\text { Dextran-induced pedal } \\
\text { edema/Intragastric }\end{array}$ & Rat & Active & [101] \\
\hline & Brazil & $\begin{array}{l}\text { Frozen } \\
\text { rhizome }\end{array}$ & $\begin{array}{l}\mathrm{EtOH} \mathrm{H}_{2} \mathrm{O}(50 \%) \\
\text { ext }\end{array}$ & $\begin{array}{l}\text { Carrageenan-induced pedal } \\
\text { edema/IP }\end{array}$ & Rat & Active & [101] \\
\hline & Brazil & $\begin{array}{l}\text { Frozen } \\
\text { rhizome }\end{array}$ & $\begin{array}{l}\text { EtOH } \mathrm{H}_{2} \mathrm{O}(50 \%) \\
\text { ext }\end{array}$ & $\begin{array}{l}\text { Cellulose sulfate induced rat } \\
\text { paw edema/Intragastric }\end{array}$ & Rat & Active & [101] \\
\hline & Brazil & $\begin{array}{l}\text { Frozen } \\
\text { rhizome }\end{array}$ & $\begin{array}{l}\mathrm{EtOH} \mathrm{H}_{2} \mathrm{O}(50 \%) \\
\text { ext }\end{array}$ & $\begin{array}{l}\text { Paltelet aggretating factor- } \\
\text { acether induced rat paw } \\
\text { edema/Intragastric }\end{array}$ & Rat & Active & [101] \\
\hline & Brazil & $\begin{array}{l}\text { Frozen } \\
\text { rhizome }\end{array}$ & $\begin{array}{l}\mathrm{EtOH} \mathrm{H}_{2} \mathrm{O}(50 \%) \\
\text { ext }\end{array}$ & $\begin{array}{l}\text { Zymosan indued rat paw } \\
\text { edema/Intragastric }\end{array}$ & Rat & Active & [101] \\
\hline & Brazil & $\begin{array}{l}\text { Frozen } \\
\text { rhizome }\end{array}$ & $\begin{array}{l}\mathrm{EtOH} \mathrm{H}_{2} \mathrm{O}(50 \%) \\
\text { ext }\end{array}$ & $\begin{array}{l}\text { Bothrops jararaca induced rat } \\
\text { paw edema/Intragastric }\end{array}$ & Rat & Inactive & [101] \\
\hline $\begin{array}{l}\text { Peschiera australis var. } \\
\text { australis }\end{array}$ & Brazil & Dried leaf & EtOH $(100 \%)$ ext & $\begin{array}{l}\text { Carrageenan-induced paw } \\
\text { edema/IP }\end{array}$ & Rat & Active & [102] \\
\hline
\end{tabular}


Table 1. Cont

\begin{tabular}{|c|c|c|c|c|c|c|c|}
\hline & Brazil & Dried leaf & $\mathrm{H}_{2} \mathrm{O}$ ext & $\begin{array}{l}\text { Carrageenan-induced paw } \\
\text { edema/IP }\end{array}$ & Rat & Active & {$[102]$} \\
\hline Peschiera vanheurckii & Peru & $\begin{array}{l}\text { Dried } \\
\text { stembark }\end{array}$ & EtOH $(100 \%)$ ext & $\begin{array}{l}\text { EPP-induced rat ear } \\
\text { oedema/External }\end{array}$ & Rat & Active & [103] \\
\hline $\begin{array}{l}\text { Araliaceae } \\
\text { Hedera helix } \\
\text { Arecaceae }\end{array}$ & Uruguay & Dried leaf & EtOH $(95 \%)$ ext & $* * /$ Oral & Human adult & Active & [104] \\
\hline \multirow[t]{3}{*}{ Orbignya phalerata } & Brazil & Dried fruit & $\mathrm{CHCl}_{3}$ ext & $\begin{array}{l}\text { Cotton pellet } \\
\text { granuloma/Intragastric }\end{array}$ & Rat & Active & [105] \\
\hline & Brazil & Dried fruit & $\mathrm{CHCl}_{3}$ ext & $\begin{array}{l}\text { Carrageenan-induced pedal } \\
\text { edema/Intragastric }\end{array}$ & Rat & Active & [105] \\
\hline & Brazil & Dried fruit & $\mathrm{CHCl}_{3}$ ext & $\begin{array}{l}\text { Carrageenan-induced pedal } \\
\text { edema/IP }\end{array}$ & Rat & Active & [105] \\
\hline \multicolumn{8}{|l|}{ Aristolochiaceae } \\
\hline \multirow[t]{6}{*}{ Aristolochia triangularis } & Argentina & Dried root & $\mathrm{MeOH}$ ext & $\begin{array}{l}\text { Croton oil-induced } \\
\text { edema/External }\end{array}$ & Mouse & Active & [106] \\
\hline & Argentina & Dried root & $\mathrm{CH}_{2} \mathrm{Cl}_{2}$ ext & $\begin{array}{l}\text { Croton oil-induced } \\
\text { edema/External }\end{array}$ & Mouse & Active & [106] \\
\hline & Argentina & Dried root & $\mathrm{H}_{2} \mathrm{O}$ ext & $\begin{array}{l}\text { Croton oil-induced } \\
\text { edema/External }\end{array}$ & Mouse & Active & [106] \\
\hline & Argentina & Dried root & $\mathrm{H}_{2} \mathrm{O}$ ext & $\begin{array}{l}\text { Carrageenan-induced pedal } \\
\text { edema/IP }\end{array}$ & Mouse & Active & [106] \\
\hline & Argentina & Dried root & $\mathrm{CH}_{2} \mathrm{Cl}_{2}$ ext & $\begin{array}{l}\text { Carrageenan-induced pedal } \\
\text { edema/IP }\end{array}$ & Mouse & Active & [106] \\
\hline & Argentina & Dried root & $\mathrm{MeOH}$ ext & $\begin{array}{l}\text { Carrageenan-induced pedal } \\
\text { edema/IP }\end{array}$ & Mouse & Inactive & [106] \\
\hline \multicolumn{8}{|l|}{ Asclepiadaceae } \\
\hline Marsdenia cundurango & Ecuador & $\begin{array}{l}\text { Part not } \\
\text { specified }\end{array}$ & $\mathrm{CH}_{2} \mathrm{Cl}_{2}$ ext & $\begin{array}{l}\text { Carrageenan-induced pedal } \\
\text { edema/Intragastric }\end{array}$ & Mouse & Active & [96] \\
\hline
\end{tabular}


Table 1. Cont

\begin{tabular}{|c|c|c|c|c|c|c|c|}
\hline & Ecuador & $\begin{array}{l}\text { Dried entire } \\
\text { plant }\end{array}$ & EtOH $(100 \%)$ ext & $\begin{array}{l}\text { Carrageenan-induced pedal } \\
\text { edema/Intragastric }\end{array}$ & Mouse & Active & [95] \\
\hline \multicolumn{8}{|l|}{ Asteraceae } \\
\hline \multirow[t]{6}{*}{ Achyrocline satureioides } & Brazil & $\begin{array}{l}\text { Dried } \\
\text { inflorescence }\end{array}$ & $\mathrm{H}_{2} \mathrm{O}$ ext & $\begin{array}{l}\text { Carrageenan-induced pedal } \\
\text { edema/IP }\end{array}$ & Rat & Active & [107] \\
\hline & Brazil & $\begin{array}{l}\text { Dried } \\
\text { inflorescence }\end{array}$ & $\mathrm{EtOH}(95 \%)$ ext & $\begin{array}{l}\text { Carrageenan-induced pedal } \\
\text { edema/IP }\end{array}$ & Rat & Active & [107] \\
\hline & Brazil & $\begin{array}{l}\text { Dried } \\
\text { inflorescence }\end{array}$ & Hot $\mathrm{H}_{2} \mathrm{O}$ ext & $\begin{array}{l}\text { Carrageenan-induced pedal } \\
\text { edema/IP }\end{array}$ & Rat & Active & [107] \\
\hline & Brazil & $\begin{array}{l}\text { Dried } \\
\text { inflorescence }\end{array}$ & EtOH $(95 \%)$ ext & $\begin{array}{l}\text { Croton oil ear edema } \\
\text { test/External }\end{array}$ & Mouse & Active & [107] \\
\hline & Brazil & $\begin{array}{l}\text { Dried } \\
\text { inflorescence }\end{array}$ & $\mathrm{H}_{2} \mathrm{O}$ ext & $\begin{array}{l}\text { Croton oil ear edema } \\
\text { test/External }\end{array}$ & Mouse & Active & [107] \\
\hline & Brazil & $\begin{array}{l}\text { Dried } \\
\text { inflorescence }\end{array}$ & Hot $\mathrm{H}_{2} \mathrm{O}$ ext & $\begin{array}{l}\text { Croton oil ear edema } \\
\text { test/External }\end{array}$ & Mouse & Active & [107] \\
\hline \multirow[t]{6}{*}{ Ageratum conyzoides } & Brazil & Dried leaf & $\mathrm{EtOH}(70 \%)$ ext & $\begin{array}{l}\text { Formalin-induced pedal } \\
\text { edema/Intragastric }\end{array}$ & Rat & Active & [62] \\
\hline & Brazil & Dried leaf & $\mathrm{EtOH}(70 \%)$ ext & $\begin{array}{l}\text { Cotton pellet } \\
\text { granuloma/Intragastric }\end{array}$ & Rat & Active & [62] \\
\hline & Brazil & Dried leaf & $\mathrm{EtOH}(70 \%)$ ext & $\begin{array}{l}\text { Carrageenan-induced pedal } \\
\text { edema/SC }\end{array}$ & Rat & Active & [62] \\
\hline & Brazil & Dried leaf & $\begin{array}{l}\text { Hydro-alcoholic } \\
\text { ext }\end{array}$ & $\begin{array}{l}\text { Formalin-induced pedal } \\
\text { edema/Intragastric }\end{array}$ & Rat & Active & [65] \\
\hline & Brazil & Dried leaf & $\begin{array}{l}\text { Hydro-alcoholic } \\
\text { ext }\end{array}$ & $\begin{array}{l}\text { Cotton pellet } \\
\text { granuloma/Intragastric }\end{array}$ & Rat & Active & [65] \\
\hline & Brazil & Dried leaf & EtOH $(70 \%)$ ext & $\begin{array}{l}\text { Yeast-induced inflammation } \\
\text { of the paw/IP }\end{array}$ & Rat & Active & [108] \\
\hline Ambrosia tenuifolia & Argentina & $\begin{array}{l}\text { Dried aerial } \\
\text { parts }\end{array}$ & $\mathrm{CH}_{2} \mathrm{Cl}_{2}$ ext & $\begin{array}{l}\text { Croton oil-induced } \\
\text { edema/External }\end{array}$ & Mouse & Active & [106] \\
\hline
\end{tabular}


Table 1. Cont.

\begin{tabular}{|c|c|c|c|c|c|c|c|}
\hline & Argentina & $\begin{array}{l}\text { Dried aerial } \\
\text { parts }\end{array}$ & $\mathrm{MeOH}$ ext & $\begin{array}{l}\text { Croton oil-induced } \\
\text { edema/External }\end{array}$ & Mouse & Active & [106] \\
\hline & Argentina & $\begin{array}{l}\text { Dried aerial } \\
\text { parts }\end{array}$ & $\mathrm{H}_{2} \mathrm{O}$ ext & $\begin{array}{l}\text { Croton oil-induced } \\
\text { edema/External }\end{array}$ & Mouse & Active & [106] \\
\hline & Argentina & $\begin{array}{l}\text { Dried aerial } \\
\text { parts }\end{array}$ & $\mathrm{MeOH}$ ext & $\begin{array}{l}\text { Carrageenan-induced pedal } \\
\text { edema/IP }\end{array}$ & Mouse & Inactive & [106] \\
\hline & Argentina & $\begin{array}{l}\text { Dried aerial } \\
\text { parts }\end{array}$ & $\mathrm{H}_{2} \mathrm{O}$ ext & $\begin{array}{l}\text { Carrageenan-induced pedal } \\
\text { edema/IP }\end{array}$ & Mouse & Active & [106] \\
\hline & Argentina & $\begin{array}{l}\text { Dried aerial } \\
\text { parts }\end{array}$ & $\mathrm{CH}_{2} \mathrm{Cl}_{2}$ ext & $\begin{array}{l}\text { Carrageenan-induced pedal } \\
\text { edema/IP }\end{array}$ & Mouse & Active & [106] \\
\hline \multirow[t]{5}{*}{ Artemisia copa } & Argentina & $\begin{array}{l}\text { Dried entire } \\
\text { plant }\end{array}$ & Hot $\mathrm{H}_{2} \mathrm{O}$ ext & $\begin{array}{l}\text { Carrageenan-induced pedal } \\
\text { edema/IP }\end{array}$ & Rat & Inactive & [109] \\
\hline & Argentina & $\begin{array}{l}\text { Dried entire } \\
\text { plant }\end{array}$ & $\mathrm{CH}_{2} \mathrm{Cl}_{2}$ ext & $\begin{array}{l}\text { Carrageenan-induced pedal } \\
\text { edema/IP }\end{array}$ & Rat & Inactive & [109] \\
\hline & Argentina & $\begin{array}{l}\text { Dried entire } \\
\text { plant }\end{array}$ & $\mathrm{MeOH}$ ext & $\begin{array}{l}\text { Carrageenan-induced pedal } \\
\text { edema/IP }\end{array}$ & Rat & Inactive & [109] \\
\hline & Argentina & $\begin{array}{l}\text { Dried aerial } \\
\text { parts }\end{array}$ & $\mathrm{H}_{2} \mathrm{O}$ ext & $\begin{array}{l}\text { 12-O-tetradecanoylphorbol- } \\
\text { 13-acetate (TPA)-induced ear } \\
\text { inflammation/External }\end{array}$ & Mouse & Active & [71] \\
\hline & Argentina & $\begin{array}{l}\text { Dried aerial } \\
\text { parts }\end{array}$ & $\mathrm{CH}_{2} \mathrm{Cl}_{2}$ ext & $\begin{array}{l}\text { 12- } O \text {-tetradecanoylphorbol- } \\
\text { 13-acetate (TPA)-induced ear } \\
\text { inflammation/External }\end{array}$ & Mouse & Active & [71] \\
\hline \multirow[t]{2}{*}{ Baccharis articulata } & Argentina & $\begin{array}{l}\text { Dried aerial } \\
\text { parts }\end{array}$ & $\mathrm{H}_{2} \mathrm{O}$ ext & $\begin{array}{l}\text { Carrageenan-induced pedal } \\
\text { edema/Intragastric }\end{array}$ & Rat & Inactive & [110] \\
\hline & Argentina & $\begin{array}{l}\text { Dried aerial } \\
\text { parts }\end{array}$ & $\mathrm{H}_{2} \mathrm{O}$ ext & $\begin{array}{l}\text { Carrageenan-induced pedal } \\
\text { edema/IP }\end{array}$ & Rat & Inactive & [110] \\
\hline Baccharis crispa & Argentina & $\begin{array}{l}\text { Dried aerial } \\
\text { parts }\end{array}$ & $\mathrm{H}_{2} \mathrm{O}$ ext & $\begin{array}{l}\text { Carrageenan-induced pedal } \\
\text { edema/Intragastric }\end{array}$ & Rat & Inactive & [110] \\
\hline
\end{tabular}


Table 1. Cont

\begin{tabular}{|c|c|c|c|c|c|c|c|}
\hline & Argentina & $\begin{array}{l}\text { Dried aerial } \\
\text { parts }\end{array}$ & $\mathrm{H}_{2} \mathrm{O}$ ext & $\begin{array}{l}\text { Carrageenan-induced pedal } \\
\text { edema/IP }\end{array}$ & Rat & Active & [110] \\
\hline Baccharis decussata & Colombia & Dried leaf & $\mathrm{MeOH}$ ext & $* * /$ Route not given & $* *$ & Active & [111] \\
\hline \multirow[t]{3}{*}{ Baccharis incarum } & Argentina & $\begin{array}{l}\text { Dried entire } \\
\text { plant }\end{array}$ & $\mathrm{CH}_{2} \mathrm{Cl}_{2}$ ext & $\begin{array}{l}\text { Carrageenan-induced pedal } \\
\text { edema/IP }\end{array}$ & Rat & Active & [109] \\
\hline & Argentina & $\begin{array}{l}\text { Dried entire } \\
\text { plant }\end{array}$ & $\mathrm{MeOH}$ ext & $\begin{array}{l}\text { Carrageenan-induced pedal } \\
\text { edema/IP }\end{array}$ & Rat & Inactive & [109] \\
\hline & Argentina & $\begin{array}{l}\text { Dried entire } \\
\text { plant }\end{array}$ & Hot $\mathrm{H}_{2} \mathrm{O}$ ext & $\begin{array}{l}\text { Carrageenan-induced pedal } \\
\text { edema/IP }\end{array}$ & Rat & Inactive & [109] \\
\hline \multirow[t]{4}{*}{ Baccharis medullosa } & Argentina & $\begin{array}{l}\text { Dried aerial } \\
\text { parts }\end{array}$ & $\mathrm{CHCl}_{3}$ ext & $\begin{array}{l}\text { Carrageenan-induced pedal } \\
\text { edema/IP }\end{array}$ & Mouse & Inactive & [112] \\
\hline & Argentina & $\begin{array}{l}\text { Dried aerial } \\
\text { parts }\end{array}$ & EtoAc ext & $\begin{array}{l}\text { Carrageenan-induced pedal } \\
\text { edema/IP }\end{array}$ & Mouse & Inactive & [112] \\
\hline & Argentina & $\begin{array}{l}\text { Dried aerial } \\
\text { parts }\end{array}$ & $\mathrm{CCl}_{4}$ & $\begin{array}{l}\text { Carrageenan-induced pedal } \\
\text { edema/IP }\end{array}$ & Mouse & Inactive & [112] \\
\hline & Argentina & $\begin{array}{l}\text { Dried aerial } \\
\text { parts }\end{array}$ & Hexane ext & $\begin{array}{l}\text { Carrageenan-induced pedal } \\
\text { edema/IP }\end{array}$ & Mouse & Active & [112] \\
\hline \multirow[t]{3}{*}{ Baccharis rufescens } & Argentina & $\begin{array}{l}\text { Dried aerial } \\
\text { parts }\end{array}$ & Hexane ext & $\begin{array}{l}\text { Carrageenan-induced pedal } \\
\text { edema/IP }\end{array}$ & Mouse & Inactive & [112] \\
\hline & Argentina & $\begin{array}{l}\text { Dried aerial } \\
\text { parts }\end{array}$ & Acetone ext & $\begin{array}{l}\text { Carrageenan-induced pedal } \\
\text { edema/IP }\end{array}$ & Mouse & Active & [112] \\
\hline & Argentina & $\begin{array}{l}\text { Dried aerial } \\
\text { parts }\end{array}$ & $\mathrm{CHCl}_{3} \mathrm{ext}$ & $\begin{array}{l}\text { Carrageenan-induced pedal } \\
\text { edema/IP }\end{array}$ & Mouse & Active & [112] \\
\hline \multirow[t]{4}{*}{ Baccharis trimera } & Uruguay & $\begin{array}{l}\text { Dried aerial } \\
\text { parts }\end{array}$ & $\mathrm{H}_{2} \mathrm{O}$ ext & $\begin{array}{l}\text { Carrageenan-induced pedal } \\
\text { edema/Intragastric }\end{array}$ & Rat & Inactive & [110] \\
\hline & Uruguay & $\begin{array}{l}\text { Dried aerial } \\
\text { parts }\end{array}$ & $\mathrm{H}_{2} \mathrm{O}$ ext & $\begin{array}{l}\text { Carrageenan-induced pedal } \\
\text { edema/IP }\end{array}$ & Rat & Active & [110] \\
\hline & Uruguay & $\begin{array}{l}\text { Dried aerial } \\
\text { parts }\end{array}$ & Butanol ext & $\begin{array}{l}\text { Carrageenan-induced edema } \\
\text { in rat paw/IP }\end{array}$ & Rat & Active & [113] \\
\hline & Uruguay & $\begin{array}{l}\text { Dried aerial } \\
\text { parts }\end{array}$ & Butanol ext & $\begin{array}{l}\text { Dextran-induced edema in rat } \\
\text { paw/IP }\end{array}$ & Rat & Active & [113] \\
\hline
\end{tabular}


Table 1. Cont.

\begin{tabular}{|c|c|c|c|c|c|c|c|}
\hline & Uruguay & $\begin{array}{l}\text { Dried aerial } \\
\text { parts }\end{array}$ & Butanol ext & $\begin{array}{l}\text { Arachindonic acid-induced } \\
\text { edema in pat paw/IP }\end{array}$ & Rat & Equivocal & [113] \\
\hline & Uruguay & $\begin{array}{l}\text { Dried aerial } \\
\text { parts }\end{array}$ & Butanol ext & C16-PAF-induced edema/IP & Rat & $\begin{array}{l}\text { Weak } \\
\text { activity }\end{array}$ & [113] \\
\hline & Uruguay & $\begin{array}{l}\text { Dried aerial } \\
\text { parts }\end{array}$ & Butanol ext & $\begin{array}{l}\text { Zymosan-induced edema in } \\
\text { rat paw/IP }\end{array}$ & Rat & Equivocal & [113] \\
\hline Baccharis trinervis & Ecuador & $\begin{array}{l}\text { Dried entire } \\
\text { plant }\end{array}$ & $\mathrm{EtOH}(100 \%)$ ext & $\begin{array}{l}\text { Carrageenan-induced pedal } \\
\text { edema/Intragastric }\end{array}$ & Mouse & $\begin{array}{l}\text { Weak } \\
\text { activity }\end{array}$ & [95] \\
\hline \multirow[t]{6}{*}{ Baccharis tucumanensis } & Argentina & $\begin{array}{l}\text { Dried aerial } \\
\text { parts }\end{array}$ & $\mathrm{H}_{2} \mathrm{O}$ ext & $\begin{array}{l}\text { Croton oil-induced } \\
\text { edema/External }\end{array}$ & Mouse & Active & [106] \\
\hline & Argentina & $\begin{array}{l}\text { Dried aerial } \\
\text { parts }\end{array}$ & $\mathrm{CH}_{2} \mathrm{Cl}_{2}$ ext & $\begin{array}{l}\text { Croton oil-induced } \\
\text { edema/External }\end{array}$ & Mouse & Active & [106] \\
\hline & Argentina & $\begin{array}{l}\text { Dried aerial } \\
\text { parts }\end{array}$ & $\mathrm{MeOH}$ ext & $\begin{array}{l}\text { Croton oil-induced } \\
\text { edema/External }\end{array}$ & Mouse & Active & [106] \\
\hline & Argentina & $\begin{array}{l}\text { Dried aerial } \\
\text { parts }\end{array}$ & $\mathrm{CH}_{2} \mathrm{Cl}_{2}$ ext & $\begin{array}{l}\text { Carrageenan-induced pedal } \\
\text { edema/IP }\end{array}$ & Mouse & Inactive & [106] \\
\hline & Argentina & $\begin{array}{l}\text { Dried aerial } \\
\text { parts }\end{array}$ & $\mathrm{H}_{2} \mathrm{O}$ ext & $\begin{array}{l}\text { Carrageenan-induced pedal } \\
\text { edema/IP }\end{array}$ & Mouse & Active & [106] \\
\hline & Argentina & $\begin{array}{l}\text { Dried aerial } \\
\text { parts }\end{array}$ & $\mathrm{MeOH}$ ext & $\begin{array}{l}\text { Carrageenan-induced pedal } \\
\text { edema/IP }\end{array}$ & Mouse & Active & [106] \\
\hline Bidens pilosa & Brazil & Dried leaf & $\mathrm{MeOH}$ ext & $\begin{array}{l}\text { Zymosan-induced pedal } \\
\text { edema/IP }\end{array}$ & Mouse & Active & [114] \\
\hline \multirow[t]{2}{*}{ Bidens subalternans } & Argentina & $\begin{array}{l}\text { Dried entire } \\
\text { plant }\end{array}$ & $\mathrm{MeOH}$ ext & $\begin{array}{l}\text { Carrageenan-induced pedal } \\
\text { edema/IP }\end{array}$ & Mouse & $\begin{array}{l}\text { Weak } \\
\text { activity }\end{array}$ & [115] \\
\hline & Argentina & $\begin{array}{l}\text { Dried entire } \\
\text { plant }\end{array}$ & $\mathrm{CHcl}_{3} \mathrm{ext}$ & $\begin{array}{l}\text { Carrageenan-induced pedal } \\
\text { edema/IP }\end{array}$ & Mouse & Active & [115] \\
\hline \multirow[t]{2}{*}{ Centaurea chilensis } & Chile & $\begin{array}{l}\text { Dried aerial } \\
\text { parts }\end{array}$ & $\mathrm{MeOH}$ ext & $* * /$ Intragastric & Guinea pig & Active & [116] \\
\hline & Chile & $\begin{array}{l}\text { Dried aerial } \\
\text { parts }\end{array}$ & $\mathrm{CHCl}_{3} \mathrm{ext}$ & **/Intragastric & Guinea pig & Active & [116] \\
\hline
\end{tabular}


Table 1. Cont

\begin{tabular}{|c|c|c|c|c|c|c|c|}
\hline \multirow[t]{6}{*}{ Chromolaena christieana } & Argentina & $\begin{array}{l}\text { Dried aerial } \\
\text { parts }\end{array}$ & $\mathrm{MeOH}$ ext & $\begin{array}{l}\text { Croton oil-induced } \\
\text { edema/External }\end{array}$ & Mouse & Active & [106] \\
\hline & Argentina & $\begin{array}{l}\text { Dried aerial } \\
\text { parts }\end{array}$ & $\mathrm{CH}_{2} \mathrm{Cl}_{2}$ ext & $\begin{array}{l}\text { Croton oil-induced } \\
\text { edema/External }\end{array}$ & Mouse & Active & [106] \\
\hline & Argentina & $\begin{array}{l}\text { Dried aerial } \\
\text { parts }\end{array}$ & $\mathrm{H}_{2} \mathrm{O}$ ext & $\begin{array}{l}\text { Croton oil-induced } \\
\text { edema/External }\end{array}$ & Mouse & Active & [106] \\
\hline & Argentina & $\begin{array}{l}\text { Dried aerial } \\
\text { parts }\end{array}$ & $\mathrm{CH}_{2} \mathrm{Cl}_{2}$ ext & $\begin{array}{l}\text { Carrageenan-induced pedal } \\
\text { edema/IP }\end{array}$ & Mouse & Inactive & [106] \\
\hline & Argentina & $\begin{array}{l}\text { Dried aerial } \\
\text { parts }\end{array}$ & $\mathrm{H}_{2} \mathrm{O}$ ext & $\begin{array}{l}\text { Carrageenan-induced pedal } \\
\text { edema/IP }\end{array}$ & Mouse & Inactive & [106] \\
\hline & Argentina & $\begin{array}{l}\text { Dried aerial } \\
\text { parts }\end{array}$ & $\mathrm{MeOH}$ ext & $\begin{array}{l}\text { Carrageenan-induced pedal } \\
\text { edema/IP }\end{array}$ & Mouse & Inactive & [106] \\
\hline Conyza bonariensis & Brazil & $\begin{array}{l}\text { Aerial part } \\
\text { essent oil }\end{array}$ & Essential oil & $\begin{array}{l}\text { LPS-induced leukocyte } \\
\text { recruitement/Intragastric }\end{array}$ & Mouse & Active & [117] \\
\hline Conyza floribunda & Ecuador & $\begin{array}{l}\text { Dried entire } \\
\text { plant }\end{array}$ & $\mathrm{EtOH}(100 \%)$ ext & $\begin{array}{l}\text { Carrageenan-induced pedal } \\
\text { edema/Intragastric }\end{array}$ & Mouse & $\begin{array}{l}\text { Weak } \\
\text { activity }\end{array}$ & [95] \\
\hline \multirow[t]{3}{*}{ Conyza sophiifolia } & Argentina & $\begin{array}{l}\text { Dried aerial } \\
\text { parts }\end{array}$ & Hexane ext & $\begin{array}{l}\text { Paw edema test/Route not } \\
\text { given }\end{array}$ & Rat & Active & [118] \\
\hline & Argentina & $\begin{array}{l}\text { Dried aerial } \\
\text { parts }\end{array}$ & Acetone ext & $\begin{array}{l}\text { Paw edema test/Route not } \\
\text { given }\end{array}$ & Rat & Active & [118] \\
\hline & Argentina & $\begin{array}{l}\text { Dried aerial } \\
\text { parts }\end{array}$ & $\mathrm{CHCl}_{3}$ ext & $\begin{array}{l}\text { Paw edema test/Route not } \\
\text { given }\end{array}$ & Rat & Active & [118] \\
\hline Cynara scolymus & Brazil & Fresh leaf & Infusion & $\begin{array}{l}\text { Dye diffusion } \\
\text { assay/Intragastric }\end{array}$ & Mouse & Active & [119] \\
\hline \multirow[t]{3}{*}{ Elephantopus scaber } & Brazil & Fresh leaf & Infusion & $\begin{array}{l}\text { Dye diffusion } \\
\text { assay/Intragastric }\end{array}$ & Mouse & Active & [119] \\
\hline & Brazil & $\begin{array}{l}\text { Dried entire } \\
\text { plant }\end{array}$ & $\begin{array}{l}\mathrm{EtOH}-\mathrm{H}_{2} \mathrm{O}(50 \%) \\
\text { ext }\end{array}$ & $\begin{array}{l}\text { Carrageenan-induced pedal } \\
\text { edema/Intragastric }\end{array}$ & Rat & Inactive & [120] \\
\hline & Brazil & Dried entire & Decoction & $\begin{array}{l}\text { Carrageenan-induced pedal } \\
\text { edema/Intragastric }\end{array}$ & Rat & Inactive & [120] \\
\hline
\end{tabular}


Table 1. Cont.

\begin{tabular}{|c|c|c|c|c|c|c|c|}
\hline Eremanthus erythropappus & Brazil & $\begin{array}{l}\text { Dried aerial } \\
\text { parts }\end{array}$ & $\mathrm{EtOH}(95 \%)$ ext & $\begin{array}{l}\text { Carrageenan-induced pedal } \\
\text { edema/Intragastric }\end{array}$ & Rat & Active & [121] \\
\hline \multirow[t]{2}{*}{ Eupatorium buniifolium } & Argentina & $\begin{array}{l}\text { Dried aerial } \\
\text { parts }\end{array}$ & $\mathrm{CH}_{2} \mathrm{Cl}_{2}$ ext & $\begin{array}{l}\text { 12-O-tetradecanoylphorbol- } \\
\text { 13-acetate (TPA)-induced ear } \\
\text { inflammation/External }\end{array}$ & Mouse & Active & [122] \\
\hline & Equador & $\begin{array}{l}\text { Dried entire } \\
\text { plant }\end{array}$ & $\mathrm{EtOH}(100 \%)$ ext & $\begin{array}{l}\text { Carrageenan-induced pedal } \\
\text { edema/Intragastric }\end{array}$ & Mouse & Active & [95] \\
\hline \multirow[t]{2}{*}{$\begin{array}{l}\text { Eupatorium inulaefolium var. } \\
\text { suaveolens }\end{array}$} & Argentina & $\begin{array}{l}\text { Oven dried } \\
\text { aerial parts }\end{array}$ & $\mathrm{CH}_{2} \mathrm{Cl}_{2}$ ext & $\begin{array}{l}\text { Phorbol myristate acetate- } \\
\text { induced ear }\end{array}$ & Mouse & Active & [123] \\
\hline & Argentina & $\begin{array}{l}\text { Oven dried } \\
\text { aerial parts }\end{array}$ & $\mathrm{CH}_{2} \mathrm{Cl}_{2}$ ext & $\begin{array}{l}\text { Carrageenan-induced pedal } \\
\text { edema/Intragastric }\end{array}$ & Rat & Active & [123] \\
\hline \multirow[t]{5}{*}{ Gochnatia polymorpha } & Brazil & Dried leaf & $\mathrm{H}_{2} \mathrm{O}$ ext & $\begin{array}{l}\text { Carrageenan-induced pedal } \\
\text { edema/Intragastric }\end{array}$ & Rat & Active & [124] \\
\hline & Brazil & Dried leaf & $\mathrm{EtOH}(100 \%)$ ext & $\begin{array}{l}\text { Carrageenan-induced pedal } \\
\text { edema/Intragastric }\end{array}$ & Rat & Active & [124] \\
\hline & Brazil & Dried leaf & Butanol ext & $\begin{array}{l}\text { Carrageenan-induced pedal } \\
\text { edema/Intragastric }\end{array}$ & Rat & Inactive & [124] \\
\hline & Brazil & Dried leaf & EtoAc ext & $\begin{array}{l}\text { Carrageenan-induced pedal } \\
\text { edema/Intragastric }\end{array}$ & Rat & Active & [124] \\
\hline & Brazil & Dried leaf & $\begin{array}{l}\text { Dichloromethane } \\
\text { ext }\end{array}$ & $\begin{array}{l}\text { Carrageenan-induced pedal } \\
\text { edema/Intragastric }\end{array}$ & Rat & Inactive & [124] \\
\hline \multirow[t]{2}{*}{ Laennecia sophiifolia } & Argentina & $\begin{array}{l}\text { Dried aerial } \\
\text { parts }\end{array}$ & Hexane ext & $\begin{array}{l}\text { Carrageenan-induced pedal } \\
\text { edema/IP }\end{array}$ & Mouse & Active & [112] \\
\hline & Argentina & $\begin{array}{l}\text { Dried aerial } \\
\text { parts }\end{array}$ & Acetone ext & $\begin{array}{l}\text { Carrageenan-induced pedal } \\
\text { edema/IP }\end{array}$ & Mouse & Active & [112] \\
\hline Mikania glomerata & Brazil & Fresh leaf & Infusion & $\begin{array}{l}\text { Dye diffusion } \\
\text { assay/Intragastric }\end{array}$ & Mouse & Active & [119] \\
\hline
\end{tabular}


Table 1. Cont.

\begin{tabular}{|c|c|c|c|c|c|c|c|}
\hline & Brazil & Dried leaf & $\begin{array}{l}\text { EtOH- } \mathrm{H}_{2} \mathrm{O}(1: 1) \\
\text { ext }\end{array}$ & $\begin{array}{l}\text { PAF-induced } \\
\text { edema/Histamine-induced } \\
\text { edema/SC }\end{array}$ & Rat & Inactive & {$[125]$} \\
\hline & Brazil & Dried leaf & Dichloromethanol & $\begin{array}{l}\text { Carrageenan-induced } \\
\text { pleurisy/IP }\end{array}$ & Mouse & Active & [126] \\
\hline & Brazil & Dried leaf & $\begin{array}{l}\mathrm{EtOH}-\mathrm{H}_{2} \mathrm{O}(1: 1) \\
\text { ext }\end{array}$ & $\begin{array}{l}\text { Serotonin-induced pleural } \\
\text { edema/SC }\end{array}$ & Rat & Inactive & [125] \\
\hline \multirow[t]{3}{*}{ Mutisia kurtzii } & Argentina & $\begin{array}{l}\text { Dried entire } \\
\text { plant }\end{array}$ & $\mathrm{CH}_{2} \mathrm{Cl}_{2}$ ext & $\begin{array}{l}\text { Carrageenan-induced pedal } \\
\text { edema/IP }\end{array}$ & Rat & Inactive & [109] \\
\hline & Argentina & $\begin{array}{l}\text { Dried entire } \\
\text { plant }\end{array}$ & $\mathrm{MeOH}$ ext & $* * / \mathrm{IP}$ & Rat & Inactive & [109] \\
\hline & Argentina & $\begin{array}{l}\text { Dried entire } \\
\text { plant }\end{array}$ & Hot $\mathrm{H}_{2} \mathrm{O}$ ext & $\begin{array}{l}\text { Carrageenan-induced pedal } \\
\text { edema/IP }\end{array}$ & Rat & Active & [109] \\
\hline Neurolaena lobata & Ecuador & $\begin{array}{l}\text { Dried entire } \\
\text { plant }\end{array}$ & $\mathrm{EtOH}(100 \%)$ ext & $\begin{array}{l}\text { Carrageenan-induced pedal } \\
\text { edema/Intragastric }\end{array}$ & Mouse & Active & [95] \\
\hline \multirow[t]{5}{*}{ Pluchea sagittalis } & Argentina & $\begin{array}{l}\text { Dried entire } \\
\text { plant }\end{array}$ & Hot $\mathrm{H}_{2} \mathrm{O}$ ext & $\begin{array}{l}\text { Carrageenan-induced pedal } \\
\text { edema/IP }\end{array}$ & Rat & Active & [123] \\
\hline & Argentina & $\begin{array}{l}\text { Dried entire } \\
\text { plant }\end{array}$ & $\mathrm{CH}_{2} \mathrm{Cl}_{2}$ ext & $\begin{array}{l}\text { Carrageenan-induced pedal } \\
\text { edema/IP }\end{array}$ & Rat & Active & [123] \\
\hline & Argentina & $\begin{array}{l}\text { Oven dried } \\
\text { aerial parts }\end{array}$ & $\mathrm{CH}_{2} \mathrm{Cl}_{2}$ ext & $\begin{array}{l}\text { Phorbol myristate acetate- } \\
\text { induced ear } \\
\text { inflammation/External }\end{array}$ & Mouse & Active & [109] \\
\hline & Argentina & $\begin{array}{l}\text { Oven dried } \\
\text { aerial parts }\end{array}$ & $\mathrm{CH}_{2} \mathrm{Cl}_{2}$ ext & $\begin{array}{l}\text { Carrageenan-induced pedal } \\
\text { edema/Intragastric }\end{array}$ & Rat & Active & [109] \\
\hline & Argentina & $\begin{array}{l}\text { Dried entire } \\
\text { plant }\end{array}$ & $\mathrm{MeOH}$ ext & $\begin{array}{l}\text { Carrageenan-induced pedal } \\
\text { edema/IP }\end{array}$ & Rat & Inactive & [109] \\
\hline Porophyllum ruderale & Brazil & $\begin{array}{l}\text { Aerial part } \\
\text { essent oil }\end{array}$ & Essential oil & $\begin{array}{l}\text { LPS-induced leukocyte } \\
\text { recruitement/Intragastric }\end{array}$ & Mouse & Active & [117] \\
\hline
\end{tabular}


Table 1. Cont.

\begin{tabular}{|c|c|c|c|c|c|c|c|}
\hline \multirow[t]{6}{*}{ Proustia pyrifolia } & Chile & $\begin{array}{l}\text { Dried aerial } \\
\text { parts }\end{array}$ & $\mathrm{CH}_{2} \mathrm{Cl}_{2}$ ext & $\begin{array}{l}\text { Acetic acid-induced pedal } \\
\text { edema/External }\end{array}$ & Mouse & Active & [59] \\
\hline & Chile & $\begin{array}{l}\text { Dried aerial } \\
\text { parts }\end{array}$ & $\mathrm{CH}_{2} \mathrm{Cl}_{2}$ ext & $\begin{array}{l}\text { 12-O-tetradecanoylphorbol- } \\
\text { 13-acetate (TPA)-induced ear } \\
\text { inflammation/External }\end{array}$ & Mouse & Active & [59] \\
\hline & Chile & $\begin{array}{l}\text { Dried aerial } \\
\text { parts }\end{array}$ & $\mathrm{MeOH}$ ext & $\begin{array}{l}\text { 12-O-tetradecanoylphorbol- } \\
13 \text {-acetate (TPA)-induced ear } \\
\text { inflammation/External }\end{array}$ & Mouse & Active & [59] \\
\hline & Chile & $\begin{array}{l}\text { Dried aerial } \\
\text { parts }\end{array}$ & $\mathrm{MeOH}$ ext & $\begin{array}{l}\text { Acetic acid-induced pedal } \\
\text { edema/External }\end{array}$ & Mouse & Active & [59] \\
\hline & Chile & $\begin{array}{l}\text { Dried aerial } \\
\text { parts }\end{array}$ & Hexane ext & $\begin{array}{l}\text { Acetic acid-induced pedal } \\
\text { edema/External }\end{array}$ & Mouse & Active & [59] \\
\hline & Chile & $\begin{array}{l}\text { Dried aerial } \\
\text { parts }\end{array}$ & Hexane ext & $\begin{array}{l}\text { 12-O-tetradecanoylphorbol- } \\
\text { 13-acetate (TPA)-induced ear } \\
\text { inflammation/External }\end{array}$ & Mouse & Active & [59] \\
\hline \multirow[t]{2}{*}{ Synedrella nodiflora } & Venezuela & Dried leaf & $\mathrm{EtOH}(100 \%)$ ext & $\begin{array}{l}\text { Carrageenan-induced pedal } \\
\text { edema/Intragastric }\end{array}$ & Rat & Active & [94] \\
\hline & Venezuela & Dried leaf & Hexane ext & $\begin{array}{l}\text { Carrageenan-induced pedal } \\
\text { edema/Intragastric }\end{array}$ & Rat & Active & [94] \\
\hline Tagetes pusilla & Ecuador & $\begin{array}{l}\text { Dried entire } \\
\text { plant }\end{array}$ & $\mathrm{EtOH}(100 \%)$ ext & $\begin{array}{l}\text { Carrageenan-induced pedal } \\
\text { edema/Intragastric }\end{array}$ & Mouse & Active & [95] \\
\hline \multirow[t]{3}{*}{ Tanacetum vulgare } & Argentina & $\begin{array}{l}\text { Dried aerial } \\
\text { parts }\end{array}$ & $\begin{array}{l}\text { Dichloromethane } \\
\text { ext }\end{array}$ & $\begin{array}{l}\text { 12-O-tetradecanoylphorbol- } \\
\text { 13-acetate (TPA)-induced ear } \\
\text { inflammation/External }\end{array}$ & Mouse & Active & [127] \\
\hline & Argentina & $\begin{array}{l}\text { Dried aerial } \\
\text { parts }\end{array}$ & $\mathrm{EtOH}(100 \%)$ ext & $\begin{array}{l}\text { 12-O-tetradecanoylphorbol- } \\
\text { 13-acetate (TPA)-induced ear } \\
\text { inflammation/External }\end{array}$ & Mouse & $\begin{array}{l}\text { Weak } \\
\text { activity }\end{array}$ & [128] \\
\hline & Argentina & $\begin{array}{l}\text { Dried aerial } \\
\text { parts }\end{array}$ & $\mathrm{CHCl}_{3}$ ext & $\begin{array}{l}\text { 12-O-tetradecanoylphorbol- } \\
\text { 13-acetate (TPA)-induced ear } \\
\text { inflammation/External }\end{array}$ & Mouse & Active & [128] \\
\hline
\end{tabular}


Table 1. Cont.

\begin{tabular}{|c|c|c|c|c|c|c|c|}
\hline Vanillosmopsis arborea & Brazil & $\begin{array}{l}\text { Dried } \\
\text { trunkwood }\end{array}$ & Essential oil & $* * /$ Gastric intubation & Mouse & Active & [129] \\
\hline \multicolumn{8}{|l|}{ Bignoniaceae } \\
\hline Adenocalymma alliacea & Peru & $\begin{array}{l}\text { Dried root }+ \\
\text { stem }\end{array}$ & $\mathrm{EtOH}(100 \%)$ ext & $\begin{array}{l}\text { EPP-induced rat ear } \\
\text { oedema/External }\end{array}$ & Rat & $\begin{array}{l}\text { Weak } \\
\text { activity }\end{array}$ & [103] \\
\hline Tabebuia impetiginosa & Brazil & Dried bark & $\begin{array}{l}\text { Type ext not } \\
\text { stated }\end{array}$ & $\begin{array}{l}\text { Formalin-induced pedal } \\
\text { edema/Route not given }\end{array}$ & Rat & Active & [130] \\
\hline \multirow[t]{4}{*}{ Tecoma sambucifolia } & Peru & Dried flowers & $\mathrm{H}_{2} \mathrm{O}$ ext & $\begin{array}{l}\text { Carrageenan-induced pedal } \\
\text { edema/IP }\end{array}$ & Rat & Active & [131] \\
\hline & Peru & Dried flowers & $\mathrm{EtOH}(95 \%)$ ext & $\begin{array}{l}\text { Carrageenan-induced pedal } \\
\text { edema/IP }\end{array}$ & Rat & Active & [131] \\
\hline & Peru & Dried perianth & $\mathrm{H}_{2} \mathrm{O}$ ext & $\begin{array}{l}\text { Carrageenan-induced pedal } \\
\text { edema/IP }\end{array}$ & Rat & Active & [131] \\
\hline & Peru & Dried perianth & $\mathrm{EtOH}(95 \%)$ ext & $\begin{array}{l}\text { Carrageenan-induced pedal } \\
\text { edema/IP }\end{array}$ & Rat & Active & [131] \\
\hline Tynnanthus myrianthus & Peru & $\begin{array}{l}\text { Dried part not } \\
\text { specified }\end{array}$ & $\mathrm{EtOH}(95 \%)$ ext & $\begin{array}{l}\text { Carrageenan-induced pedal } \\
\text { edema/IP }\end{array}$ & Rat & Active & [132] \\
\hline \multicolumn{8}{|l|}{ Boraginaceae } \\
\hline \multirow[t]{3}{*}{ Auxemma oncocalyx } & Brazil & $\begin{array}{l}\text { Dried } \\
\text { heartwood }\end{array}$ & Quinone fraction & $\begin{array}{l}\text { Carrageenan-induced pedal } \\
\text { edema/Intragastric }\end{array}$ & Rat & Active & [133] \\
\hline & Brazil & $\begin{array}{l}\text { Dried } \\
\text { heartwood }\end{array}$ & Quinone fraction & $\begin{array}{l}\text { Dextran-induced pedal } \\
\text { edema/IP }\end{array}$ & Rat & Active & [133] \\
\hline & Brazil & $\begin{array}{l}\text { Dried } \\
\text { heartwood }\end{array}$ & Quinone fraction & $\begin{array}{l}\text { Carrageenan-induced pedal } \\
\text { edema/IP }\end{array}$ & Rat & Active & [133] \\
\hline \multirow[t]{3}{*}{ Cordia verbenacea } & Brazil & $\begin{array}{l}\text { Freeze-dried } \\
\text { leaf }\end{array}$ & $\begin{array}{l}\text { Lyophilized } \\
\text { extract }\end{array}$ & $\begin{array}{l}\text { Miconazole-induced } \\
\text { edema/Intragastric }\end{array}$ & Rat & Active & [134] \\
\hline & Brazil & $\begin{array}{l}\text { Freeze-dried } \\
\text { leaf }\end{array}$ & $\begin{array}{l}\text { Lyophilized } \\
\text { extract }\end{array}$ & $\begin{array}{l}\text { Nystatin-induced } \\
\text { edema/External }\end{array}$ & Rat & Active & [134] \\
\hline & Brazil & Fresh leaf & $\mathrm{EtOH}(70 \%)$ ext & $\begin{array}{l}\text { Cotton pellet } \\
\text { granuloma/External }\end{array}$ & Rat & Active & [135] \\
\hline
\end{tabular}


Table 1. Cont.

\begin{tabular}{|c|c|c|c|c|c|c|c|}
\hline & Brazil & Fresh leaf & $\mathrm{EtOH}(70 \%)$ ext & $\begin{array}{l}\text { Cotton pellet } \\
\text { granuloma/Intragastric }\end{array}$ & Rat & Active & [135] \\
\hline & Brazil & Dried leaf & EtOH $(70 \%)$ ext & $\begin{array}{l}\text { Croton oil-induced } \\
\text { edema/External }\end{array}$ & Mouse & Active & [136] \\
\hline & Brazil & Dried leaf & EtOH $(70 \%)$ ext & $\begin{array}{l}\text { Nystatin-induced pedal } \\
\text { edema/Gastric intubation }\end{array}$ & Rat & Active & [136] \\
\hline & Brazil & Dried leaf & $\mathrm{EtOH}(70 \%)$ ext & $\begin{array}{l}\text { Cold stress and carrageenin- } \\
\text { induced edema } \\
\text { combined/Gastric intubation }\end{array}$ & Rat & Active & [136] \\
\hline & Brazil & Fresh leaf & $\mathrm{EtOH}(70 \%)$ ext & $\begin{array}{l}\text { Carrageenan-induced pedal } \\
\text { edema/Oral }\end{array}$ & Rat & Active & [137] \\
\hline & Brazil & Fresh leaf & $\mathrm{EtOH}(70 \%)$ ext & Cotton pellet granuloma/Oral & Rat & Active & [137] \\
\hline & Brazil & $\begin{array}{l}\text { Freeze-dried } \\
\text { leaf }\end{array}$ & $\begin{array}{l}\text { Lyophilized } \\
\text { extract }\end{array}$ & $\begin{array}{l}\text { Nystatin-induced } \\
\text { edema/External }\end{array}$ & Rat & Active & [134] \\
\hline Symphytum officinale & Brazil & Dried leaf & $\begin{array}{l}\text { Aqueous high } \\
\text { speed supernatant }\end{array}$ & $\begin{array}{l}\text { Carrageenan-induced pedal } \\
\text { edema/Gastric intubation }\end{array}$ & Rat & Inactive & [138] \\
\hline Bromeliaceae & & & & & & & \\
\hline Nidularium procerum & Brazil & Dried leaf & $\mathrm{H}_{2} \mathrm{O}$ ext & LPS-induced inflammatory/IP & Mouse & Active & [139] \\
\hline Tillandsia streptocarpa & Brazil & $\begin{array}{l}\text { Dried entire } \\
\text { plant }\end{array}$ & $\mathrm{MeOH}$ ext & $\begin{array}{l}\text { Croton oil-induced } \\
\text { edema/External }\end{array}$ & Mouse & Active & [140] \\
\hline Burseraceae & & & & & & & \\
\hline Bursera simaruba & Venezuela & Dried leaf & Hexane ext & $\begin{array}{l}\text { Carrageenan-induced pedal } \\
\text { edema/Intragastric }\end{array}$ & Rat & Active & [94] \\
\hline & Venezuela & Dried leaf & EtOH $(100 \%)$ ext & $\begin{array}{l}\text { Carrageenan-induced pedal } \\
\text { edema/Intragastric }\end{array}$ & Rat & Active & [94] \\
\hline & Venezuela & Dried bark & EtOH $(100 \%)$ ext & $\begin{array}{l}\text { Carrageenan-induced pedal } \\
\text { edema/Intragastric }\end{array}$ & Rat & Active & [94] \\
\hline & Venezuela & Dried leaf & Hexane ext & $\begin{array}{l}\text { Carrageenan-induced pedal } \\
\text { edema/Intragastric }\end{array}$ & Rat & Active & [141] \\
\hline
\end{tabular}


Table 1. Cont.

\begin{tabular}{|c|c|c|c|c|c|c|c|}
\hline \multirow[t]{2}{*}{ Protium kleinii } & Brazil & Dried bark & Ether ext & $\begin{array}{l}\text { Arachidonic acid-induced } \\
\text { edema/External }\end{array}$ & Mouse & Inactive & [142] \\
\hline & Brazil & Dried bark & Ether ext & $\begin{array}{l}\text { 12-O-tetradecanoylphorbol- } \\
\text { 13-acetate (TPA)-induced ear } \\
\text { inflammation/External }\end{array}$ & Mouse & Active & [142] \\
\hline \multicolumn{8}{|l|}{ Celastraceae } \\
\hline Cheiloclinium cognatum & Brazil & Dried rootbark & $\mathrm{MeCl}_{2}$ ext & $\begin{array}{l}\text { Croton oil-induced } \\
\text { edema/Intragastric }\end{array}$ & Mouse & Active & [143] \\
\hline \multirow[t]{2}{*}{ Maytenus aquifolium } & Brazil & $\begin{array}{l}\text { Dried leaf/plus } \\
\text { piroxican }\end{array}$ & $\begin{array}{l}\text { Hydro-alcoholic } \\
\text { ext }\end{array}$ & $\begin{array}{l}\text { Carrageenan-induced pedal } \\
\text { edema/Intragastric }\end{array}$ & Rat & Active & [144] \\
\hline & Brazil & Dried leaf & $\begin{array}{l}\text { Hydro-alcoholic } \\
\text { ext }\end{array}$ & $\begin{array}{l}\text { Carrageenan-induced pedal } \\
\text { edema/Intragastric }\end{array}$ & Rat & Active & [144] \\
\hline Maytenus boaria & Chile & $\begin{array}{l}\text { Dried aerial } \\
\text { parts }\end{array}$ & $\mathrm{MeOH}$ ext & $\begin{array}{l}\text { Carrageenan-induced pedal } \\
\text { edema/Intragastric }\end{array}$ & Guinea pig & Active & [145] \\
\hline \multirow[t]{4}{*}{ Maytenus ilicifolia } & Brazil & Dried leaf & Hexane-acetone & $* * /$ Intragastric & Rat & Active & [82] \\
\hline & Brazil & Dried leaf & EtoAc ext & $\begin{array}{l}\text { Carrageenan-induced pedal } \\
\text { edema/Intragastric }\end{array}$ & Rat & Active & [82] \\
\hline & Brazil & Dried leaf & Hexane-acetone & $\begin{array}{l}\text { Formalin-induced pedal } \\
\text { edema/Intragastric }\end{array}$ & Mouse & Active & [82] \\
\hline & Brazil & Dried leaf & EtoAc ext & $\begin{array}{l}\text { Formalin-induced pedal } \\
\text { edema/Intragastric }\end{array}$ & Mouse & Active & [82] \\
\hline Maytenus laevis & Colombia & Bark & EtOH $(95 \%)$ ext & $\begin{array}{l}\text { Carrageenin-induced pedal } \\
\text { edema/SC }\end{array}$ & Rat & Active & [146] \\
\hline Maytenus rigida & Brazil & Dried bark & $\mathrm{EtOH}(95 \%)$ ext & $\begin{array}{l}\text { Carrageenan-induced pedal } \\
\text { edema/Intragastric }\end{array}$ & Rat & Active & [147] \\
\hline \multicolumn{8}{|l|}{ Chloranthaceae } \\
\hline Hedyosmum bonplandianum & Colombia & Dried leaf & Butanol ext & $\begin{array}{l}\text { Carrageenan-induced pedal } \\
\text { edema/Intragastric }\end{array}$ & Mouse & Active & [148] \\
\hline
\end{tabular}


Table 1. Cont.

\begin{tabular}{|c|c|c|c|c|c|c|c|}
\hline Hypericum brasiliense & Brazil & Dried leaf & $\begin{array}{l}\text { Type ext not } \\
\text { stated }\end{array}$ & $\begin{array}{l}\text { Carrageenan-induced pedal } \\
\text { edema/Oral }\end{array}$ & Rat & Active & [149] \\
\hline \multicolumn{8}{|l|}{ Convolvulaceae } \\
\hline \multirow[t]{2}{*}{ Cuscuta chilensis } & Chile & $\begin{array}{l}\text { Dried entire } \\
\text { plant }\end{array}$ & $\mathrm{MeOH}$ ext & $\begin{array}{l}\text { Carrageenan-induced pedal } \\
\text { edema/Intragastric }\end{array}$ & Guinea pig & Active & {$[150]$} \\
\hline & Chile & $\begin{array}{l}\text { Dried entire } \\
\text { plant }\end{array}$ & Infusion & $\begin{array}{l}\text { Carrageenan-induced pedal } \\
\text { edema/Intragastric }\end{array}$ & Guinea pig & Active & [150] \\
\hline \multirow[t]{2}{*}{ Ipomoea fistulosa } & Argentina & $\begin{array}{l}\text { Oven dried } \\
\text { aerial parts }\end{array}$ & $\mathrm{MeOH}$ ext & $\begin{array}{l}\text { Carrageenan-induced pedal } \\
\text { edema/Intragastric }\end{array}$ & Rat & Active & [123] \\
\hline & Argentina & $\begin{array}{l}\text { Oven dried } \\
\text { aerial parts }\end{array}$ & $\mathrm{CH}_{2} \mathrm{Cl}_{2}$ ext & $\begin{array}{l}\text { Phorbol myristate acetate- } \\
\text { induced ear } \\
\text { inflammation/External }\end{array}$ & Mouse & Active & [123] \\
\hline \multicolumn{8}{|l|}{ Crassulaceae } \\
\hline Bryophyllum calcinum & Brazil & Dried leaf & $\begin{array}{l}\text { Lyophilized } \\
\text { extract }\end{array}$ & $\begin{array}{l}\text { Carrageenan-induced pedal } \\
\text { edema/Intragastric }\end{array}$ & Rat & Active & [151] \\
\hline \multirow[t]{3}{*}{ Kalanchoe brasiliensis } & Brazil & Fresh leaf & Plant juice & $\begin{array}{l}\text { Carrageenan-induced pedal } \\
\text { edema/Intragastric }\end{array}$ & Rat & Active & [152] \\
\hline & Brazil & Fresh leaf & Juice & $\begin{array}{l}\text { Zymosan-induced } \\
\text { inflammation/IP }\end{array}$ & Mouse & Active & [153] \\
\hline & Brazil & $\begin{array}{l}\text { Fresh fruit } \\
\text { juice (unripe) }\end{array}$ & Juice & $* * / \mathrm{IP}$ & Mouse & Active & [154] \\
\hline \multicolumn{8}{|l|}{ Cucurbitaceae } \\
\hline \multirow[t]{4}{*}{ Cayaponia tayuya } & Brazil & Dried root & $\mathrm{MeOH}$ ext & $\begin{array}{l}\text { Carrageenan-induced pedal } \\
\text { edema/Gastric intubation }\end{array}$ & Mouse & Inactive & [155] \\
\hline & Brazil & Dried root & $\mathrm{CHCl}_{3}$ ext & $\begin{array}{l}\text { Carrageenan-induced pedal } \\
\text { edema/Gastric intubation }\end{array}$ & Mouse & $\begin{array}{l}\text { Weak } \\
\text { activity }\end{array}$ & [155] \\
\hline & Brazil & Dried root & $\mathrm{MeOH}$ ext & $\begin{array}{l}\text { Carrageenan-induced pedal } \\
\text { edema/IP }\end{array}$ & Mouse & $\begin{array}{l}\text { Weak } \\
\text { activity }\end{array}$ & [155] \\
\hline & Brazil & Dried root & $\mathrm{CHCl}_{3}$ ext & $\begin{array}{l}\text { Carrageenan-induced pedal } \\
\text { edema/IP }\end{array}$ & Mouse & Active & [155] \\
\hline
\end{tabular}


Table 1. Cont.

\begin{tabular}{|c|c|c|c|c|c|c|c|}
\hline & Brazil & Dried root & Infusion & $\begin{array}{l}\text { Dye diffusion } \\
\text { assay/Intragastric }\end{array}$ & Mouse & Equivocal & [119] \\
\hline \multirow[t]{5}{*}{ Wilbrandia ebracteata } & Brazil & Dried root & $\mathrm{CH}_{2} \mathrm{Cl}_{2}$ ext & $\begin{array}{l}\text { Carrageenan-induced pedal } \\
\text { edema/Intragastric }\end{array}$ & Rat & $\begin{array}{l}\text { Weak } \\
\text { activity }\end{array}$ & [156] \\
\hline & Brazil & Dried root & $\begin{array}{l}\mathrm{CHCl}_{3} \text { soluble } \\
\text { fraction }\end{array}$ & $\begin{array}{l}\text { Carrageenan-induced } \\
\text { pleurisy/Intragastric }\end{array}$ & Mouse & Active & [156] \\
\hline & Brazil & Dried root & $\mathrm{CH}_{2} \mathrm{Cl}_{2}$ ext & $\begin{array}{l}\text { Carrageenan-induced pedal } \\
\text { edema/IP }\end{array}$ & Rat & Active & [156] \\
\hline & Brazil & Dried root & $\begin{array}{l}\text { Chromatographic } \\
\text { fraction }\end{array}$ & $\begin{array}{l}\text { Carrageenan-induced } \\
\text { pleurisy/IP }\end{array}$ & Mouse & Active & [156] \\
\hline & Brazil & Dried root & $\begin{array}{l}\mathrm{CHCl}_{3} \text { soluble } \\
\text { fraction }\end{array}$ & $\begin{array}{l}\text { Carrageenan-induced } \\
\text { pleurisy/IP }\end{array}$ & Mouse & Active & [156] \\
\hline \multirow[t]{3}{*}{ Wilbrandia species } & Brazil & Dried rhizome & EtOH $(70 \%)$ ext & $\begin{array}{l}\text { Acetic acid-induced pedal } \\
\text { edema/Intragastric }\end{array}$ & Mouse & Active & [157] \\
\hline & Brazil & Dried rhizome & $\mathrm{EtOH}(70 \%)$ ext & $\begin{array}{l}\text { Carrageenan-induced pedal } \\
\text { edema/Intragastric }\end{array}$ & Rat & Active & [157] \\
\hline & Brazil & Dried rhizome & EtOH (70\%) ext & $\begin{array}{l}\text { Carrageenan-induced } \\
\text { granuloma/Intragastric }\end{array}$ & Rat & Active & [157] \\
\hline \multicolumn{8}{|l|}{ Cyatheaceae } \\
\hline $\begin{array}{l}\text { Trichipteris procera } \\
\text { Cyperaceae }\end{array}$ & Peru & Inner bark & EtOH (95\%) ext & $* * / * *$ & Rabbit & Active & [158] \\
\hline Mariscus pedunculatus & Brazil & Venom & Essential oil & $\begin{array}{l}\text { LPS-induced pleurisy } \\
\text { model/Intragastric }\end{array}$ & Mouse & Active & [159] \\
\hline \multicolumn{8}{|l|}{ Dilleniaceae } \\
\hline \multirow[t]{2}{*}{ Curatella americana } & Brazil & $\begin{array}{l}\text { Dried } \\
\text { stembark }\end{array}$ & $\begin{array}{l}\text { Hydro-alcoholic } \\
\text { ext }\end{array}$ & $\begin{array}{l}\text { Carrageenan-induced pedal } \\
\text { edema/IP }\end{array}$ & Rat & Active & [160] \\
\hline & Brazil & $\begin{array}{l}\text { Dried } \\
\text { stembark }\end{array}$ & $\begin{array}{l}\text { Hydro-alcoholic } \\
\text { ext }\end{array}$ & $\begin{array}{l}\text { 12-O-tetradecanoylphorbol- } \\
\text { 13-acetate(TPA)-induced ear } \\
\text { inflammation/IP }\end{array}$ & Mouse & Active & [160] \\
\hline
\end{tabular}


Table 1. Cont.

\begin{tabular}{|c|c|c|c|c|c|c|c|}
\hline & Brazil & $\begin{array}{l}\text { Dried } \\
\text { stembark }\end{array}$ & $\begin{array}{l}\text { Hydro-alcoholic } \\
\text { ext }\end{array}$ & $\begin{array}{l}\text { Capsaicin induced mouse ear } \\
\text { edema/IP }\end{array}$ & Mouse & Active & [160] \\
\hline \multicolumn{8}{|l|}{ Equisetaceae } \\
\hline Equisetum arvense & Brazil & Stem & $\begin{array}{l}\text { EtOH }-\mathrm{H}_{2} \mathrm{O}(1: 1) \\
\text { ext }\end{array}$ & $\begin{array}{l}\text { Carrageenan-induced pedal } \\
\text { edema/IP }\end{array}$ & Mouse & Active & [161] \\
\hline \multicolumn{8}{|l|}{ Erythroxylaceae } \\
\hline \multirow[t]{2}{*}{ Erythroxylum argentinum } & Brazil & Dried leaf & EtOH $(70 \%)$ ext & $\begin{array}{l}\text { Carrageenan-induced pedal } \\
\text { edema/Intragastric }\end{array}$ & Rat & Active & [162] \\
\hline & Brazil & Dried leaf & EtOH $(70 \%)$ ext & $\begin{array}{l}\text { Carrageenan-induced pedal } \\
\text { edema/IP }\end{array}$ & Rat & Active & [162] \\
\hline \multicolumn{8}{|l|}{ Euphorbiaceae } \\
\hline \multirow[t]{2}{*}{ Alchornea castaneaefolia } & Peru & $\begin{array}{l}\text { Dried part not } \\
\text { specified }\end{array}$ & EtOH $(95 \%)$ ext & $\begin{array}{l}\text { Carrageenan-induced pedal } \\
\text { edema/IP }\end{array}$ & Rat & $* *$ & [132] \\
\hline & Peru & $\begin{array}{l}\text { Dried } \\
\text { stembark }\end{array}$ & $\mathrm{EtOH}(100 \%)$ ext & Epp-induced rat ear edema/** & Rat & Active & [103] \\
\hline \multirow[t]{2}{*}{ Croton cajucara } & Brazil & $\begin{array}{l}\text { Bark essential } \\
\text { oil }\end{array}$ & Essential oil & $\begin{array}{l}\text { Carrageenan-induced pedal } \\
\text { edema/Intragastric }\end{array}$ & Mouse & Active & [163] \\
\hline & Brazil & $\begin{array}{l}\text { Bark essential } \\
\text { oil }\end{array}$ & Essential oil & $\begin{array}{l}\text { Cotton pellet } \\
\text { granuloma/Intragastric }\end{array}$ & Rat & Active & [163] \\
\hline \multirow[t]{5}{*}{ Croton celtidifolius } & Brazil & Dried bark & $\mathrm{H}_{2} \mathrm{O}$ ext & $\begin{array}{l}\text { Carrageenan-induced pedal } \\
\text { edema/Intragastric }\end{array}$ & Mouse & Active & [164] \\
\hline & Brazil & Dried bark & EtoAc ext & $\begin{array}{l}\text { Carrageenan-induced pedal } \\
\text { edema/Intragastric }\end{array}$ & Mouse & Active & [164] \\
\hline & Brazil & Dried bark & $\mathrm{EtOH}(80 \%)$ ext & $\begin{array}{l}\text { Carrageenan-induced pedal } \\
\text { edema/Intragastric }\end{array}$ & Mouse & Active & [164] \\
\hline & Brazil & Dried bark & Butanol ext & $\begin{array}{l}\text { Carrageenan-induced pedal } \\
\text { edema/Intragastric }\end{array}$ & Mouse & Active & [164] \\
\hline & Brazil & Dried bark & EtoAc ext & $\begin{array}{l}\text { Carrageenan-induced pedal } \\
\text { edema/IP }\end{array}$ & Mouse & Active & [164] \\
\hline
\end{tabular}


Table 1. Cont

\begin{tabular}{|c|c|c|c|c|c|c|c|}
\hline & Brazil & Dried bark & $\mathrm{H}_{2} \mathrm{O}$ ext & $\begin{array}{l}\text { Carrageenan-induced pedal } \\
\text { edema/IP }\end{array}$ & Mouse & Active & {$[164]$} \\
\hline & Brazil & Dried bark & Butanol ext & $\begin{array}{l}\text { Carrageenan-induced pedal } \\
\text { edema/IP }\end{array}$ & Mouse & Active & [164] \\
\hline \multirow[t]{2}{*}{ Croton lechleri } & Peru & Fresh sap & Latex & **/Iinjection & Rat & Active & [165] \\
\hline & Ecuador & $\begin{array}{l}\text { Freeze-drild } \\
\text { latex }\end{array}$ & $* *$ & $\begin{array}{l}\text { Carrageenan-induced pedal } \\
\text { edema/IP }\end{array}$ & Rat & Active & [166] \\
\hline Croton malambo & Venezuela & Dried bark & $\mathrm{H}_{2} \mathrm{O}$ ext & Albumin-induced edema/IP & Mouse & Active & [167] \\
\hline \multirow[t]{2}{*}{ Croton menthodorus } & Ecuador & Dried seed & $\mathrm{CH}_{2} \mathrm{Cl}_{2}$ ext & $\begin{array}{l}\text { Carrageenan-induced pedal } \\
\text { edema/Intragastric }\end{array}$ & Mouse & Active & [96] \\
\hline & Ecuador & $\begin{array}{l}\text { Dried entire } \\
\text { plant }\end{array}$ & $\mathrm{EtOH}(100 \%)$ ext & $\begin{array}{l}\text { Carrageenan-induced pedal } \\
\text { edema/Intragastric }\end{array}$ & Mouse & $\begin{array}{l}\text { Weak } \\
\text { activity }\end{array}$ & [95] \\
\hline Croton pullei var. glabrior & Brazil & Dried leaf & $\mathrm{MeOH}$ ext & $\begin{array}{l}\text { Carrageenan-induced pedal } \\
\text { edema/Intragastric }\end{array}$ & Mouse & Active & [78] \\
\hline \multirow[t]{3}{*}{ Jatropha elliptica } & Brazil & Fresh tuber & $\begin{array}{l}\text { EtOH- } \mathrm{H}_{2} \mathrm{O}(50 \%) \\
\text { ext }\end{array}$ & $\begin{array}{l}\text { Carrageenan-induced pedal } \\
\text { edema/Intragastric }\end{array}$ & Rat & Active & [168] \\
\hline & Brazil & Fresh tuber & $\begin{array}{l}\text { EtOH- } \mathrm{H}_{2} \mathrm{O}(50 \%) \\
\text { ext }\end{array}$ & $\begin{array}{l}\text { Dextran-induced pedal } \\
\text { edema/Intragastric }\end{array}$ & Rat & Inactive & [168] \\
\hline & Brazil & Fresh tuber & $\begin{array}{l}\text { EtOH- } \mathrm{H}_{2} \mathrm{O}(50 \%) \\
\text { ext }\end{array}$ & $\begin{array}{l}\text { Serotonin-induced pedal } \\
\text { edema/Intragastric }\end{array}$ & Rat & Active & [168] \\
\hline Phyllanthus amarus & Brazil & $\begin{array}{l}\text { Dried aerial } \\
\text { parts }\end{array}$ & Hexane ext & $\begin{array}{l}\text { Cfa induced } \\
\text { edema/Intragastric }\end{array}$ & Mouse & Active & [169] \\
\hline Phyllanthus carolinensis & Brazil & $\begin{array}{l}\text { Dried entire } \\
\text { plant }\end{array}$ & $\begin{array}{l}\text { Hydro-alcoholic } \\
\text { ext }\end{array}$ & $\begin{array}{l}\text { Formalin-induced pedal } \\
\text { edema/IP }\end{array}$ & Mouse & Active & [170] \\
\hline Phyllanthus corcovadensis & Brazil & $\begin{array}{l}\text { Dried leaf }+ \\
\text { root }+ \text { stem }\end{array}$ & $\begin{array}{l}\mathrm{EtOH}-\mathrm{H}_{2} \mathrm{O}(1: 1) \\
\text { ext }\end{array}$ & $\begin{array}{l}\text { Carrageenan-induced pedal } \\
\text { edema/vs.dextran-induced } \\
\text { pedal edema/IP }\end{array}$ & Mouse & Inactive & [171] \\
\hline \multicolumn{8}{|l|}{ Fabaceae } \\
\hline Apuleia leiocarpa & Brazil & Fresh bark & Infusion & $\begin{array}{l}\text { Dye diffusion } \\
\text { assay/Intragastric }\end{array}$ & Mouse & Active & [119] \\
\hline
\end{tabular}


Table 1. Cont.

\begin{tabular}{|c|c|c|c|c|c|c|c|}
\hline \multirow[t]{7}{*}{ Bauhinia guianensis } & Brazil & $\begin{array}{l}\text { Dried } \\
\text { stembark }\end{array}$ & $\mathrm{CH}_{2} \mathrm{Cl}_{2}$ ext & $\begin{array}{l}\text { Dextran-induced pedal } \\
\text { edema/IP }\end{array}$ & Rat & Active & {$[172]$} \\
\hline & Brazil & $\begin{array}{l}\text { Dried } \\
\text { stembark }\end{array}$ & $\mathrm{CH}_{2} \mathrm{Cl}_{2}$ ext & Histamine-induced edema/IP & Rat & Inactive & [172] \\
\hline & Brazil & $\begin{array}{l}\text { Dried } \\
\text { stembark }\end{array}$ & EtoAc ext & Histamine-induced edema/IP & Rat & Active & [172] \\
\hline & Brazil & $\begin{array}{l}\text { Dried } \\
\text { stembark }\end{array}$ & EtoAc ext & $\begin{array}{l}\text { Dextran-induced pedal } \\
\text { edema/IP }\end{array}$ & Rat & Active & [172] \\
\hline & Brazil & $\begin{array}{l}\text { Dried } \\
\text { stembark }\end{array}$ & $\mathrm{MeOH}$ ext & $\begin{array}{l}\text { Carrageenan-induced pedal } \\
\text { edema/IP }\end{array}$ & Rat & Active & [172] \\
\hline & Brazil & $\begin{array}{l}\text { Dried } \\
\text { stembark }\end{array}$ & $\mathrm{MeOH}$ ext & $\begin{array}{l}\text { Dextran-induced pedal } \\
\text { edema/IP }\end{array}$ & Rat & Active & [172] \\
\hline & Brazil & $\begin{array}{l}\text { Dried } \\
\text { stembark }\end{array}$ & $\mathrm{MeOH}$ ext & Histamine-induced edema/IP & Rat & Active & [172] \\
\hline \multirow[t]{5}{*}{ Bauhinia tarapotensis } & Ecuador & Dried leaf & $\mathrm{H}_{2} \mathrm{O}$ ext & Croton oil-induced edema/** & Mouse & Active & [76] \\
\hline & Ecuador & Dried leaf & $\begin{array}{l}\text { Dichloromethane } \\
\text { ext }\end{array}$ & Croton oil-induced edema/** & Mouse & Active & [76] \\
\hline & Ecuador & Dried leaf & $\mathrm{MeOH}$ ext & Croton oil-induced edema/** & Mouse & Active & [76] \\
\hline & Ecuador & Dried leaf & Hexane ext & Croton oil-induced edema/** & Mouse & Active & [76] \\
\hline & Ecuador & Dried leaf & $\mathrm{CHCl}_{3}$ ext & Croton oil-induced edema/** & Mouse & Active & [76] \\
\hline Caesalpinia ferrea & Brazil & Dried fruit & $\mathrm{H}_{2} \mathrm{O}$ ext & $\begin{array}{l}\text { Carrageenan-induced pedal } \\
\text { edema/Intragastric }\end{array}$ & Rat & Active & [173] \\
\hline Calliandra angustifolia & Peru & Dried bark & $\mathrm{EtOH}(100 \%)$ ext & Epp-induced rat ear edema/** & Rat & Inactive & [103] \\
\hline Copaifera cearensis & Brazil & Dried balsam & Oleoresin & $\begin{array}{l}\text { Carrageenan-induced pedal } \\
\text { edema/Intragastric }\end{array}$ & Mouse & Active & [174] \\
\hline Copaifera langsdorfii & Brazil & $\begin{array}{l}\text { Dried } \\
\text { oleoresin }\end{array}$ & Resin & $\begin{array}{l}\text { Acetic acid-induced } \\
\text { colitis/Intragastric }\end{array}$ & Rat & Active & [174] \\
\hline
\end{tabular}


Table 1. Cont.

\begin{tabular}{|c|c|c|c|c|c|c|c|}
\hline \multirow[t]{3}{*}{ Copaifera species } & Brazil & Oleoresin & Oleoresin & $\begin{array}{l}\text { Carrageenan-induced pedal } \\
\text { edema/Intragastric }\end{array}$ & Rat & Active & [174] \\
\hline & Brazil & Oleoresin & Oleoresin & $\begin{array}{l}\text { Cotton pellet } \\
\text { granuloma/Intragastric }\end{array}$ & Rat & Active & [174] \\
\hline & Brazil & Oleoresin & Oleoresin & $\begin{array}{l}\text { Histamine-induced vascular } \\
\text { peremability/Intragastric }\end{array}$ & Rat & Active & [174] \\
\hline \multirow[t]{3}{*}{ Erythrina velutina } & Brazil & Dried leaf & Decoction & $\begin{array}{l}\text { Carrageenan-induced pedal } \\
\text { edema/Intragastric }\end{array}$ & Rat & Inactive & [175] \\
\hline & Brazil & Dried leaf & Decoction & $\begin{array}{l}\text { Carrageenan-induced pedal } \\
\text { edema/Intragastric }\end{array}$ & Rat & Inactive & [175] \\
\hline & Brazil & Dried leaf & Decoction & $\begin{array}{l}\text { Carrageenan-induced pedal } \\
\text { edema/Intragastric }\end{array}$ & Rat & Inactive & [175] \\
\hline \multirow[t]{6}{*}{ Erythrina crista-galli } & Argentina & $\begin{array}{l}\text { Dried aerial } \\
\text { parts }\end{array}$ & $\begin{array}{l}\text { Dichloromethane } \\
\text { ext }\end{array}$ & $\begin{array}{l}\text { 12-O-tetradecanoylphorbol- } \\
13 \text {-acetate (TPA)-induced ear } \\
\text { inflammation/** }\end{array}$ & Mouse & Active & [176] \\
\hline & Argentina & $\begin{array}{l}\text { Dried aerial } \\
\text { parts }\end{array}$ & $\mathrm{MeOH}$ ext & $\begin{array}{l}\text { 12- } O \text {-tetradecanoylphorbol- } \\
13 \text {-acetate (TPA)-induced ear } \\
\text { inflammation/** }\end{array}$ & Mouse & Active & [176] \\
\hline & Argentina & $\begin{array}{l}\text { Dried aerial } \\
\text { parts }\end{array}$ & $\mathrm{H}_{2} \mathrm{O}$ ext & $\begin{array}{l}\text { 12- } O \text {-tetradecanoylphorbol- } \\
13 \text {-acetate }(\mathrm{TPA} \text {-induced ear } \\
\text { inflammation/** }\end{array}$ & Mouse & Active & [176] \\
\hline & Argentina & $\begin{array}{l}\text { Dried aerial } \\
\text { parts }\end{array}$ & $\mathrm{MeOH}$ ext & $\begin{array}{l}\text { Carrageenan-induced pedal } \\
\text { edema/Intragastric }\end{array}$ & Rat & Active & [176] \\
\hline & Argentina & $\begin{array}{l}\text { Dried aerial } \\
\text { parts }\end{array}$ & $\mathrm{H}_{2} \mathrm{O}$ ext & $\begin{array}{l}\text { Carrageenan-induced pedal } \\
\text { edema/Intragastric }\end{array}$ & Rat & Active & [176] \\
\hline & Argentina & $\begin{array}{l}\text { Dried aerial } \\
\text { parts }\end{array}$ & $\begin{array}{l}\text { Dichloromethane } \\
\text { ext }\end{array}$ & $\begin{array}{l}\text { Carrageenan-induced pedal } \\
\text { edema/Intragastric }\end{array}$ & Rat & Active & [176] \\
\hline Marsypianthes chamaedrys & Brazil & Fresh leaf & Infusion & $\begin{array}{l}\text { Dye diffusion } \\
\text { assay/Intragastric }\end{array}$ & Mouse & Active & [119] \\
\hline
\end{tabular}


Table 1. Cont.

\begin{tabular}{|c|c|c|c|c|c|c|c|}
\hline \multirow[t]{5}{*}{ Psoralea glandulosa } & Chile & $\begin{array}{l}\text { Dried aerial } \\
\text { parts }\end{array}$ & Infusion & $\begin{array}{l}\text { Carrageenan-induced pedal } \\
\text { edema/Intragastric }\end{array}$ & Guinea pig & Active & [150] \\
\hline & Chile & $\begin{array}{l}\text { Dried aerial } \\
\text { parts }\end{array}$ & $\mathrm{MeOH}$ ext & $\begin{array}{l}\text { Carrageenan-induced pedal } \\
\text { edema/Intragastric }\end{array}$ & Guinea pig & Active & [150] \\
\hline & Chile & $\begin{array}{l}\text { Dried aerial } \\
\text { parts }\end{array}$ & Pet ether ext & $\begin{array}{l}\text { Carrageenan-induced pedal } \\
\text { edema/Intragastric }\end{array}$ & Guinea pig & Active & [177] \\
\hline & Chile & $\begin{array}{l}\text { Dried aerial } \\
\text { parts }\end{array}$ & $\begin{array}{l}\text { Dichloromethane } \\
\text { ext }\end{array}$ & $\begin{array}{l}\text { Carrageenan-induced pedal } \\
\text { edema/Intragastric }\end{array}$ & Guinea pig & Active & [177] \\
\hline & Chile & $\begin{array}{l}\text { Dried aerial } \\
\text { parts }\end{array}$ & $\mathrm{MeOH}$ ext & $\begin{array}{l}\text { Carrageenan-induced pedal } \\
\text { edema/Intragastric }\end{array}$ & Guinea pig & Active & [177] \\
\hline Pterocarpus ulei & Peru & $\begin{array}{l}\text { Dried } \\
\text { stembark }\end{array}$ & $\mathrm{EtOH}(100 \%)$ ext & $\begin{array}{l}\text { EPP-induced rat ear } \\
\text { oedema/** }\end{array}$ & Rat & Inactive & [103] \\
\hline \multirow[t]{2}{*}{ Pterodon emarginatus } & Brazil & Dried fruit & Hexane ext & $\begin{array}{l}\text { Carrageenan-induced pedal } \\
\text { edema/Intragastric }\end{array}$ & Rat & Active & [178] \\
\hline & Brazil & Dried fruit & Hexane ext & $\begin{array}{l}\text { Carrageenan-induced pedal } \\
\text { edema/Intragastric }\end{array}$ & Rat & Active & [178] \\
\hline \multirow[t]{3}{*}{ Stryphnodendron adstringens } & Brazil & $\begin{array}{l}\text { Dried } \\
\text { stembark }\end{array}$ & & $\begin{array}{l}\text { Acetic acid induced vascular } \\
\text { permeability/Intragastric }\end{array}$ & Mouse & Active & [179] \\
\hline & Brazil & $\begin{array}{l}\text { Dried } \\
\text { stembark }\end{array}$ & Acetone ext & $\begin{array}{l}\text { Dextran-induced pedal } \\
\text { edema/carrageenan-induced } \\
\text { pedal edema/Intragastric }\end{array}$ & Rat & Active & [179] \\
\hline & Brazil & $\begin{array}{l}\text { Dried } \\
\text { stembark }\end{array}$ & Acetone ext & $* * /$ Intragastric & Rat & $\begin{array}{l}\text { Weak } \\
\text { activity }\end{array}$ & [179] \\
\hline Torresea cearensis & Brazil & $\begin{array}{l}\text { Dried } \\
\text { stembark }\end{array}$ & & $\begin{array}{l}\text { Carrageenan-induced pedal } \\
\text { edema/Intragastric }\end{array}$ & Rat & Active & [180] \\
\hline \multicolumn{8}{|l|}{ Flacourtiaceae } \\
\hline Casearia sylvestris & Brazil & $\begin{array}{l}\text { Fresh bark }+ \\
\text { leaf }\end{array}$ & Infusion & $\begin{array}{l}\text { Dye diffusion } \\
\text { assay/Intragastric }\end{array}$ & Mouse & $\begin{array}{l}\text { Weak } \\
\text { activity }\end{array}$ & [119] \\
\hline
\end{tabular}


Table 1. Cont.

\begin{tabular}{|c|c|c|c|c|c|c|c|}
\hline \multirow[t]{7}{*}{ Gentianella achalensis } & Argentina & $\begin{array}{l}\text { Dried aerial } \\
\text { parts }\end{array}$ & $\begin{array}{l}\text { Chromatographic } \\
\text { fraction }\end{array}$ & $\begin{array}{l}\text { 12-O-tetradecanoylphorbol- } \\
\text { 13-acetate(TPA)-induced ear } \\
\text { inflammation/** }\end{array}$ & Mouse & Active & {$[181]$} \\
\hline & Argentina & $\begin{array}{l}\text { Dried aerial } \\
\text { parts }\end{array}$ & Pet ether ext & $\begin{array}{l}\text { 12-O-tetradecanoylphorbol- } \\
13 \text {-acetate(TPA)-induced ear } \\
\text { inflammation/** }\end{array}$ & Mouse & Inactive & [181] \\
\hline & Argentina & $\begin{array}{l}\text { Dried aerial } \\
\text { parts }\end{array}$ & $\mathrm{MeOH}$ ext & $\begin{array}{l}\text { 12-O-tetradecanoylphorbol- } \\
\text { 13-acetate(TPA)-induced ear } \\
\text { inflammation/** }\end{array}$ & Mouse & Inactive & [181] \\
\hline & Argentina & $\begin{array}{l}\text { Dried aerial } \\
\text { parts }\end{array}$ & $\begin{array}{l}\text { Dichloromethane } \\
\text { ext }\end{array}$ & $\begin{array}{l}\text { 12-O-tetradecanoylphorbol- } \\
13 \text {-acetate(TPA)-induced ear } \\
\text { inflammation/** }\end{array}$ & Mouse & Active & [181] \\
\hline & Argentina & $\begin{array}{l}\text { Dried aerial } \\
\text { parts }\end{array}$ & $\begin{array}{l}\text { Dichloromethane } \\
\text { ext }\end{array}$ & $\begin{array}{l}\text { Carrageenan-induced pedal } \\
\text { edema/Intragastric }\end{array}$ & Rat & Inactive & [181] \\
\hline & Argentina & $\begin{array}{l}\text { Dried aerial } \\
\text { parts }\end{array}$ & Pet ether ext & $\begin{array}{l}\text { Carrageenan-induced pedal } \\
\text { edema/Intragastric }\end{array}$ & Rat & Inactive & [181] \\
\hline & Argentina & $\begin{array}{l}\text { Dried aerial } \\
\text { parts }\end{array}$ & $\mathrm{MeOH}$ ext & $\begin{array}{l}\text { Carrageenan-induced pedal } \\
\text { edema/Intragastric }\end{array}$ & Rat & Inactive & [181] \\
\hline \multicolumn{8}{|l|}{ Lamiaceae } \\
\hline \multirow[t]{2}{*}{ Hyptis pectinata } & Brazil & Dried leaf & $\mathrm{H}_{2} \mathrm{O}$ ext & $\begin{array}{l}\text { Arachidonic acid-induced } \\
\text { edema/Intragastric }\end{array}$ & Rat & Active & [182] \\
\hline & Brazil & Dried leaf & $\mathrm{H}_{2} \mathrm{O}$ ext & $\begin{array}{l}\text { Carrageenan-induced pedal } \\
\text { edema/Intragastric }\end{array}$ & Rat & Active & [182] \\
\hline \multirow[t]{2}{*}{ Lavandula latifolia } & Paraguay & Aerial parts & $\begin{array}{l}\text { Chromatographic } \\
\text { fraction }\end{array}$ & $\begin{array}{l}\text { Carrageenan-induced pedal } \\
\text { edema/*** }\end{array}$ & Rat & Active & [183] \\
\hline & Paraguay & Aerial parts & $\mathrm{EtOH}(70 \%)$ ext & $\begin{array}{l}\text { Carrageenan-induced pedal } \\
\text { edema/*** }\end{array}$ & Rat & Active & [183] \\
\hline Raphiodon echinus & Brazil & $\begin{array}{l}\text { Dried aerial } \\
\text { parts }\end{array}$ & $\mathrm{H}_{2} \mathrm{O}$ ext & $\begin{array}{l}\text { Acetic acid-induced dye } \\
\text { diffusion/Intragastric }\end{array}$ & Mouse & Active & [129] \\
\hline Liliaceae & & & & & & & \\
\hline
\end{tabular}


Table 1. Cont.

\begin{tabular}{|c|c|c|c|c|c|c|c|}
\hline \multirow[t]{2}{*}{ Polygonatum punctatum } & Argentina & $\begin{array}{l}\text { Oven dried } \\
\text { aerial parts }\end{array}$ & $\mathrm{CH}_{2} \mathrm{Cl}_{2}$ ext & $\begin{array}{l}\text { Phorbol myristate acetate- } \\
\text { induced ear inflammation/** }\end{array}$ & Mouse & Active & [123] \\
\hline & Argentina & $\begin{array}{l}\text { Oven dried } \\
\text { aerial parts }\end{array}$ & $\mathrm{H}_{2} \mathrm{O}$ ext & $\begin{array}{l}\text { Carrageenan-induced pedal } \\
\text { edema/Intragastric }\end{array}$ & Rat & $\begin{array}{l}\text { Weak } \\
\text { activity }\end{array}$ & [123] \\
\hline \multicolumn{8}{|l|}{ Linaceae } \\
\hline Vantanea peruviana & Peru & $\begin{array}{l}\text { Dried } \\
\text { stembark }\end{array}$ & $\mathrm{EtOH}(100 \%)$ ext & $\begin{array}{l}\text { EPP-induced rat ear } \\
\text { oedema/** }\end{array}$ & Rat & $\begin{array}{l}\text { Strong } \\
\text { activity }\end{array}$ & [103] \\
\hline \multicolumn{8}{|l|}{ Loasaceae } \\
\hline \multirow[t]{2}{*}{ Mentzelia chilensis } & Peru & Dried stem & EtoAc ext & $\begin{array}{l}\text { Carrageenan-induced pedal } \\
\text { edema/Intragastric }\end{array}$ & Rat & Active & [184] \\
\hline & Peru & Dried stem & $\mathrm{H}_{2} \mathrm{O}$ ext & $\begin{array}{l}\text { Carrageenan-induced pedal } \\
\text { edema/Intragastric }\end{array}$ & Rat & Active & [184] \\
\hline \multicolumn{8}{|l|}{ Lythraceae } \\
\hline Adenaria floribunda & Peru & Dried stem & $\mathrm{EtOH}(100 \%)$ ext & $\begin{array}{l}\text { EPP-induced rat ear } \\
\text { oedema/** }\end{array}$ & Rat & Active & [103] \\
\hline \multicolumn{8}{|l|}{ Magnoliaceae } \\
\hline Talauma ovata & Brazil & Dried leaf & $\mathrm{EtOH}(95 \%)$ ext & $\begin{array}{l}\text { Carrageenan-induced pedal } \\
\text { edema/IP }\end{array}$ & Rat & Inactive & [185] \\
\hline \multicolumn{8}{|l|}{ Malvaceae } \\
\hline Sida cordifolia & Brazil & Dried leaf & $\mathrm{H}_{2} \mathrm{O}$ ext & $\begin{array}{l}\text { Carrageenan-induced pedal } \\
\text { edema/Intragastric }\end{array}$ & Rat & Active & [186] \\
\hline Urena lobata & Ecuador & $\begin{array}{l}\text { Dried entire } \\
\text { plant }\end{array}$ & $\mathrm{EtOH}(100 \%)$ ext & $\begin{array}{l}\text { Carrageenan-induced pedal } \\
\text { edema/Intragastric }\end{array}$ & Mouse & $\begin{array}{l}\text { Weak } \\
\text { activity }\end{array}$ & [95] \\
\hline \multicolumn{8}{|l|}{ Meliaceae } \\
\hline \multirow[t]{2}{*}{ Guarea guidonia } & Brazil & Seed & $\mathrm{EtOH}(90 \%)$ ext & $\begin{array}{l}\text { Carrageenan-induced pedal } \\
\text { edema/Gastric Intubation }\end{array}$ & Rat & Active & [187] \\
\hline & Brazil & Seed & $\mathrm{EtOH}(90 \%)$ ext & $\begin{array}{l}\text { Cotton pellet } \\
\text { granuloma/Gastric Intubation }\end{array}$ & Rat & Active & [187] \\
\hline Trichilia glabra & Argentina & Dried leaf & & $\begin{array}{l}\text { Zymosan-induced immediate } \\
\text { inflammation moded/IP }\end{array}$ & Mouse & Active & [188] \\
\hline
\end{tabular}


Table 1. Cont.

\begin{tabular}{|c|c|c|c|c|c|c|c|}
\hline \multicolumn{8}{|l|}{ Menispermaceae } \\
\hline Abuta grandifolia & Peru & $\begin{array}{l}\text { Dried part not } \\
\text { specified }\end{array}$ & $\mathrm{EtOH}(95 \%)$ ext & $\begin{array}{l}\text { Carrageenan-induced pedal } \\
\text { edema/IP }\end{array}$ & Rat & $* *$ & [132] \\
\hline \multirow[t]{3}{*}{ Cissampelos sympodialis } & Brazil & Dried leaf & EtOH $(80 \%)$ ext & Capsaicin induced edema/IP & Mouse & Active & [189] \\
\hline & Brazil & Dried leaf & $\mathrm{EtOH}(80 \%)$ ext & $\begin{array}{l}\text { 12-O-tetradecanoylphorbol- } \\
13 \text {-acetate(TPA)-induced ear } \\
\text { inflammation/IP }\end{array}$ & Mouse & Active & [189] \\
\hline & Brazil & Dried leaf & $\mathrm{EtOH}(80 \%)$ ext & $\begin{array}{l}\text { Carrageenan-induced pedal } \\
\text { edema/IP }\end{array}$ & Rat & Active & [189] \\
\hline \multicolumn{8}{|l|}{ Monimiaceae } \\
\hline Peumus boldus & Chile & Dried leaf & EtOH $(70 \%)$ ext & $\begin{array}{l}\text { Carrageenan-induced pedal } \\
\text { edema/IP }\end{array}$ & Rat & Active & [190] \\
\hline \multicolumn{8}{|l|}{ Moraceae } \\
\hline Dorstenia brasiliensis & Brazil & Fresh root & Infusion & $\begin{array}{l}\text { Dye diffusion } \\
\text { assay/Intragastric }\end{array}$ & Mouse & $\begin{array}{l}\text { Weak } \\
\text { activity }\end{array}$ & [119] \\
\hline \multicolumn{8}{|l|}{ Myristicaceae } \\
\hline Virola pavonis & Peru & Dried vine & $\mathrm{EtOH}(95 \%)$ ext & $\begin{array}{l}\text { Carrageenan-induced pedal } \\
\text { edema/IP }\end{array}$ & Rat & Active & [132] \\
\hline Virola peruviana & Peru & $\begin{array}{l}\text { Dried part not } \\
\text { specified }\end{array}$ & $\mathrm{EtOH}(95 \%)$ ext & $\begin{array}{l}\text { Carrageenan-induced pedal } \\
\text { edema/IP }\end{array}$ & Rat & Active & [132] \\
\hline \multirow[t]{5}{*}{ Eugenia uniflora } & Brazil & Fresh leaf & Infusion & $\begin{array}{l}\text { Carrageenan-induced pedal } \\
\text { edema/Intragastric }\end{array}$ & Rat & Active & [191] \\
\hline & Brazil & Fresh leaf & $\mathrm{EtOH}(100 \%)$ ext & $\begin{array}{l}\text { Carrageenan-induced pedal } \\
\text { edema/Intragastric }\end{array}$ & Rat & Active & [191] \\
\hline & Brazil & Fresh leaf & Decoction & $\begin{array}{l}\text { Carrageenan-induced pedal } \\
\text { edema/Intragastric }\end{array}$ & Rat & Active & [191] \\
\hline & Brazil & Dried leaf & Infusion & $\begin{array}{l}\text { Carrageenan-induced pedal } \\
\text { edema/Intragastric }\end{array}$ & Rat & Inactive & [191] \\
\hline & Brazil & Dried leaf & $\mathrm{EtOH}(100 \%)$ ext & $\begin{array}{l}\text { Carrageenan-induced pedal } \\
\text { edema/Intragastric }\end{array}$ & Rat & Inactive & [191] \\
\hline
\end{tabular}


Table 1. Cont.

\begin{tabular}{|c|c|c|c|c|c|c|c|}
\hline Psidium guineense & Brazil & $\begin{array}{l}\text { Fresh leaf } \\
\text { essential oil }\end{array}$ & Essential oil & $\begin{array}{l}\text { Carrageenan-induced pedal } \\
\text { edema/Intragastric }\end{array}$ & Rat & Active & {$[192]$} \\
\hline \multicolumn{8}{|l|}{ Olacaceae } \\
\hline \multirow[t]{2}{*}{ Heisteria acuminata } & Ecuador & $\begin{array}{l}\text { Dried part not } \\
\text { specified }\end{array}$ & $\mathrm{CH}_{2} \mathrm{Cl}_{2}$ ext & $\begin{array}{l}\text { Carrageenan-induced pedal } \\
\text { edema/Intragastric }\end{array}$ & Mouse & Inactive & [96] \\
\hline & Ecuador & $\begin{array}{l}\text { Dried entire } \\
\text { plant }\end{array}$ & $\mathrm{EtOH}(100 \%)$ ext & $\begin{array}{l}\text { Carrageenan-induced pedal } \\
\text { edema/Intragastric }\end{array}$ & Mouse & Active & [95] \\
\hline \multicolumn{8}{|l|}{ Orchidaceae } \\
\hline Catasetum barbatum & Paraguay & $\begin{array}{l}\text { Dried aerial } \\
\text { parts }\end{array}$ & $\mathrm{EtOH}(70 \%)$ ext & $\begin{array}{l}\text { Carrageenan-induced pedal } \\
\text { edema/** }\end{array}$ & Rat & Active & [193] \\
\hline \multicolumn{8}{|l|}{ Phytolaccaceae } \\
\hline \multirow[t]{7}{*}{ Petiveria alliacea } & Brazil & Dried root & $\mathrm{EtOH}(70 \%)$ ext & $\begin{array}{l}\text { Croton oil-induced } \\
\text { irritation/** }\end{array}$ & Rat & Active & [194] \\
\hline & Brazil & Dried root & $\mathrm{EtOH}(70 \%)$ ext & Cotton pellet granuloma/** & Rat & Active & [194] \\
\hline & Brazil & Dried root & $\begin{array}{l}\text { Hydro-alcoholic } \\
\text { ext }\end{array}$ & $\begin{array}{l}\text { Nystatin induced } \\
\text { edema/Intragastric }\end{array}$ & Rat & Active & [195] \\
\hline & Brazil & Dried root & $\begin{array}{l}\text { Hydro-alcoholic } \\
\text { ext }\end{array}$ & $\begin{array}{l}\text { Carrageenan-induced pedal } \\
\text { edema/Intragastric }\end{array}$ & Rat & Active & [195] \\
\hline & Brazil & Dried root & $\begin{array}{l}\text { Lyophilized } \\
\text { extract }\end{array}$ & $\begin{array}{l}\text { Carrageenan-induced pedal } \\
\text { edema/Intragastric }\end{array}$ & Rat & Active & [196] \\
\hline & Brazil & Dried root & $\begin{array}{l}\text { Hydro-alcoholic } \\
\text { ext }\end{array}$ & $\begin{array}{l}\text { Cotton pellet } \\
\text { granuloma/Intragastric }\end{array}$ & Rat & Active & [195] \\
\hline & Peru & $\begin{array}{l}\text { Dried entire } \\
\text { plant }\end{array}$ & $\mathrm{EtOH}(100 \%)$ ext & $\begin{array}{l}\text { EPP-induced rat ear } \\
\text { oedema/** }\end{array}$ & Rat & Inactive & [103] \\
\hline \multirow[t]{2}{*}{ Phytolacca bogotensis } & Ecuador & $\begin{array}{l}\text { Dried entire } \\
\text { plant }\end{array}$ & EtOH $(100 \%)$ ext & $\begin{array}{l}\text { Carrageenan-induced pedal } \\
\text { edema/Intragastric }\end{array}$ & Mouse & Inactive & [95] \\
\hline & Ecuador & $\begin{array}{l}\text { Dried entire } \\
\text { plant }\end{array}$ & $\mathrm{CH}_{2} \mathrm{Cl}_{2}$ ext & $\begin{array}{l}\text { Carrageenan-induced pedal } \\
\text { edema/Intragastric }\end{array}$ & Mouse & Inactive & [96] \\
\hline Phytolacca rivinoides & Ecuador & $\begin{array}{l}\text { Dried entire } \\
\text { plant }\end{array}$ & EtOH $(100 \%)$ ext & $\begin{array}{l}\text { Carrageenan-induced pedal } \\
\text { edema/Intragastric }\end{array}$ & Mouse & $\begin{array}{l}\text { Weak } \\
\text { activity }\end{array}$ & [95] \\
\hline
\end{tabular}


Table 1. Cont.

\section{Piperaceae}

Peperomia pellucida

Piper lenticellosum

Piper marginatum

Plantaginaceae

Plantago australis

\begin{tabular}{|c|c|c|c|c|c|c|c|}
\hline & Ecuador & $\begin{array}{l}\text { Dried entire } \\
\text { plant }\end{array}$ & $\mathrm{CH}_{2} \mathrm{Cl}_{2}$ ext & $\begin{array}{l}\text { Carrageenan-induced pedal } \\
\text { edema/Intragastric }\end{array}$ & Mouse & Inactive & [96] \\
\hline \multicolumn{8}{|l|}{ Piperaceae } \\
\hline Peperomia pellucida & Brazil & Dried aerial & $\mathrm{H}_{2} \mathrm{O}$ ext & $\begin{array}{l}\text { Carrageenan-induced pedal } \\
\text { edema/Intragastric }\end{array}$ & Rat & Active & [197] \\
\hline \multirow[t]{2}{*}{ Piper lenticellosum } & Ecuador & $\begin{array}{l}\text { Dried entire } \\
\text { plant }\end{array}$ & $\mathrm{EtOH}(100 \%) \mathrm{ext}$ & $\begin{array}{l}\text { Carrageenan-induced pedal } \\
\text { edema/Intragastric }\end{array}$ & Mouse & Active & [95] \\
\hline & Ecuador & Dried fruit & $\mathrm{CH}_{2} \mathrm{Cl}_{2}$ ext & & Mouse & Active & [96] \\
\hline Piper marginatum & Brazil & Dried leaf & $\mathrm{H}_{2} \mathrm{O}$ ext & $\begin{array}{l}\text { Carrageenan-induced pedal } \\
\text { edema/Intragastric }\end{array}$ & Rat & Active & [198] \\
\hline \multicolumn{8}{|l|}{ Plantaginaceae } \\
\hline \multirow[t]{3}{*}{ Plantago australis } & Brazil & Dried root & $\begin{array}{l}\text { Hydro-alcoholic } \\
\text { ext }\end{array}$ & $\begin{array}{l}\text { Carrageenan-induced pedal } \\
\text { edema/Intragastric }\end{array}$ & Rat & Active & [199] \\
\hline & Brazil & Dried leaf & $\begin{array}{l}\text { Hydro-alcoholic } \\
\text { ext }\end{array}$ & $\begin{array}{l}\text { Carrageenan-induced pedal } \\
\text { edema/Intragastric }\end{array}$ & Rat & Active & [199] \\
\hline & Brazil & Dried fruit & $\begin{array}{l}\text { Hydro-alcoholic } \\
\text { ext }\end{array}$ & $\begin{array}{l}\text { Carrageenan-induced pedal } \\
\text { edema/Intragastric }\end{array}$ & Rat & Active & [199] \\
\hline \multirow{5}{*}{ Plantago major } & Brazil & Dried leaf & $\mathrm{H}_{2} \mathrm{O}$ ext & Croton oil-induced edema/** & Mouse & Inactive & {$[200]$} \\
\hline & Brazil & Dried leaf & $\mathrm{H}_{2} \mathrm{O}$ ext & $\begin{array}{l}\text { Croton oil granuloma/** } \\
\text { pouch/Intragastric }\end{array}$ & Rat & Active & [200] \\
\hline & Brazil & Dried leaf & $\mathrm{H}_{2} \mathrm{O}$ ext & $\begin{array}{l}\text { Dextran-induced pedal } \\
\text { edema/Intragastric }\end{array}$ & Rat & Inactive & {$[200]$} \\
\hline & Brazil & Dried leaf & $\mathrm{H}_{2} \mathrm{O}$ ext & $\begin{array}{l}\text { Carrageenan-induced } \\
\text { pleurisy/Intragastric }\end{array}$ & Rat & Active & [200] \\
\hline & Brazil & Dried leaf & $\mathrm{H}_{2} \mathrm{O}$ ext & $\begin{array}{l}\text { Carrageenan-induced pedal } \\
\text { edema/Intragastric }\end{array}$ & Mouse & $\begin{array}{l}\text { Weak } \\
\text { activity }\end{array}$ & [200] \\
\hline
\end{tabular}


Table 1. Cont.

\begin{tabular}{|c|c|c|c|c|c|c|c|}
\hline \multicolumn{8}{|l|}{ Polygonaceae } \\
\hline \multirow[t]{4}{*}{ Polygonum punctatum } & Brazil & $\begin{array}{l}\text { Dried entire } \\
\text { plant }\end{array}$ & Decoction & $\begin{array}{l}\text { Carrageenan-induced pedal } \\
\text { edema/Gastric intubation }\end{array}$ & Rat & Active & [201] \\
\hline & Brazil & $\begin{array}{l}\text { Dried entire } \\
\text { plant }\end{array}$ & $\begin{array}{l}\mathrm{EtOH}-\mathrm{H}_{2} \mathrm{O}(1: 1) \\
\text { ext }\end{array}$ & $\begin{array}{l}\text { Carrageenan-induced pedal } \\
\text { edema/Gastric intubation }\end{array}$ & Rat & Active & [201] \\
\hline & Brazil & $\begin{array}{l}\text { Dried entire } \\
\text { plant }\end{array}$ & $\begin{array}{l}\mathrm{EtOH}-\mathrm{H}_{2} \mathrm{O}(1: 1) \\
\text { ext }\end{array}$ & $\begin{array}{l}\text { Carrageenan-induced pedal } \\
\text { edema/*** }\end{array}$ & Rat & Inactive & [201] \\
\hline & Brazil & $\begin{array}{l}\text { Dried entire } \\
\text { plant }\end{array}$ & Decoction & $\begin{array}{l}\text { Carrageenan-induced pedal } \\
\text { edema/** }\end{array}$ & Rat & Inactive & [201] \\
\hline \multicolumn{8}{|l|}{ Polypodiaceae } \\
\hline \multirow[t]{6}{*}{ Campyloneurum phyllitidis } & Paraguay & Dried leaf & $\mathrm{H}_{2} \mathrm{O}$ ext & Croton oil-induced edema/** & Mouse & Active & [106] \\
\hline & Paraguay & Dried leaf & $\mathrm{CH}_{2} \mathrm{Cl}_{2}$ ext & Croton oil-induced edema/** & Mouse & Active & [106] \\
\hline & Paraguay & Dried leaf & $\mathrm{MeOH}$ ext & Croton oil-induced edema/** & Mouse & Active & [106] \\
\hline & Paraguay & Dried leaf & $\mathrm{H}_{2} \mathrm{O}$ ext & $\begin{array}{l}\text { Carrageenan-induced pedal } \\
\text { edema/IP }\end{array}$ & Mouse & Active & [106] \\
\hline & Paraguay & Dried leaf & $\mathrm{MeOH}$ ext & $\begin{array}{l}\text { Carrageenan-induced pedal } \\
\text { edema/IP }\end{array}$ & Mouse & Active & [106] \\
\hline & Paraguay & Dried leaf & $\mathrm{CH}_{2} \mathrm{Cl}_{2}$ ext & $\begin{array}{l}\text { Carrageenan-induced pedal } \\
\text { edema/IP }\end{array}$ & Mouse & Active & [106] \\
\hline \multicolumn{8}{|l|}{ Proteaceae } \\
\hline Lomatia hirsuta & Chile & Dried leaf & Infusion & $\begin{array}{l}\text { Carrageenan-induced pedal } \\
\text { edema/Intragastric }\end{array}$ & Guinea pig & Active & [202] \\
\hline \multicolumn{8}{|l|}{ Rhamnaceae } \\
\hline Trevoa trinervis & Chile & $\begin{array}{l}\text { Dried aerial } \\
\text { parts }\end{array}$ & $\mathrm{MeOH}$ ext & $\begin{array}{l}\text { Carrageenan-induced pedal } \\
\text { edema/Intragastric }\end{array}$ & Guinea pig & $\begin{array}{l}\text { Weak } \\
\text { activity }\end{array}$ & [203] \\
\hline
\end{tabular}


Table 1. Cont.

\begin{tabular}{|c|c|c|c|c|c|c|c|}
\hline & Chile & $\begin{array}{l}\text { Dried aerial } \\
\text { parts }\end{array}$ & Hexane ext & $\begin{array}{l}\text { Carrageenan-induced pedal } \\
\text { edema/Intragastric }\end{array}$ & Guinea pig & $\begin{array}{l}\text { Weak } \\
\text { activity }\end{array}$ & [203] \\
\hline & Chile & $\begin{array}{l}\text { Dried aerial } \\
\text { parts }\end{array}$ & $\begin{array}{l}\text { Dichloromethane } \\
\text { ext }\end{array}$ & $\begin{array}{l}\text { Carrageenan-induced pedal } \\
\text { edema/Intragastric }\end{array}$ & Guinea pig & $\begin{array}{l}\text { Weak } \\
\text { activity }\end{array}$ & [203] \\
\hline & Chile & $\begin{array}{l}\text { Dried aerial } \\
\text { parts }\end{array}$ & $\mathrm{H}_{2} \mathrm{O}$ ext & $\begin{array}{l}\text { Carrageenan-induced pedal } \\
\text { edema/Intragastric }\end{array}$ & Guinea pig & $\begin{array}{l}\text { Weak } \\
\text { activity }\end{array}$ & [203] \\
\hline & Chile & $\begin{array}{l}\text { Dried aerial } \\
\text { parts }\end{array}$ & $\mathrm{MeOH}$ ext & $\begin{array}{l}\text { Carrageenan-induced pedal } \\
\text { edema/Intragastric }\end{array}$ & Guinea pig & Active & [203] \\
\hline \multicolumn{8}{|l|}{ Rosaceae } \\
\hline \multirow[t]{3}{*}{ Acaena splendens } & Chile & $\begin{array}{l}\text { Dried bark }+ \\
\text { spines }\end{array}$ & $\mathrm{CH}_{2} \mathrm{Cl}_{2}$ ext & $\begin{array}{l}\text { Carrageenan-induced pedal } \\
\text { edema/Intragastric }\end{array}$ & Guinea pig & $\begin{array}{l}\text { Weak } \\
\text { activity }\end{array}$ & [204] \\
\hline & Chile & $\begin{array}{l}\text { Dried bark + } \\
\text { spines }\end{array}$ & Infusion & $\begin{array}{l}\text { Carrageenan-induced pedal } \\
\text { edema/Intragastric }\end{array}$ & Guinea pig & $\begin{array}{l}\text { Weak } \\
\text { activity }\end{array}$ & [204] \\
\hline & Chile & $\begin{array}{l}\text { Dried bark + } \\
\text { spines }\end{array}$ & $\mathrm{MeOH}$ ext & $\begin{array}{l}\text { Carrageenan-induced pedal } \\
\text { edema/Intragastric }\end{array}$ & Guinea pig & $\begin{array}{l}\text { Weak } \\
\text { activity }\end{array}$ & [204] \\
\hline \multirow[t]{4}{*}{ Kageneckia oblonga } & Chile & $\begin{array}{l}\text { Dried aerial } \\
\text { parts }\end{array}$ & Hexane ext & $\begin{array}{l}\text { Acetic acid-induced pedal } \\
\text { edema/** }\end{array}$ & Mouse & Active & [205] \\
\hline & Chile & $\begin{array}{l}\text { Dried aerial } \\
\text { parts }\end{array}$ & $\begin{array}{l}\mathrm{CHCl}_{3}-\mathrm{MeOH} \\
\text { extract }(2: 1)\end{array}$ & $\begin{array}{l}\text { Acetic acid-induced pedal } \\
\text { edema/** }\end{array}$ & Mouse & Active & [205] \\
\hline & Chile & $\begin{array}{l}\text { Dried aerial } \\
\text { parts }\end{array}$ & $\mathrm{MeOH}$ ext & $\begin{array}{l}\text { Acetic acid-induced pedal } \\
\text { edema/** }\end{array}$ & Mouse & Active & [205] \\
\hline & Chile & $\begin{array}{l}\text { Dried aerial } \\
\text { parts }\end{array}$ & $\begin{array}{l}\mathrm{CHCl}_{3}-\mathrm{MeOH} \\
\text { extract }(2: 1)\end{array}$ & $\begin{array}{l}\text { Carrageenan-induced pedal } \\
\text { edema/Intragastric }\end{array}$ & Guinea pig & Active & [205] \\
\hline
\end{tabular}


Table 1. Cont.

\begin{tabular}{|c|c|c|c|c|c|c|c|}
\hline & Chile & $\begin{array}{l}\text { Dried aerial } \\
\text { parts }\end{array}$ & $\begin{array}{l}\mathrm{H}_{2} \mathrm{O} \text { soluble } \\
\text { fraction }\end{array}$ & $\begin{array}{l}\text { Carrageenan-induced pedal } \\
\text { edema/Intragastric }\end{array}$ & Guinea pig & Active & [205] \\
\hline & Chile & $\begin{array}{l}\text { Dried aerial } \\
\text { parts }\end{array}$ & $\mathrm{MeOH}$ ext & $\begin{array}{l}\text { Carrageenan-induced pedal } \\
\text { edema/Intragastric }\end{array}$ & Guinea pig & Active & [205] \\
\hline & Chile & $\begin{array}{l}\text { Dried aerial } \\
\text { parts }\end{array}$ & Hexane ext & $\begin{array}{l}\text { Carrageenan-induced pedal } \\
\text { edema/Intragastric }\end{array}$ & Guinea pig & Active & [205] \\
\hline \multicolumn{8}{|l|}{ Rubiaceae } \\
\hline Chiococca brachiata & Brazil & Fresh root & Infusion & $\begin{array}{l}\text { Dye diffusion } \\
\text { assay/Intragastric }\end{array}$ & Mouse & active & [119] \\
\hline Coutarea hexandra & Brazil & $\begin{array}{l}\text { Dried } \\
\text { stembark }\end{array}$ & EtOH $(95 \%)$ ext & $\begin{array}{l}\text { Carrageenan-induced pedal } \\
\text { edema/Intragastric }\end{array}$ & Rat & Active & [206] \\
\hline Uncaria guianensis & Peru & Dried bark & $\begin{array}{l}\text { Lyophilized } \\
\text { extract }\end{array}$ & $* * / * *$ & Human adult & Active & [207] \\
\hline \multirow[t]{8}{*}{ Uncaria tomentosa } & Peru & $\begin{array}{l}\text { Freeze-dried } \\
\text { bark }\end{array}$ & $\mathrm{H}_{2} \mathrm{O}$ ext & $\begin{array}{l}\text { Carrageenan-induced pedal } \\
\text { edema/Intragastric }\end{array}$ & Mouse & Active & [208] \\
\hline & Peru & $\begin{array}{l}\text { Freeze-dried } \\
\text { bark }\end{array}$ & $\begin{array}{l}\text { Hydro-alcoholic } \\
\text { ext }\end{array}$ & $\begin{array}{l}\text { Carrageenan-induced pedal } \\
\text { edema/Intragastric }\end{array}$ & Mouse & Active & [208] \\
\hline & Peru & Dried bark & $\begin{array}{l}\text { Lyophilized } \\
\text { extract }\end{array}$ & $* * / \mathrm{IP}$ & Mouse & Active & [209] \\
\hline & Peru & Dried bark & $\begin{array}{l}\text { Lyophilized } \\
\text { extract }\end{array}$ & $* * /$ Oral & Human adult & Active & [209] \\
\hline & Peru & Dried bark & $\mathrm{H}_{2} \mathrm{O}$ ext & Cell Culture & In vitro & Active & [210] \\
\hline & Peru & Dried bark & $\mathrm{H}_{2} \mathrm{O}$ ext & $\begin{array}{l}\text { 5-ht-induced pedal } \\
\text { edema/Intragastric }\end{array}$ & Rat & Active & [211] \\
\hline & Peru & Dried bark & $\begin{array}{l}\text { Lyophilized } \\
\text { extract }\end{array}$ & $* * /$ Oral & Human adult & Active & [207] \\
\hline & Peru & Dried vine & $\begin{array}{l}\text { Type ext not } \\
\text { stated }\end{array}$ & $* * /$ Route not given & Human adult & Active & [212] \\
\hline
\end{tabular}


Table 1. Cont.

\begin{tabular}{|c|c|c|c|c|c|c|c|}
\hline & Peru & Dried bark & Pet ether ext & 5-ht-Induced pedal edema/IP & Rat & Active & [213] \\
\hline & Peru & Dried bark & $\mathrm{H}_{2} \mathrm{O}$ ext & $\begin{array}{l}\text { Chronic intestinal } \\
\text { inflammation induced by } \\
\text { indomethacin/** }\end{array}$ & Rat & Active & [210] \\
\hline & Peru & Dried root & Rootbark & $\begin{array}{l}\text { Convulsions strychnine- } \\
\text { induced/carrageenan-induced } \\
\text { pedal edemaI/Intragastric }\end{array}$ & Rat & Active & [214] \\
\hline & Peru & Dried bark & EtoAc ext & $\begin{array}{l}\text { 5-ht-Induced pedal } \\
\text { edema/Intragastric }\end{array}$ & Rat & Active & [211] \\
\hline & Peru & $\begin{array}{l}\text { Part not } \\
\text { specified }\end{array}$ & $\begin{array}{l}\text { Type ext not } \\
\text { stated }\end{array}$ & $* * / * *$ & Human adult & Equivocal & [215] \\
\hline \multicolumn{8}{|l|}{ Rutaceae } \\
\hline Zanthoxylum chiloperone & Brazil & dried leaf & Pet ether ext & $\begin{array}{l}\text { Carrageenan-induced pedal } \\
\text { edema/Intragastric }\end{array}$ & & Active & [216] \\
\hline \multicolumn{8}{|l|}{ Sapindaceae } \\
\hline Dodonaea viscosa & Brazil & Dried leaf & $\mathrm{EtOH}(70 \%)$ ext & $\begin{array}{l}\text { Carrageenan-induced pedal } \\
\text { edema/Intragastric }\end{array}$ & Rat & Active & [217] \\
\hline \multicolumn{8}{|l|}{ Sapotaceae } \\
\hline Bumelia sartorum & Brazil & Dried rootbark & $\mathrm{EtOH}(95 \%)$ ext & $\begin{array}{l}\text { Carrageenan-induced pedal } \\
\text { edema/Gastric Intubation }\end{array}$ & Rat & Active & [218] \\
\hline \multirow[t]{3}{*}{ Scoparia dulcis } & Brazil & $\begin{array}{l}\text { Dried entire } \\
\text { plant }\end{array}$ & $\mathrm{EtOH}(95 \%)$ ext & $\begin{array}{l}\text { Histamine-induced } \\
\text { edema/carrageenan-induced } \\
\text { pedal edema/Intragastric }\end{array}$ & Rat & Active & [219] \\
\hline & Brazil & $\begin{array}{l}\text { Dried entire } \\
\text { plant }\end{array}$ & $\mathrm{H}_{2} \mathrm{O}$ ext & $\begin{array}{l}\text { Carrageenan-induced pedal } \\
\text { edema/Intragastric }\end{array}$ & Rat & Inactive & [219] \\
\hline & Brazil & $\begin{array}{l}\text { Dried entire } \\
\text { plant }\end{array}$ & $\mathrm{EtOH}(95 \%)$ ext & $\begin{array}{l}\text { Dextran-induced pedal } \\
\text { edema/Intragastric }\end{array}$ & Rat & Active & [219] \\
\hline
\end{tabular}


Table 1. Cont.

\begin{tabular}{|c|c|c|c|c|c|c|c|}
\hline & Brazil & $\begin{array}{l}\text { Dried entire } \\
\text { plant }\end{array}$ & $\mathrm{EtOH}(95 \%)$ ext & $\begin{array}{l}\text { Cotton pellet } \\
\text { granuloma/Intragastric }\end{array}$ & Rat & Inactive & [219] \\
\hline \multicolumn{8}{|l|}{ Simaroubaceae } \\
\hline \multirow[t]{4}{*}{ Simaba cedron } & $\begin{array}{l}\text { South } \\
\text { America }\end{array}$ & Seed & Ether ext & $* * / \mathrm{SC}$ & Rat & Inactive & [220] \\
\hline & $\begin{array}{l}\text { South } \\
\text { America }\end{array}$ & Seed & Pet ether ext & $* * / \mathrm{SC}$ & Rat & Inactive & [220] \\
\hline & $\begin{array}{l}\text { South } \\
\text { America }\end{array}$ & Seed & $\mathrm{EtOH}(95 \%)$ ext & Cotton pellet granuloma/SC & Rat & $\begin{array}{l}\text { Weak } \\
\text { activity }\end{array}$ & [220] \\
\hline & $\begin{array}{l}\text { South } \\
\text { America }\end{array}$ & Seed & $\mathrm{H}_{2} \mathrm{O}$ ext & $\begin{array}{l}\text { Dextran-induced pedal } \\
\text { edema/SC }\end{array}$ & Rat & $\begin{array}{l}\text { Weak } \\
\text { activity }\end{array}$ & [220] \\
\hline \multicolumn{8}{|l|}{ Solanaceae } \\
\hline Brunfelsia bonodora & Peru & $\begin{array}{l}\text { Dried part not } \\
\text { specified }\end{array}$ & $\mathrm{EtOH}(95 \%)$ ext & $\begin{array}{l}\text { Carrageenan-induced pedal } \\
\text { edema/IP }\end{array}$ & Rat & Active & [132] \\
\hline \multirow[t]{3}{*}{ Brunfelsia uniflora } & Brazil & Root & $\mathrm{MeOH}$ ext & $\begin{array}{l}\text { Carrageenin-induced pedal } \\
\text { edema/Oral }\end{array}$ & Rat & Active & [221] \\
\hline & Brazil & Root & $\mathrm{CHCl}_{3}$ ext & Data incomplete/Oral & Rat & Active & [222] \\
\hline & Brazil & Fresh leaf & Infusion & $\begin{array}{l}\text { Dye diffusion } \\
\text { assay/Intragastric }\end{array}$ & Mouse & Inactive & [119] \\
\hline \multirow[t]{4}{*}{ Solanum ligustrinum } & Chile & $\begin{array}{l}\text { Dried aerial } \\
\text { parts }\end{array}$ & Infusion & $\begin{array}{l}\text { Carrageenan-induced pedal } \\
\text { edema/Intragastric }\end{array}$ & Guinea pig & $\begin{array}{l}\text { Weak } \\
\text { activity }\end{array}$ & [223] \\
\hline & Chile & $\begin{array}{l}\text { Dried aerial } \\
\text { parts }\end{array}$ & Decoction & $\begin{array}{l}\text { Carrageenan-induced pedal } \\
\text { edema/Intragastric }\end{array}$ & Guinea pig & $\begin{array}{l}\text { Weak } \\
\text { activity }\end{array}$ & [223] \\
\hline & Chile & $\begin{array}{l}\text { Dried aerial } \\
\text { parts }\end{array}$ & $\mathrm{MeOH}$ ext & $\begin{array}{l}\text { Carrageenan-induced pedal } \\
\text { edema/Intragastric }\end{array}$ & Guinea pig & $\begin{array}{l}\text { Weak } \\
\text { activity }\end{array}$ & [223] \\
\hline & Chile & $\begin{array}{l}\text { Dried aerial } \\
\text { parts }\end{array}$ & $\begin{array}{l}\text { Dichloromethane } \\
\text { ext }\end{array}$ & $\begin{array}{l}\text { Carrageenan-induced pedal } \\
\text { edema/Intragastric }\end{array}$ & Guinea pig & $\begin{array}{l}\text { Weak } \\
\text { activity }\end{array}$ & [223] \\
\hline
\end{tabular}


Table 1. Cont

\begin{tabular}{|c|c|c|c|c|c|c|c|}
\hline & Chile & $\begin{array}{l}\text { Dried aerial } \\
\text { parts }\end{array}$ & $\mathrm{H}_{2} \mathrm{O}$ ext & $\begin{array}{l}\text { Carrageenan-induced pedal } \\
\text { edema/Intragastric }\end{array}$ & Guinea pig & $\begin{array}{l}\text { Weak } \\
\text { activity }\end{array}$ & [223] \\
\hline & Chile & $\begin{array}{l}\text { Dried aerial } \\
\text { parts }\end{array}$ & Pet ether ext & $\begin{array}{l}\text { Carrageenan-induced pedal } \\
\text { edema/Intragastric }\end{array}$ & Guinea pig & $\begin{array}{l}\text { Weak } \\
\text { activity }\end{array}$ & [223] \\
\hline & Chile & $\begin{array}{l}\text { Dried aerial } \\
\text { parts }\end{array}$ & $\mathrm{MeOH}$ ext & $\begin{array}{l}\text { Carrageenan-induced pedal } \\
\text { edema/Intragastric }\end{array}$ & Guinea pig & $\begin{array}{l}\text { Weak } \\
\text { activity }\end{array}$ & [223] \\
\hline \multirow[t]{3}{*}{ Solanum lycocarpum } & Brazil & Dried fruit & $\mathrm{EtOH}(95 \%)$ ext & $\begin{array}{l}\text { Croton oil-induced } \\
\text { edema/Intragastric }\end{array}$ & Mouse & Active & {$[224]$} \\
\hline & Brazil & Dried fruit & Alkaloid fract & $\begin{array}{l}\text { Carrageenan-induced pedal } \\
\text { edema/SC }\end{array}$ & Mouse & Active & {$[224]$} \\
\hline & Brazil & Dried fruit & Alkaloid fract & Croton oil-induced edema/SC & Mouse & Active & [224] \\
\hline \multicolumn{8}{|l|}{ Turneraceae } \\
\hline \multirow[t]{2}{*}{ Turnera ulmifolia } & Brazil & $\begin{array}{l}\text { Dried entire } \\
\text { plant }\end{array}$ & $\begin{array}{l}\text { Hydro-alcoholic } \\
\text { ext }\end{array}$ & $\begin{array}{l}\text { Cotton pellet } \\
\text { granuloma/Intragastric }\end{array}$ & Rat & Active & [225] \\
\hline & Brazil & $\begin{array}{l}\text { Dried entire } \\
\text { plant }\end{array}$ & EtoAc ext & $\begin{array}{l}\text { Carrageenan-induced pedal } \\
\text { edema/Intragastric }\end{array}$ & Rat & Inactive & [225] \\
\hline \multirow[t]{4}{*}{$\begin{array}{l}\text { Verbenaceae } \\
\text { Bouchea fluminensis }\end{array}$} & Brazil & Dried leaf & $\mathrm{H}_{2} \mathrm{O}$ ext & $\begin{array}{l}\text { Carrageenan-induced pedal } \\
\text { edema/Route not given }\end{array}$ & Rat & Active & [87] \\
\hline & Brazil & $\begin{array}{l}\text { dried aerial } \\
\text { parts }\end{array}$ & $\mathrm{EtOH}(95 \%)$ ext & $\begin{array}{l}\text { 5-ht-induced pedal } \\
\text { edema/Intragastric }\end{array}$ & Mouse & Active & [226] \\
\hline & Brazil & $\begin{array}{l}\text { dried aerial } \\
\text { parts }\end{array}$ & $\mathrm{EtOH}(95 \%)$ ext & $\begin{array}{l}\text { Histamine-induced } \\
\text { edema/Intragastric }\end{array}$ & Mouse & Active & [226] \\
\hline & Brazil & $\begin{array}{l}\text { dried aerial } \\
\text { parts }\end{array}$ & $\mathrm{EtOH}(95 \%)$ ext & $\begin{array}{l}\text { Carrageenan-induced pedal } \\
\text { edema/Intragastric }\end{array}$ & Mouse & Active & [226] \\
\hline Stachytarpheta cayennensis & Brazil & Dried leaf & $\mathrm{EtOH}(70 \%)$ ext & $\begin{array}{l}\text { Carrageenan-induced pedal } \\
\text { edema/Intragastric }\end{array}$ & Rat & $\begin{array}{l}\text { Weak } \\
\text { activity }\end{array}$ & [227] \\
\hline
\end{tabular}


Table 1. Cont.

\begin{tabular}{|c|c|c|c|c|c|c|c|}
\hline & Brazil & Dried leaf & Infusion & $\begin{array}{l}\text { Carrageenan-induced pedal } \\
\text { edema/Intragastric }\end{array}$ & Rat & Active & [227] \\
\hline & Brazil & $\begin{array}{l}\text { Dried entire } \\
\text { plant }\end{array}$ & $\mathrm{H}_{2} \mathrm{O}$ ext & $\begin{array}{l}\text { Dextran-induced pedal } \\
\text { edema/carrageenan-induced } \\
\text { pedal edema/histamine- } \\
\text { induced edema/Intragastric }\end{array}$ & Mouse & Inactive & [227] \\
\hline & Brazil & Dried leaf & Butanol ext & $\begin{array}{l}\text { Carrageenan-induced pedal } \\
\text { edema/IP }\end{array}$ & $\begin{array}{l}\text { Salvelinus } \\
\text { alpinus }\end{array}$ & $\begin{array}{l}\text { Weak } \\
\text { activity }\end{array}$ & [227] \\
\hline & Brazil & Dried leaf & Butanol ext & $\begin{array}{l}\text { Carrageenan-induced pedal } \\
\text { edema/IP }\end{array}$ & Rat & Active & [228] \\
\hline \multicolumn{8}{|l|}{ Winteraceae } \\
\hline \multirow[t]{8}{*}{ Drimys winter } & Brazil & Dried bark & $\begin{array}{l}\text { Hydro-alcoholic } \\
\text { ext }\end{array}$ & $\begin{array}{l}\mathrm{PgE}_{2} \text { induced paw } \\
\text { oedma/Intragastric }\end{array}$ & Rat & Equivocal & [229] \\
\hline & Brazil & Dried bark & $\begin{array}{l}\text { Hydro-alcoholic } \\
\text { ext }\end{array}$ & $\begin{array}{l}\text { Histamine-induced } \\
\text { edema/Intragastric }\end{array}$ & Rat & Inactive & [229] \\
\hline & Brazil & Dried bark & $\begin{array}{l}\text { Hydro-alcoholic } \\
\text { ext }\end{array}$ & $\begin{array}{l}\text { Carrageenan-induced pedal } \\
\text { edema/Intragastric }\end{array}$ & Rat & Active & [229] \\
\hline & Brazil & Dried bark & $\begin{array}{l}\text { Hydro-alcoholic } \\
\text { ext }\end{array}$ & $\begin{array}{l}\text { Dextran-induced pedal } \\
\text { edema/Intragastric }\end{array}$ & Rat & Active & [229] \\
\hline & Brazil & Dried bark & $\begin{array}{l}\text { Hydro-alcoholic } \\
\text { ext }\end{array}$ & $\begin{array}{l}\text { Bradykinin-induced pedal } \\
\text { edema/Intragastric }\end{array}$ & Rat & $\begin{array}{l}\text { Weak } \\
\text { activity }\end{array}$ & [229] \\
\hline & Brazil & Dried bark & $\begin{array}{l}\text { Hydro-alcoholic } \\
\text { ext }\end{array}$ & Paw oedema/Intragastric & Rat & $\begin{array}{l}\text { Weak } \\
\text { activity }\end{array}$ & [229] \\
\hline & Brazil & Dried bark & $\begin{array}{l}\text { Hydro-alcoholic } \\
\text { ext }\end{array}$ & $\begin{array}{l}\text { Paf-acether induced paw } \\
\text { oedema/Intragastric }\end{array}$ & Rat & $\begin{array}{l}\text { Weak } \\
\text { activity }\end{array}$ & [229] \\
\hline & Brazil & Dried bark & $\begin{array}{l}\text { Hydro-alcoholic } \\
\text { ext }\end{array}$ & $\begin{array}{l}\text { Ovalbumine induced paw } \\
\text { oedema/Intragastric }\end{array}$ & Rat & $\begin{array}{l}\text { Weak } \\
\text { activity }\end{array}$ & [229] \\
\hline Zingiberaceae & & & & & & & [229] \\
\hline
\end{tabular}


Table 1. Cont.

\begin{tabular}{|c|c|c|c|c|c|c|c|}
\hline \multirow[t]{4}{*}{ Zingiber officinale } & Brazil & Fresh rhizome & $\begin{array}{l}\text { Hydro-alcoholic } \\
\text { ext }\end{array}$ & $\begin{array}{l}\text { Carrageenan-induced pedal } \\
\text { edema/IP }\end{array}$ & Rat & Active & [230] \\
\hline & Brazil & Fresh rhizome & $\begin{array}{l}\text { Hydro-alcoholic } \\
\text { ext }\end{array}$ & 5-ht-induced pedal edema/IP & Rat & Active & [230] \\
\hline & Brazil & Fresh rhizome & $\begin{array}{l}\text { Hydro-alcoholic } \\
\text { ext }\end{array}$ & $\begin{array}{l}48180 \text { compound-induced } \\
\text { edema/** }\end{array}$ & Rat & Active & [230] \\
\hline & Brazil & Fresh rhizome & $\begin{array}{l}\text { Hydro-alcoholic } \\
\text { ext }\end{array}$ & $\begin{array}{l}48180 \text { and } 5 \text {-ht induced skin } \\
\text { edema/IP }\end{array}$ & Rat & Active & [230] \\
\hline \multicolumn{8}{|l|}{ Zygophyllaceae } \\
\hline \multirow[t]{2}{*}{ Larrea divaricata } & Argentina & Dried leaf & $\mathrm{MeOH}$ ext & $\begin{array}{l}\text { Cotton pellet } \\
\text { granuloma/Intragastric }\end{array}$ & Rat & Active & [231] \\
\hline & Argentina & Dried leaf & $\mathrm{H}_{2} \mathrm{O}$ ext & Peritoneal macrophages/IP & Mouse & Active & [232] \\
\hline
\end{tabular}

** Incompleted dates; $\mathrm{IP}$ = intraperitoneal; $\mathrm{SC}=$ subcutaneous; $\mathrm{EtOH}=$ ethanolic extract $; \mathrm{H}_{2} \mathrm{O}$ ext = aqueous extract; $\mathrm{MeOH}$ ext = methanol extract; EtoAc ext = ethyl acetate extract; $\mathrm{CH}_{2} \mathrm{Cl}_{2}$ ext = dichloromethane extract; $\mathrm{CHCl}_{3}$ ext = chloroformic extract; $\mathrm{CCl}_{4}=$ chloroform; $\mathrm{MeCl}_{2}$ ext $=$ dichloromethane extract; EtOH- $\mathrm{H}_{2} \mathrm{O}=$ crude aqueous/alcoholic extract; $\mathrm{CHCl}_{3}-\mathrm{MeOH}$ extract $=$ dichloromethane and methanol extract. 


\section{Material and Methods}

In the present work, the anti-inflammatory activity of the plants was searched through the data bank of the University of Illinois in Chicago, the NAPRALERT (Acronym for Natural Products ALERT). The data were updated in September 2009, using anti-inflammatory plants as legend. The plant extracts studied in South America were selected for this work and the references found in the search were later consulted for details of the models or mechanisms.

\section{Conclusion}

Given the above, this review is of fundamental importance to intensify studies with medicinal plants for the discovery of new bioactive molecules in healing of many diseases, including inflammation, thus benefiting populations affected by ensuring a better quality of life.

\section{Acknowledgements}

The authors thank the University of Illinois in Chicago, U.S.A., for the use of the NAPRALERT database for this study. Thanks are also expressed for the financial support provided by $\mathrm{CNPq} /$ CAPES and PRONEX / FAPESQ, Brazil.

\section{References}

1. Vodovotz, Y.; Constantine G.; Rubin, J.; Csete, M.; Voit, E.O.; An, G. Mechanistic simulations of inflammation: Current state and future prospects. Math. Biosci. 2009, 217, 1-10.

2. Cuzzocrea, S. Shock, inflammation and PARP. Pharmacol. Res. 2005, 52, 72-82.

3. Serhan, C.N.; Brain, S.D.; Buckley, C.D.; Gilroy, D.W.; Haslett, C.; O’neall, L.A.J.; Perretti, M.; Rossi, A.G.; Wallace, J.L. Resolution of inflammation: State of the art, definitions and terms. FASEB J. 2007, 21, 325-332.

4. Conforti, F.; Sosa, S.; Marrelli, M.; Menichini, F.; Statti, G.A.; Uzunov, D.; Tubaro, A.; Menichini, F.; Loggia, R.D. In vivo anti-inflammatory and in vitro antioxidant activities of Mediterranean dietary plants. J. Ethnopharmacol. 2008, 116, 144-151.

5. Delaporte, R.H.; Sanchez, G.M.; Cuellar, A.C.; Giuliani, A.; Palazzo de Mello, J.C. Anti-inflammatory activity and lipid peroxidation inhibition of iridoid lamiide isolated from Bouchea fluminensis (Vell.) Mold. (Verbenaceae). J. Ethnopharmacol. 2002, 82, 127-130.

6. Geronikaki, A.A.; Gavalas, A.M. Antioxidants and anti-inflammatory diseases: Synthetic and natural antioxidants with anti-inflammatory activity. Comb. Chem. High Throughput Screening 2006, 9, 425-442.

7. Tincani, A.; Andreoli, L.; Bazzani, C.; Bosiso, D.; Sozzani, S. Inflammatory molecules: A target for treatment of systemic autoimmune diseases. Autoimmun. Rev. 2007, 7, 1-7.

8. Kumar, V.; Abbas, A.K.; Fausto, N. Inflamação aguda e crônica. In Robbins $e$ Cotran-Patologia, 7th ed.; Editora Saunders Elsevier: Rio de Janeiro, Brazil, 2005; pp. 49-89.

9. Chizzolini, C. Update on pathophysiology of scleroderma with special reference to immunoinflammatory events. Ann. Med. 2007, 39, 42-53. 
10. Polya, G.M. Biochemical targets of plant bioactive compounds. In A Pharmacological Reference Guide to Sites of Action and Biological Effects 2003; CRC Press: New York, NY, USA.

11. Xiao, J.; Jiang, X.; Chen, X. Antibacterial, anti-inflammatory and diuretic effect of flavonoids from Marchantia convoluta. Afr. J. Traditional Complementary Altern. Med. 2005, 2, 244-252.

12. Simões, C.M.O.; Schenkel, E.P.; Gosmann, G.; Mello, J.C.P.; Mentz, L.A. Farmacognosia da Planta ao Medicamento, 5th ed.; Editora da UFRGS: Porto Alegre, Brasil, 2004; p. 424.

13. Rimbach, G.; Melchin, M.; Moehring, J.; Wagner, A.E. Polyphenols from cocoa and vascular health - a critical review. Int. J. Mol. Sci. 2009, 10, 4290-4309.

14. Balunas, M.J.; Kinghorn, A.D. Drug discovery from medicinal plants. Life Sci. 2005, 78, 431-441.

15. Sousa, O.V.; Vieira, G.D.V.; Pinho, J.D.R.G.; Yamamoto, C.H.; Alves, M.S. Antinociceptive and anti-inflammatory activities of the ethanol extract of Annona muricata L. leaves in animal models. Int. J. Mol. Sci. 2010, 11, 2067-2078.

16. Yim, J.H.; Lee, O.-H.; Choi, U.-K.; Kim, Y.-C. Antinociceptive and anti-inflammatory effects of ethanolic extracts of Glycine max (L.) Merr and Rhynchosia nulubilis seeds. Int. J. Mol. Sci. 2009, 10, 4742-4753.

17. Yam, M.F.; Lim, V.; Salman, I.M.; Ameer, O.Z.; Ang, L.F.; Rosidah, N.; Abdulkarim, M.F.; Abdullah, G.Z.; Basir, R.; Sadikun, A.; Asmawi, M.Z. HPLC and anti-inflammatory studies of the flavonoid rich chloroform extract fraction of Orthosiphon stamineus leaves. Molecules 2010, $15,4452-4466$.

18. Souza, E.T.; Queiroz, A.C.Q.; Miranda, G.E.C.; Lorenzo, V.P.; Silva, E.F.; Freire-Dias, T.L.M.; Cupertino-Silva, Y.K.; Melo, G.M.A.; Santos, B.V.O.; Chaves, M.C.O.; Alexandre-Moreira, M.S. Antinociceptive activities of crude methanolic extract and phases, $n$-butanolic, chloroformic and ethyl acetate from Caulerpa racemosa (Caulerpaceae). Rev. Bras. Farmacogn. 2009, 19, 115-120.

19. Marzouk, M.S.; Moharram, F.A.; El-Dib, R.A.; El-Shenawy, S.M.; Tawfike, A.F. Polyphenolic profile and bioactivity study of Oenothera speciosa Nutt. aerial parts. Molecules 2009, 14, 1456-1467.

20. Potterat, O.; Hamburger, M. Drug discovery and development with plant derived compounds. Prog. Drug Res. 2008, 65, 47-118.

21. Moura, M.D.; Torres, A.R.; Oliveira, R.A.G.; Diniz, M.F.F.M.; Barbosa-Filho, J.M. Natural products as inhibitors of models of mammary neoplasia. Br. J. Phytother. 2001, 5, 124-145.

22. Moura, M.D.; Silva, J.S.; Oliveira, R.A.G.; Diniz, M.F.F.M.; Barbosa-Filho, J.M. Natural products reported as potential inhibitors of uterine cervical neoplasia. Acta Farm. Bonaer. 2002, 21, 67-74.

23. Silva, J.S.; Moura, M.D.; Oliveira, R.A.G.; Diniz, M.F.F.M.; Barbosa-Filho, J.M. Natural product inhibitors of ovarian neoplasia. Phytomedicine 2003, 10, 221-232.

24. Gonçalves, M.C.R.; Moura, L.S.A.; Rabelo, L.A.; Barbosa-Filho, J.M.; Cruz, H.M.M.; Cruz, J. Natural products inhibitors of HMG CoA reductase. Rev. Bras. Farm. 2000, 81, 63-71. 
25. Barbosa-Filho, J.M.; Martins, V.K.M.; Rabelo, L.A.; Moura, M.D.; Silva, M.S.; Cunha, E.V.L.; Souza, M.F.V.; Almeida, R.N.; Medeiros, I.A. Natural products inhibitors of the angiotensin converting enzyme (ACE). A review between 1980-2000. Rev. Bras. Farmacogn. 2006, 16, 421-446.

26. Barbosa-Filho, J.M.; Medeiros, K.C.P.; Diniz, M.F.M.; Batista, L.M.; Athayde-Filho, P.F.; Silva, M.S.; Cunha, E.V.L.; Almeida, J.R.G.S.; Quintans-Júnior, L.J. Natural products inhibitors of the enzyme acetylcholinesterase. Rev. Bras. Farmacogn. 2006, 16, 258-285.

27. Almeida, R.N.; Navarro, D.S.; Barbosa-Filho, J.M. Plants with central analgesic activity. Phytomedicine 2001, 8, 310-322.

28. Pereira, J.V.; Modesto-Filho, J.; Agra, M.F.; Barbosa-Filho, J.M. Plant and plant-derived compounds employed in prevention of the osteoporosis. Acta Farm. Bonaer. 2002, 21, 223-234.

29. Morais, L.C.S.L.; Barbosa-Filho, J.M.; Almeida, R.N.; Plants and bioactive compounds for the treatment of Parkinson's disease. Arquivos Brasileiros de Fitomedicina Científica 2003, 1, 127-132.

30. Quintans-Júnior, L.J.; Almeida, J.R.G.S.; Lima, J.T.; Nunes, X.P.; Siqueira, J.S.; Oliveira, L.E.G.; Almeida, R.N.; Athayde-Filho, P.F.; Barbosa-Filho, J.M. Plants with anticonvulsant properties-A review. Rev. Bras. Farmacogn. 2008, 18, 798-819.

31. Sousa, F.C.F.; Melo, C.T.V.; Citó, M.C.O.; Félix, F.H.C.; Vasconcelos, S.M.M.; Fonteles, M.M.F.; Barbosa-Filho, J.M.; Viana, G.S.B. Plantas medicinais e seus constituintes bioativos: Uma revisão da bioatividade e potenciais benefícios nos distúrbios da ansiedade em modelos animais. Rev. Bras. Farmacogn. 2008, 18, 642-654.

32. Rocha, L.G.; Almeida, J.R.G.S.; Macedo, R.O.; Barbosa-Filho, J.M. A review of natural products with antileishmanial activity. Phytomedicine 2005, 12, 514-535.

33. Amaral, F.M.M.; Ribeiro, M.N.S.; Barbosa-Filho, J.M.; Reis, A.S.; Nascimento, F.R.F.; Macedo, R.O. Plants and chemical constituents with giardicidal activity. Rev. Bras. Farmacogn. 2006, 16, 696-720.

34. Barbosa-Filho, J.M.; Nascimento-Júnior, F.A.; Tomaz, A.C.A.; Athayde-Filho, P.F.; Silva, M.S.; Cunha, E.V.L. Natural products with antileprotic activity. Rev. Bras. Farmacogn. 2007, 17, 141-148.

35. Barbosa-Filho, J.M.; Vasconcelos, T.H.C.; Alencar, A.A.; Batista, L.M.; Oliveira, R.A.G.; Guedes, D.N.; Falcão, H.S.; Moura, M.D.; Diniz, M.F.F.M.; Modesto-Filho, J. Plants and their active constituents from South, Central, and North America with hypoglycemic activity. Rev. Bras. Farmacogn. 2005, 15, 392-413.

36. Falcão, H.S.; Lima, I.O.; Santos, V.L.; Dantas, H.F.; Diniz, M.F.F.M.; Barbosa-Filho, J.M.; Batista, L.M. Review of the plants with anti-inflammatory activity studied in Brazil. Rev. Bras. Farmacogn. 2005, 15, 381-391.

37. Barbosa-Filho, J.M.; Piuvezam, M.R.; Moura, M.D.; Silva, M.S.; Lima, K.V.B.; Cunha, E.V.L.; Fechine, I.M.; Takemura, O.S. Anti-inflammatory activity of alkaloids: A twenty century review. Rev. Bras. Farmacogn. 2006, 16, 109-139. 
38. Mariath, I.R.; Falcão, H.S.; Barbosa-Filho, J.M.; Sousa, L.C.F.; Tomaz, A.C.A.; Batista, M.F.F.M.; Athayde-Filho, P.F.; Tavares, J.F.; Silva, M.S.; Cunha, E.V.L. Plants of the American continent with antimalarial activity. Rev. Bras. Farmacogn. 2009, 19, 158-192.

39. Falcão, H.S.; Leite, J.A.; Barbosa-Filho, J.M.; Athayde-Filho, P.F.; Chaves, M.C.O.; Moura, M.D.; Ferreira, A.L.; Almeida, A.B.A.; Souza-Brito, A.R.M.; Diniz, M.F.F.M.; Batista, L.M. Gastric and duodenal antiulcer activity of alkaloids: A review. Molecules 2008, 13, 3198-3223.

40. Falcão, H.S.; Mariath, I.R.; Diniz, M.F.F.M.; Batista, L.M.; Barbosa-Filho, J.M. Plants of the American continent with antiulcer activity. Phytomedicine 2008, 15, 132-146.

41. Mota, K.S.L.; Dias, G.E.N.; Pinto, M.E.F.; Luiz-Ferreira, A.; Souza-Brito, A.R.M.; Hiruma-Lima, C.A.; Barbosa-Filho, J.M.; Batista, L.M. Flavonoids with gastroprotective activity. Molecules 2009, 14, 979-1012.

42. Ribeiro-Filho, J.; Falcão, H.S.; Batista, L.M.; Barbosa-Filho, J.M.; Piuvezam, M.R. Effects of plant extracts on HIV-1 protease. Curr. HIV Res. 2010, 8, 531-544.

43. Agra, M.F.; França, P.F.; Barbosa-Filho, J.M. Synopsis of the plants known as medicinal and poisonous in Northeast of Brazil. Rev. Bras Farmacogn. 2007, 17, 114-140.

44. Agra, M.F.; Silva, K.N.; Basílio, I.J.L.D.; França, P.F.; Barbosa-Filho, J.M. Survey of medicinal plants used in the region Northeast of Brazil. Rev. Bras Farmacogn. 2008, 18, 472-508.

45. Barbosa-Filho, J.M.; Alencar, A.A.; Nunes, X.P.; Tomaz, A.C.A.; Sena-Filho, J.G.; Athayde-Filho, P.F.; Silva, M.S.; Souza, M.F.V.; Cunha, E.V.L. Sources of alpha-, beta-, gamma-, delta- and epsilon-carotenes: A twentieth century review. Rev. Bras. Farmacogn. 2008, $18,135-154$.

46. Alves, J.S.; Castro, J.C.; Freire, M.O.; Cunha, E.V.L.; Barbosa-Filho, J.M.; Silva, M.S. Complete assignment of the $1 \mathrm{H}$ and $13 \mathrm{C}$ spectra of four triterpenes of the ursane, artane, lupane and friedelane groups. Magn. Reson. Chem. 2000, 38, 201-206.

47. Sena-Filho, J.G.; Duringer, J.M.; Maia, G.L.A.; Tavares, J.F.; Xavier, H.S.; Silva, M.S.; Cunha, E.V.L.; Barbosa-Filho, J.M. Ecdysteroids from Vitex species: Distribution and compilation of their 13C-NMR spectral data. Chem. Biodivers. 2008, 5, 707-713.

48. Oliveira, S.L.; Silva, M.S.; Tavares, J.F.; Sena-Filho, J.G.; Lucena, H.F.S.; Romero, M.A.V.; Barbosa-Filho, J.M. Tropane alkaloids from genus Erythrorylum: Distribution and compilation of C-NMR spectral data. Chem. Biodivers. 2010, 7, 302-326.

49. Andrade, N.C.; Cunha, E.V.L.; Silva, M.S.; Agra, M.F.; Barbosa-Filho, J.M. Terpenoids of the Annonaceae: Distribution and compilation of 13C NMR data. In Recent Research Developments in Phytochemistry; Gayathri., A., Ed.; Research Signpost: Kerala, India, 2003; Volume 7, pp. 1-85.

50. Vasconcelos, S.M.M.; Honório-Júnior, J.E.R.; Abreu, R.N.D.C.; Silva, M.C.C.; Barbosa-Filho, J.M.; Lobato, R.F.G. Pharmacologic study of some plant species from the Brazilian Northeast: Calotropis procera, Agava sisalana, Solanum paludosum, Dioscorea cayenensis and Crotalaria retusa. In Medicinal Plants: Classification, Biosynthesis and Pharmacology; Varela, A., Jasiah Ibañez, J., Eds.; Nova Science Publishers, Inc.: Hauppauge, NY, USA, 2009; Volume 4, pp. 189-202. 
51. Vasconcelos, S.M.M.; Pereira, E.C.; Chaves, E.M.C.; Lobato, R.F.G.; Barbosa-Filho, J.M.; Patrocínio, M.C.A. Pharmacologic study of Amburana cearensis and Aniba genus. In Recent Progress in Medicinal Plants. Drug Plant IV; Singh, V.K., Govil, J.N., Eds.; Studium Press LLC: Houston, TX, USA, 2010; Volume 30, pp. 51-64.

52. Barbosa-Filho, J.M.; Cunha, E.V.L.; Gray, A.I. Alkaloids of the Menispermaceae. In The Alkaloids; Cordell, G.A., Ed.; Academic Press, INC: California, CA, USA, 2000; Volume 54, pp. 1-199.

53. Barbosa-Filho, J.M.; Sette, I.M.F.; Cunha, E.V.L.; Guedes, D.N.; Silva, M.S. Protoberberine alkaloids. In: The Alkaloids, Cordell, G.A., Ed.; Elsevier: Amsterdam, The Netherlands, 2005; Volume 62, pp. 1-75.

54. Conserva, L.M.; Pereira, C.A.B.; Barbosa-Filho, J.M. Alkaloids of the Hernandiaceae: Occurrence and a compilation of their biological activities. In The Alkaloids; Cordell, G.A., Ed.; Elsevier: Amsterdam, The Netherlands, 2005; Volume 62, pp. 175-243.

55. Muñoz, M.; Barrera, E.; Meza, I. El uso medicinal y alimentício de plantas nativas y naturalizadas en Chile. Museo Nacional de Historia Natural 1981, 33, 32.

56. Zdero, C.; Bohlmann, F.; King, R.M.; Robinson, H. Isocedrene derivatives, 5-methyl coumarins and other constituents from the subtribu Nassauviinae of the Compositae. Phytochemistry 1986, 25, 2873-2882.

57. Bittner, M.; Jakupovic, J.; Bohlmann, F.; Silva, M. Coumarins and guaianolides from further Chilean representatives of the subtribe Nassauviinae. Phytochemistry 1989, 28, 2867-2868.

58. Dannhardt, G.; Kiefer, W. Cyclooxygenase inhibitors - current status and future prospects. Eur. J. Med. Chem. 2001, 36, 109-126.

59. Delporte, C.; Backhouse, N.; Erazo, S.; Negrete, R.; Vidal, P.; Silva, X.; Lopez-Perez, J.L.; Feliciano, A.S.; Munoz, O. Analgesic-antiinflammatory properties of Proustia pyrifolia. J. Ethnopharmacol. 2005, 99, 119-124.

60. Abena, A.A.; Ouamba, J.M.; Keita, A. Antiinflammatory, analgesic and antipyretic activities of essential oil of Agereatum conyzoides. Phytother. Res. 1996, 10, 164-165.

61. Marques Neto, J.F.; Costallat, L.T.V.; Fernandes, S.R.M.; de Napoli, M.D.M.; Samara, A.M. Efeito do Ageratum conyzoides Lin. no tratamento da artrose. Rev. Bras. Reumatol. 1988, 28, $109-114$.

62. Magalhães, J.F.G.; Viana, C.F.G.; Aragão, A.G.M., Jr.; Moraes, V.G.; Ribeiro, R.A.; Vale, M.R. Analgesic and antiinflammatory activities of Ageratum conyzoides in rats. Phytother. Res. 1997, $11,183-188$.

63. Quellet, M.; Percival, D. Effect of inhibitor timedependency on selectivity towards ciclooxigenase isoforms. Biochem. J. 1995, 306, 247-251.

64. Terlains, B.; Jouzeau, J.Y.; Gillet, P.; Lecompte, T.; Netter, P. Cyclooxygenase inductible. Du nouveau sur les relations entre anti-inflammatoires non steroidiens et inhibition de la synthese de prostaglandines. Press. Med. 1995, 24, 491-496.

65. Moura, A.C.A.; Silva, E.L.F.; Fraga, M.C.A.; Wanderley, A.G.; Afiatpour, P.; Maia, M.B.S. Antiinflammatory and chronic toxicity study of the leaves of Ageratum conyzoides L. in rats. Phytomedicine 2005, 12, 138-142. 
66. Mendonça, C.J.; Trigo, J.R.; Barata, L.E.S.; Serra, G.E. Alcalóides Hepatotóxicos (Pirrolizidınicos) em Ageratum conyzoides (Resumo 16.45); X Reunião Anual da Federacão de Sociedades de Biologia Experimental: Serra Negra, Brasil, 1995;

67. Widenfeld, H.; Roder, E. Pyrrolizidine alkaloids from Ageratum conyzoides. Planta Med. 1991, 57, 578-579.

68. Couet, C.E.; Crews, C.; Hanley, B.A. Analysis, separation and bioassay of pyrrolizidine alkaloids from comfrey. Nat. Toxins 1996, 4, 163-167.

69. Giberti, G. Herbal folk medicine in northwestern Argentina: Compositae. J. Ethnopharmacol. 1983, 7, 321-341.

70. Ratera, E.L.; Ratera, M.O. Plantas de la Flora Argentina empleadas em Medicina Popular. Hemisferio Sur. 1980, p.108.

71. Miño, J.; Moscatelli, V.; Hnatyszyn, O.; Gorzalczany, S.; Acevedo, C.; Ferraro, G. Antinociceptive and antiinflammatory activities of Artemisia copa extracts. Pharmacol. Res. 2004, 50, 59-63.

72. Cordero, J. Enumeracion de Botanica de los Principales Plantas asi Utiles Come Nocivas, Indigenas o Aclimatadas, que se dan en la Provincias del Azuay y del Cañar de la Repubblica de Ecuador, 2nd ed.; Afrodisio Aguado: Madrid, Spain, 1950; p. 251.

73. Kohn, E.O. La cultura medica de los runas de la region Amazzonica Ecuadoriana. In Hombre y Ambiente; Ediciones Abya-Yala: Ecuador, Spain, 1992; p. 105.

74. Braca, A.; de Tommasi, N.; di Bari, L.; Pizza, C.; Politi, M.; Morelli, I. Antioxidant principles from Bauhinia tarapotensis. J. Nat. Prod. 2001, 64, 892-895.

75. Tubaro, A.; Dri, P.; Delbello, G.; Zilli, C.; Della Loggia, R. The Croton oil ear test revisited. Agents Actions 1985, 17, 347-349.

76. Sosa, S.; Braca, A.; Altinier, G.; Della Loggia, R.; Morelli, I.; Tubaro, A. Topical anti-inflammatory activity of Bauhinia tarapotensis leaves. Phytomedicine 2002, 9, 646-653.

77. Gallenmüller, F.; Müller, U.; Rowe, N.; Speck, T. The growth form of Croton pullei (Euphorbiaceae)-Functional morphology and biomechanics of a neotropical Liana. Plant Biol. 2001, 1, 50-61.

78. Rocha, F.F.; Neves, E.M.N.; Costa, E.A.; Matos, L.G.; Muller, A.H.; Guilhon, M.S.P.; Cortes, W.S.; Vanderlinde, F.A. Evaluation of antinociceptive and antiinflammatory effects of Croton pullei var. glabrior Lanj. Rev. Bras. Farmacogn. 2008, 18, 344-349.

79. Balbach, A.A. Flora Nacional na Medicina Doméstica, 11th.; Editora Edel: A Edificação do lar. São Paulo, Brasil, 1980; pp. 885.

80. Cruz, G.L. Dicionário das Plantas Úteis do Brasil. 2nd ed.; Editora Nacional: Civilização Brasileira. São Paulo, Brasil, 1982; pp. 335-336.

81. Born, G.C.C. Plantas medicinais da Mata Atlântica (Vale do Ribeira-SP), Tese de doutorado Universidade de São Paulo, São Paulo, 2000.

82. Jorge, R.M.; Leite, J.P.V.; Oliveira, A.B.; Tagliati, C.A. Evaluation of antinociceptive, anti-inflammatory and antiulcerogenic activities of Maytenus ilicifolia. J. Ethnopharmacol. 2004, 94, 93-100. 
83. Oliveira, G.M.O.; Monteiro, M.G.; Macaúbas, C.; Barbosa, V.P.; Carlini, E.A. Pharmacological and toxicologic effects of two Maytenus species in laboratory animals. J. Ethnopharmacol. 1991, 34, 29-41.

84. Lino, C.S.; Taveira, M.L.; Viana, G.S.B.; Matos, F.J.A. Analgesic and antiinflammatory activities of Justicia pectoralis Jacq and its main constituents: Coumarin and umbelliferone. Phytother. Res. 1997, 11 , 211-215.

85. Calixto, J.B.; de Lima, T.C.M.; Morato, G.S.; Nicolau, M.; Takahashi, R.N.; Valle, R.M.R.; Schmidt, C.C.; Yunes, R.A. Chemical and pharmacological analysis of the crude aqueous/alcoholic extract from Cordyline dracaenoides. Phytother. Res. 1990, 5, 167-171.

86. Dutra, R.C.; Tavares, C.Z.; Ferraz, S.O.; Sousa, O.V.; Pimenta, D.S. Investigation of analgesic and anti-inflammatory activities of Echinodorus grandiflorus rhizomes methanol extract. Rev. Bras. Farmacogn. 2006, 16, 469-474.

87. Delaporte, R.H.; Sanchez, G.M.; Cuellar, A.C.; Demello, J.C.P. Quality control and antiinflammatory activity of the plant drugs Alternanthera brasiliana (L.) Kuntze and Bouchea fluminensis (Vell.) Mold. Acta Farm. Bonaerense 2001, 20, 39-46.

88. Teixeira, C.G.L.; Piccoli, A.; Costa, P.; Soares, L.; da Silva-Santos, J.E. Involvment of the nitric oxide/soluble guanylate cyclase pathway in the anti-oedematogenic action of Pfaffia glomerata (Spreng) Pedersen in mice. J. Pharm. Pharmacol. 2006, 58, 667-675.

89. Taniguchi, S.F.; Bersani-Amado, C.; Sudo, L.S.; Assef, S.M.C.; Oga, S. Effect of Pfaffia iresinoides on the experimental inflammatory prcoess in rats. Phytother. Res. 1997, 11, 568-571.

90. Mazzanti, G.; Braghiroli, L.; Tita, B.; Bolle, P.; Piccinelli, D. Anti-inflammatory activity of Pfaffia paniculata (Martius) Kuntze and Pfaffia stenophylla (Sprengel) Stuchl. Pharmacol. Res. 1993, 27, 91-92.

91. Mazzanti, G.; Braghiroli, L. Analgesic and antiinflammatory action of Pfaffia paniculata (Marticus) Kuntze. Phytother. Res. 1994, 8, 413-416.

92. Mota, M.L.R.; Thomas, G.; Barbosa Filho, J.M. Anti-inflammatory actions of tannins isolated from the bark of Anacardium occidentale L. J. Ethnopharmacol. 1985, 13, 289-300.

93. Viana, G.S.B.; Bandeira, M.A.M.; Matos, F.J.A. Analgesic and antiinflammatory effects of chalcones isolated from Myracrodruon urundeuva Allemao. Phytomedicine 2003, 10, 189-195.

94. Abad, M.J.; Bermejo, P.; Carretero, E.; Martinez Acitores, C.; Noguera, B.; Villar, A. Antiinflammatory activity of some medicinal plant extracts from Venezuela. J. Ethnopharmacol. 1996, 55, 63-68.

95. de Las Heras, B.; Slowing, K.; Benedi, J.; Carretero, E.; Ortega, T.; Toledo, C.; Bermejo, P.; Iglesias, I.; Abad, M.J.; Gomez-Serranillos, P.; Liso, P.A.; Villar, A.; Chiriboga, X. Antiinflammatory and antioxidant activity of plants used in traditional medicine in Ecuador. J. Ethnopharmacol. 1998, 61, 161-166.

96. Ortega, T.; Carretero, M.E.; Pascual, E.; Villar, A.M.; Chiriboga, X. Anti-inflammatory activity of ethanolic extracts of plants used in traditional medicine in Ecuador. Phytother. Res. 1996, 10, S121-S122. 
97. Henriques, A.T.; Melo, A.A.; Moreno, P.R.H.; Ene, L.L.; Henriques, J.A.P.; Schapoval, E.E.S. Ervatamia coronaria: Chemical constituents and some pharmacological activities. J. Ethnopharmacol. 1996, 50, 19-25.

98. de Miranda, A.L.; Silva, J.R.; Rezende, C.M.; Neves, J.S.; Parrini, S.C.; Pinheiro, M.L.B.; Cordeiro, M.C.; Tamgborini, E.; Pinto, A.C. Anti-inflammatory and analgesic activities of the latex containing triterpenes from Himatanthus sucuuba. Planta Med. 2000, 66, 284-286.

99. Calixton, J.B.; Nicolau, M.; Trebien, H.; Henrique, M.G.O.; Weg, V.B.; Cordeiro, R.S.B.; Yunes, R.A. Antiedematogenic actions of a hydroalcoholic crude water-alcohol extract of Mandevilla velutinabraz. Braz. J. Med. Biol. Res. 1986, 19, 4-5.

100. Calixto, J.B.; Zanini, J.C.; Cruz, A.B.; Yunes, R.A.; Medeiros, Y.S. Extract and compounds obtained from Mandevilla velutina inhibit arachidonic acid-induced ear oedema in mice, but not rat stomach contraction. Prostaglandins 1991, 41, 515-526.

101. Henriques, M.G.M.O.; Fernandes, P.D.; Weg, V.B.; Yunes, R.A.; Cordeiro, R.S.B.; Calixto, J.B. Inhibition of rat paw oedema and pleurisy by the extract from Mandevilla velutina. Agents Actions 1991, 33, 272-278.

102. Rates, S.M.K.; Schapoval, E.E.S; Souza, I.A.; Henriques, A.T. Chemical constituents and pharmacological activities of Peschiera australis. Int. J. Pharmacog. 1993, 31, 288-294.

103. Dunstan, C.A.; Noreen, Y.; Serrano, G.; Cox, P.A.; Perera, P.; Bohlin, L. Evaluation of some samoan and peruvian medicinal plants by prostaglandin biosynthesis and rat ear oedema assays. J. Ethnopharmacol. 1997, 57, 35-56.

104. Fazio, S.; Pouso, J.; Dolinsky, D.; Fernandez, A.; Hernandez, M.; Clavier, G.; Hecker, M. Tolerance, safety and efficacy of Hedera helix extract in inflammatory bronchial diseases under clinical practice conditions: a prospective, open, multicentre postmarketing study in 9657 patients. Phytomedicine 2009, 16, 17-24.

105. Maia, M.B.S.; Rao, V.S. Anti-inflammatory activity of Orbignia phalerata in rats. Phytother. Res. 1989, 3, 170-174.

106. Muschietti, L.; Martino, V.; Ferraro, G.; Coussio, J.; Segura, L.; Cartana, C.; Canigueral, S.; Adzet, T. The antiinflammatory effect of some species from South America. Phytother. Res. 1996, 10, 84-86.

107. Simões, C.M.O.; Schenkel, E.P.; Bauer, L.; Langeloh, A. Pharmacological investigations on Achyrocline satureioides (Lam). DC., Compositae. J. Ethnopharmacol. 1988, 22, 281-293.

108. Viana, C.F.G.; Aragao, A.G.M., Jr.; Ribeiro, R.A.; Magalhaes, J.F.G.; Vale, M.R. Effects of Ageratum conyzoides in nociception and inflammatory response induced by Zymosan. Fitoterapia 1998, 69, 349-354.

109. Perez, F.; Marin, E.; Adzet, T. The antiinflammatory effect of several Compositae from South America extracts in rats. Phytother. Res. 1995, 9, 145-146.

110. Gene, R.M.; Marin, E.; Adzet, T. Anti-inflammatory effect of aqueous extracts of three species of the genus Baccharis. Planta Med. 1992, 58, 656-566.

111. Salama, A.M.; Polo, N.A.; Contreras, C.R.; Maldonado, L. Preliminary phytochemical and pharmacological analysis of Baccharis decussata leaves. Rev. Colomb Cienc. Quim. Farm. 1987, $16,45-50$. 
112. Cifuente, D.A.; Simirgiotis, M.J.; Favier, L.S.; Rotelli, A.E.; Pelzer, E. Anti-inflammatory activity from aerial parts of Baccharis medullosa, Baccharis rufescens and Laennecia sophiifolia in mice. Phytother. Res. 2001, 15, 529-531.

113. Gene, R.M.; Cartana, C.; Adzet, T.; Marin, E.; Parella, T.; Canigueral, S. Anti-inflammatory and analgesic activity of Baccharis trimera: Identification of its active constituents. Planta Med. 1996, 62, 232-235.

114. Pereira, R.L.C.; Ibrahim, T.; Lucchetti, L.; da Silva, A.J.R.; de Moraes, V.L.G. Immunosuppressive and anti-inflammatory effects of methanolic extract and the polyacetylene isolated from Bidens pilosa L. Immunopharmacol. 1999, 43, 31-37.

115. Ortega, C.A.; Rotelli, A.E.; Gianello, J.C. Chemical components and anti-inflammatory activity from Bidens subalternans. Planta Med. 1998, 64, 778.

116. Negrete, R.E.; Backhouse, N.; Cajigal, I.; Delporte, C.; Cassels, B.R.; Breitmaier, E.; Eckhardt, G. Two new antiinflammatory elemanolides from Centaurea chilensis. J. Ethnopharmacol. 1993, 40, 149-153.

117. Souza, M.C.; Siani, A.C.; Ramos, M.F.S.; Menezes-De-Lima, O.; Henriques, M.G.M.O. Evaluation of anti-inflammatory activity of essential oils from two Asteraceae species. Pharmazie 2003, 58, 582-586.

118. Simirgiotis, M.J.; Favier, L.S.; Rossomando, P.C.; Tonn, C.E.; Juarez, A.; Giordano, O.S. Phytochemical study of Conyza sophiaefolia. antiinflammatory activity. Molecules 2000, 5, 605-606.

119. Ruppelt, B.M.; Pereira, E.F.R.; Goncalves, L.C.; Pereira, N.A. Pharmacological screening of plants recommended by folk medicine as anti-snake venom-1. Analgesic and antiinflammatory activities. Mem. Inst. Oswaldo Cruz 1991, 86, 203-205.

120. Poli, A.; Nicolau, M.; Simoes, C.M.O.; Nicolau, R.M.R.D.V.; Zanin, M. Preliminary pharmacologic evaluation of crude whole plant extracts of Elephantopus scaber. Part I: In vivo studies. J. Ethnopharmacol. 1992, 37, 71-76.

121. Silverio, M.S.; Sousa, O.V.; Del-Vechio-Viera, G.; Miranda, M.A.; Matheus, F.C.; Kaplan, M.A.C. Pharmacological properties of the ethanol extract from Eremanthus erythropappus (DC.) Mcleisch (Asteraceae). Rev. Bras. Farmacogn. 2008, 18, 430-435.

122. Muschietti, L.; Gorzalczany, S.; Ferraro, G.; Acevedo, C.; Acevedo, C.; Martino, V. Phenolic compounds with antiinflammatory activity from Eupatorium buniifolium. Planta Med. 2001, 67, 743-744.

123. Gorzalczany, S.; Acevedo, C.; Msuchietti, L.; Martino, V.; Ferraro, G. Search for antiinflammatory activity in Argentine medicinal plants. Phytomedicine 1996, 3, 181-184.

124. Moreira, A.S.; Spitzer, V.; Schapoval, E.E.S.; Schnekel, E.P. Antiinflammatory activity of extracts and fractions from the leaves of Gochnatia polymorpha. Phytother. Res. 2000, 14, 638-640.

125. Fierro, I.M.; da Silva, A.C.B.; Lopes, C.S.; de Moura, R.S.; Barja-Fidalgo, C. Studies on the anti-allergic activity of Mikania glomerata. J. Ethnopharmacol. 1999, 66, 19-24. 
126. de Moura, R.S.; Costa, S.S.; Jansen, J.; Silva, C.A.; Lopes, C.S.; Bernardo Filho, M.; da Silva, V.N.; Criddle, D.N.; Portela, N.; Rubenich, L.M.S.; Araujo, R.G.; Carvalho, L.C.R.M. Bronchodilator activity of Mikania glomerata sprengel on human bronchi and guinea-pig trachea. J. Pharm. Pharmacol. 2002, 54, 249-256.

127. Benoit, P.S.; Fong, H.H.S.; Svoboda, G.H.; Farnsworth, N.R. Biological and phytochemical evaluation of plants. XIV. Antiinflammatory evaluation of 163 species of plants. Lloydia 1976, 39, 160-171.

128. Schinella, G.R.; Giner, R.M.; Recio, M.D.C.; de Buschiazzo, F.M.; Rios, J.L.; Manez, S. Anti-inflammatory effects of South American Tanacetum vulgare. J. Pharm. Pharmacol. 1998, 50, 1069-1074.

129. Menezes, A.M.S.; Almeida, F.R.C.; Rao, V.S.N.; Matos, M.E.O. Anti-inflammatory activity of the essential oil of Vanillosmopsis arborea. Fitoterapia 1990, 61, 252-254.

130. Oga, S.; Sekino, T. Toxicity and antiinflammatory activity of Tabebuia avellanedae extracts. Rev. Fac. Farm. Bioquim. Univ. Sao Paulo 1969, 7, 47-53.

131. Alguacil, L.F.; Mera, A.G.; Gomez, J.; Llinares, F.; Morales, L.; Munoz-Mingarro, M.D.; Pozuelo, J.M.; Orellana, J.A.V. Tecoma sambucifolia: Anti-inflammatory and antiociceptive activities, and "in vitro" toxicity of extracts of the "huarumo" of peruvian incas. J. Ethnopharmacol. 2000, 70, 227-233.

132. Persinos-Perdue, G.; Mc Daniel, S. Evaluation of peruvian folk medicine by the natural products research laboratories (Abstract). Am. Soc. Pharmacogn. Soc. Econ. Bot. 1981, 1, 5.

133. Ferreira, M.A.D.; Nunes, D.R.H.; Fontenele, J.B.; Pessoa, D.L.; Lomos, T.L.G.; Viana, G.S.B. Analgesic and anti-inflammatory activities of a fraction rich in oncocalyxone a isolated from Auxemma oncocalyx. Phytomedicine 2004, 11, 315-322.

134. Sertie, J.A.A.; Woisky, R.G.; Wiezel, G.; Rodrigues, M. Pharmacological assay of Cordia verbenacea: Oral and topical anti-inflammatory activity, analgesic effect and fetus toxicity of a crude leaf extract. Phytomedicine 2005, 5, 338-344.

135. Basile, A.C.; Sertie, J.A.A.; Oshiro, T.; Caly, K.D.V.; Panizza, S. Topical anti-inflammatory activity and toxicity of Cordia verbenacea. Fitoterapia 1989, 60, 260-263.

136. Sertie, J.A.A.; Basile, A.C.; Panizza, S.; Oshiro, T.T.; Azzolini, C.P.; Penna, S.C. Pharmacological assay of Cordia verbenaceae III. Oral and topical antiinflammatory activtiy and gastrotoxicity of crude leaf extract. J. Ethnopharmacol. 1991, 31, 239-247.

137. Sertie, J.A.A.; Basile, A.C.; Panizza, S.; Matida, A.K.; Zelnik, R. Pharmacological assay of Cordia verbenacea: Part 1. Anti-inflammatory activity and toxicity of the crude extract of the leaves. Planta Med. 1988, 54, 7-10.

138. Goldman, R.S.; Freitas, P.C.D.; Oga, S. Wound healing and analgesic effect of crude extracts of Symphytum officinale rats. Fitoterapia 1985, 56, 323-329.

139. Amendoeira, F.C.; Frutuoso, V.S.; Chedier, L.M.; Pearman, A.T.; Figueiredo, M.R.; Kaplan, M.A.C.; Prescott, S.M.; Bozza, P.T.; Castro-Farianeto, H.C. Antinociceptive effect of Nidularium procerum: A Bromeliaceae from the Brazilian coastal rain forest. Phytomedicine 2005, 12, 78-87. 
140. Delaporte, R.H.; Sarragiotto, M.H.; Takemura, O.S.; Sanchez, G.M.; Filho, B.P.D.; Nakamura, C.V. Evaluation of the antioedematogenic, free radical scavenging and antimicrobial activities of aerial parts of Tillandsia streptocarpa Baker-Bromeliaceae. J. Ethnopharmacol. 2004, 95, 229-233.

141. Noguera, B.; Diaz, E.; Garcia, M.V.; Feliciano, A.S.; Lopez-perez, J.L.; Israel, A. Anti-inflammatory activity of leaf extract and fractions of Bursera simaruba (L.) Sarg (Burseraceae). J. Ethnopharmacol. 2004, 92, 129-133.

142. Otuki, M.F.; Vieira-Lima, F.; Malheiros, A.; Yunes, R.A.; Calixto, J.B. Topical antiinflammatory effects of the ether extract from Protium kleinii and alpha amyrin pentacyclic triterpene. Eur. J. Pharmacol. 2005, 507, 253-259.

143. Costa, E.A.; Santos, L.R.; Pontes, I.S.; Matos, L.G.; Silva, G.A.; Liao, L.M. Analgesic and anti-inflammatory effects of Cheiloclinium cognatum root barks. Rev. Bras. Farmacogn. 2007, $17,508-513$.

144. Kimura, E.; Albiero, A.L.M.; Cuman, R.K.N.; Caparroz-Assef, S.M.; Oga, S.; Bersani-Amado, C.A. Effect of Maytenus aquifolium extract on the pharmacokinetic and antiinflammatory effectivenes of piroxicam in rats. Phytomedicine 2000, 7, 117-121.

145. Backhouse, N.; Delporte, C.; Negrete, R.; Munoz, O.; Ruiz, R. Antiinflammatory and antipyretic activities of Maytenus boaria. Int. J. Pharmacogn. 1994, 32, 239-244.

146. Moya, S.M.; Olarte, C.J.E. Phytochemical and pharmacological studies on the antiarthritics of plant origin. Rev. Colomb. Cienc. Quim. Farm. 1977, 3, 5-6.

147. Santos, V.L.D.; Costa, V.B.M.; Agra, M.F.; Silva, B.A.; Batista, L.M. Pharmacological studies of ethanolic extracts of Maytenus Rigida mart (Celastraceae) in animal models. Rev. Bras. Farmacogn. 2007, 17, 336-342.

148. Cardenas, L.C.; Rodriguez, J.; Villaverde, M.C.; Riguera, R.; Cadena, R.; Otero, J.A. The analgesic activity of Hedyosmum bonplandianum: flavonoid glycosides. Planta Med. 1993, 59, 26-27.

149. Perazzo, F.F.; Lima, L.M.; Padilha, M.D.M.; Rocha, L.M.; Sousa, P.J.C.; Carvalho, J.C.T. Anti-inflammatory and analgesic activities of Hypericum brasiliense (Willd) standardized extract. Rer. Bras. Farmacogn. 2008, 18, 320-325.

150. Bakchouse, N.; Delporte, C.; Negrete, R.; Salinas, P.; Pinto, A.; Aravena, S.; Cassels, B.K.; Antiinflammatory and antipyretic activities of Cuscuta chilensis, Cestrum parqui and Psoralea glandulosa. Int. J. Pharmacogn. 1996, 34, 53-57.

151. Sousa, P.J.C.; Rocha, J.C.S.; Pessoa, A.M.; Alves, L.A.D.; Carvalho, J.C.T. Preliminary study of the anti-inflammatory activity of Bryophyllum calcinum Salisb. Rev. Bras. Farmacogn. 2005, 15, 60-64.

152. Mourao, R.H.V.; Santos, F.O.; Franzotti, E.M.; Moreno, M.P.N.; Antoniolli, A.R. Antiinflammatory activity and acute toxicity (LD50) of the juice of Kalanchoe brasiliensis (Comb.) leaves picked before and during blooming. Phytother. Res. 1999, 13, 352-354.

153. Ibrahim, T.; Cunha, J.M.T.; Madi, K.; Fonseca, L.M.B.; Costa, S.S.; Koatz, V.L.G. Immunomodulatory and anti-inflammatory effects of Kalachoe brasiliensis. Int. Immunopharmacol. 2002, 2, 875-883. 
154. Ibrahim, T.; Pereira, R.L.C.; Almeida, A.P.; Madi, K.; Fonseca, L.B.M.; Costa, S.S.; Goncalves-Moraes, V.L. Antiinflammatory effect of Kalanchoe brasiliensis on zymosan-induced arthritis in mice. Phytomedicine 2000, 7, 110.

155. Rios, J.L.; Giner, R.M.; Jimenez, M.J.; Wickman, G.; Hancke, J.L. A study on the anti-inflammatory activity of Cayaponia tayuya root. Fitoterapia 1990, 61, 275-278.

156. Peters, R.R.; Farias, M.R.; Ribeiro-Do-Valle, R.M. Anti-inflammatory and analgesic effects of curcubitacins from Wilbrandia ebracteata. Planta Med. 1997, 63, 525-528.

157. Almeida, F.R.C.; Rao, V.S.N.; Matos, M.E.O. Antiinflammatory, antitumour and antifertility effects in rodents of two nor-cucurbitacin glucosides from Wilbrandia species. Phytother. Res. 1992, 6, 189-193.

158. Nalvarte, E.L.; Kehl, H. Pharmacological characteristics of Trichipteris procera. Int. J. Crude Drug Res. 1990, 28, 97-102.

159. Siani, A.C.; Silva, A.M.P.; Nakamura, M.J.; de Carvalho, M.V.; Henriques, M.G.M.O.; Ramos, M.F.S.; Kaiser, C.R. Chemical composition and anti-inflammatory activity of the hydrodistillat from Mariscus pedunculatus. J. Braz. Chem. Soc. 2001, 12, 354-359.

160. Alexandre-Moreira, M.S.; Piuvezam, M.R.; Araujo, C.C.; Thomas, G. Studies on the anti-inflammatory and analgesic activity of Curatella americana L. J. Ethnopharmacol. 1999, 67, 171-177.

161. Monte, F.H.M.D.; Santos J.R.J.G.; Russi, M.; Lanziotti, V.M.N.B.; Leal, L.K.A.M.; Cunha, G.M.D.A. Antinociceptive and anti-inflammatory properties of the hydroalcoholic ectract of stems from Equisetum arvense L. In mice. Pharmacol. Res. 2004, 49, 239-243.

162. Chaves, C.G.; Schapoval, E.E.S.; Zuanazzi, J.A.; Diehl, E.; Siqueira, N.C.S.; Henriques, A.T. Erythroxylum argentinum: Assays for antiinflammatory activity. J. Ethnopharmacol. 1988, 22, 117-120.

163. Bighetti, E.J.B.; Hirum-Lima, C.A.; Gracioso, J.S.; Brito, A.R.M.S. Anti-inflamamtory and antinociceptive effects in rodents of the essential oil of Croton cajucara Benth. J. Pharm. Pharmacol. 1999, 51, 1447-1453.

164. Nardi, G.M.; Felippi, R.; Dalbo, S.; Siqueira-Junior, J.M.; Arruda, D.C.; Monache, F.D.; Timbola, A.K.; Pizzolatti, M.G.; Ckless, K.; Ribeiro-Dovalle, R.M. Anti-inflammatory and antioxidant effects of Croton celtidifolius bark. Phytomedicine 2003, 10, 176-184.

165. Miller, M.J.S.; Vergnolle, N.; Mc Knight, W.; Musah, R.A.; Davison, C.A.; Trentacostik, A.M.; Thompson, J.H.; Sandoval, M.; Wallace, J.L. Inhibition of neurogenic inflammation by the amazonian herbal medicine sangre de grado. J. Invest. Dermatol. 2001, 117, 725-730.

166. Risco, E.; Ghia, F.; Vila, R.; Iglesias, J.; Alvarez, E.; Caniqueral, S. Immunomodulatory activity and chemical characterisation of sangre de drago (dragon's blood) from Croton lechleri. Planta Med. 2003, 69, 785-794.

167. Suarez, A.I.; Compagnone, R.S.; Salazar-Bookaman, M.M.; Tillett, S.; Monache, F.D.; di Giulio, C.; Bruges, G. Antinociceptive and anti-inflammatory effects of Croton malambo bark aqueous extract. J. Ethnopharmacol. 2003, 88, 11-14.

168. Trebien, H.A.; Neves, P.C.A.; Yunes, R.A.; Calixto, J.B. Evaluation of pharmacological activity of a crude hydroalcoholic extract from Jatropha elliptica. Phytother. Res. 1988, 2, 115-118. 
169. Kassuya, C.A.L.; Silvestre, A.A.; Rehder, V.L.G.; Calixto, J.B. Anti-allodynic and anti-oedematogenic properties of the extract and lignans from Phyllanthus amarus in models of persistent inflammatory and neuropathic pain. Eur. J. Pharmacol. 2003, 478, 145-153.

170. Filho, V.C.; Santos, A.R.S.; de Campos, R.O.P.; Migueo, O.G.; Yunes, R.A.; Ferrari, F.; Messna, I.; Calixto, J.B. Chemical and pharmacological studies of Phyllanthus caroliniensis in mice. J. Pharm. Pharmacol. 1996, 48, 1231-1236.

171. Gorski, F.; Correa, C.R.; Filho, V.C.; Yunes, R.A.; Calixto, J.B. Potent antinociceptive activity of a hydroalcoholic extract of Phyllanthus corcovadensis. J. Pharm. Pharmacol. 1993, 45, 1046-1049.

172. Carvalho, J.C.T.; Santos, L.S.; Viana, E.P.; de Almeide, S.S.M.S.; Marconato, E.; Rodrigues, M.; Ferreira, L.R.; van de Kamp, A. Anti-inflammatory and analgesic activities of the crude extracts from stem bark on Bauhinia guianensis. Pharm. Biol. 1999, 37, 281-284.

173. Carvalho, J.C.T.; Teixeira, J.R.M.; Souza, P.J.C.; Bastos, J.K.; Filho, D.D.S.; Sarti, S.J. Preliminary studies of analgesic and anti-inflammatory properties of Caesalpinia ferrea crude extract. J. Ethnopharmacol. 1996, 53, 175-178.

174. Fernandes, R.M.; Pereira, N.A.; Paulo, L.G. Anti-inflammatory activity of copaiba balsam (Copaifera cearensis Huber). Rev. Bras. Farm. 1992, 73, 53-56.

175. Marchioro, M.; Blank, M.D.F.A.; Mourao, R.H.V.; Antoniolli, A.R. Anti-nociceptive activity of the aqueous extract of Erythrina velutina leaves. Fitoterapia 2005, 76, 637-642.

176. Miño, J.; Gorzalczany, S.; Moscatelli, V.; Ferraro, G.; Acevedo, C.; Hnatyszyn, O. Actividad antinociceptiva y antiinflammatoria de Erythrina crista-galli L. ("ceibo"). Acta Farm. Bonaerense 2002, 21, 93-98.

177. Backhouse, C.N.; Delporte, C.L.; Negrete, R.E.; Erazo, S.; Zuniga, A.; Pinto, A.; Cassels, B.K. Active constituents isolated from Psoralea glandulosa L. with antiinflammatory and antipyretic activities. J. Ethnopharmacol. 2001, 78, 27-31.

178. Carvalho, J.C.T.; Sertie, J.A.A.; Barbosa, M.V.J.; Patricio, K.C.M.; Caputo, L.R.G.; Sarti, S.J.; Ferreira, L.P.; Bastos, J.K. Anti-inflammatory activity of the crude extract from the fruits of Pterodon emarginatus Vog. J. Ethnopharmacol. 1999, 64, 127-133.

179. Lima, J.C.S.; Martins, D.T.O.; dve Souza, P.T., Jr. Experimental evaluation of stem bark of Stryphnodendron adstringens (Mart.) Coville for antiinflammatory activity. Phytother. Res. 1998, 12, 218-220.

180. Leal, L.; Matos, M.E.; Matos, F.J.A.; Rieiro, R.A.; Ferreira, F.V.; Viana, G.S.B. Antinociceptive and antiedematogenic effects of the hydroalcoholic extract and coumarin from Torresea cearensis Fr. All. Phytomedicine 1997, 4, 221-227.

181. Nadinic, E.; Gorzalczany, S.; Rojo, A.; van Baren, C.; Debenedetti, S.; Acevedo, C. Topical anti-inflammatory activity of Gentianella achalensis. Fitoterapia 1999, 70, 166-171.

182. Bispo, M.D.; Mourao, R.H.V.; Franzotti, E.M.; Bomfim, K.B.R.; Arrigoni Blank, M.D.F.; Moreno, M.P.N.; Marchioro, M.; Antoniolli, A.R. Antinociceptive and antiedematogenic effects of the aqueous extract of Hyptis pectinata leaves in experimental animals. J. Ethnopharmacol. 2001, 76, 81-86. 
183. Shimizu, M.; Shogawa, H.; Matsuzawa, T.; Yonezawa, S.; Hayashi, T.; Arisawa, M.; Suzuki, S.; Yoshizaki, M.; Morita, N.; Ferro, E.; Basualdo, I.; Berganza, L.H. Anti-inflammatory constituents of topically applied crude drugs. IV. Constituents and anti-inflammatory effect of Paraguayan crude drug "alhucema" (Lavandula latifolia Vill.). Chem. Pharm. Bull. 1990, 38, 2283-2284.

184. Bucar, F.; Knauder, E.; Schubert-Zsilavecz, M. Studies on the antiinflammatory principle of Mentzelia chilensis. Phytother. Res. 1998, 12, 275-278.

185. Morato, G.S.; Calixto, J.B.; Cordeiro, L.; de Lima, T.C.M.; Morato, E.F.; Nicolau, M.; Rae, G.A.; Takahashi, R.N.; Valle, R.M.R.; Yunes, R.A. Chemical and pharmacological studies on Talauma ovata St. Hil. (Magnoliaceae). J. Ethnopharmacol. 1989, 26, 277-286.

186. Franzotti, E.M.; Santos, C.V.F.; Rodrigues, H.M.S.L.; Mourao, R.H.V.; Andrade, M.R.; Antoniolli, A.R. Anti-inflammatory, analgesic activity and acute toxicity of Sida cordifolia L. (Malva-branca). J. Ethnopharmacol. 2000, 72, pp. 273-278.

187. Oga, S.; Sertie, J.A.; Brasile, A.C.; Hanada, S. Antiinflammatory effect of crude extract from Guarea guidonia. Planta Med. 1981, 42, 310-312.

188. Benencia, F.; Courreges, M.C.; Coulombie, F.C. Anti-inflammatory activities of Trichilia glabra aqueous leaf extract. J. Ethnopharmacol. 2000, 71, 293-300.

189. Batista-Lima, K.V.; Ribeiro, R.; Balestieri, F.M.P.; Thomas, G.; Piuvezam, M.R. Anti-inflammatory activity of Cissampleos sympodialis Eichl. (Menispermaceae) leaf extract. Acta Farm. Bonaerense 2001, 20, 275-279.

190. Lanhers, M.C.; Joyeux, M.; Soulimani, R.; Fleurentin, J.; Sayag, M.; Mortier, F.; Younos, C.; Pelt, J.M. Hepatoprotective and anti-inflammatory effects of a traditional medicinal plant of Chile, Peumus boldus. Planta Med. 1991, 57, 110-115.

191. Schapoval, E.E.S.; Silveira, S.M.; Miranda, M.L.; Alice, C.B.; Henriques, A.T. Evaluation of some pharmacological activities of Eugenia uniflora L. J. Ethnopharmacol. 1994, 44, 137-142.

192. Santos, F.A.; Rao, V.S.N.; Silveira, E.R. Anti-inflammatory and analgesic activities of the essential oil of Psidium guianense. Fitoterapia 1997, 68, 65-68.

193. Shimizu, M.; Shogawa, H.; Hayashi, T.; Arisawa, M.; Suzuki, S.; Yoshizaki, M.; Morita, N.; Ferro, E.; Basualdo, I.L.; Berganza, L.H. Anti-inflammotory constituents of topically applied crude drug. III. Constituents and anti-inflammatory effect of Paraguayan crude drug "tamanda cuna" (Cataesetum barbatum Lindle). Chem. Pharm. Bull. 1988, 36, 4447-4452.

194. Germano, D.H.P.; Caldeira, T.T.O.; Mazella, A.A.G.; Sertie, J.A.A.; Bacchi, E.M. Topical anti-inflammatory activity and toxicity of Petiveria alliaceae. Fitoterapia 1993, 64, 459-467.

195. Germano, D.H.P.; Sertie, J.A.A.; Bacchi, E.M. Pharmacological assay of Petiveria alliacea. Ii: Oral anti-inflammatory activity and gastrotoxicity of a hydroalcoholic root extract. Fitoterapia 1995, 66, 195-202.

196. Lopes-Martins, R.A.B.; Pegoraro, D.H.; Woisky, R.; Penna, S.C.; Sertie, J.A.A. The anti-inflammatory and analgesic effects of a crude extract of Petiveria alliacea L. (Phytolaccaceae). Phytomedicine 2002, 9, 245-248.

197. Arrigoni-Blank, M.F.; Dmitrieva, E.G.; Franzotti, E.M.; Antoniolli, A.R.; Andrade, M.R.; Marchioro, M. Anti-inflammatory and analgesic activity of Peperomia pellucida (L.) HBK (Piperaceae). J. Ethnopharmacol. 2004, 91, 215-218. 
198. D'angelo, L.C.A.; Zavier, H.S.; Torres, L.M.B.; Lapa, A.J.; Souccar, C. Pharmacology of Piper marginatum Jacq. a folk medicinal plant used as an analgesic, antiinflammatory and hemostatic. Phytomedicine 1997, 4, 33-40.

199. Palmeriro, N.S.; Almeida, C.E.; Ghedini, P.C.; Goulart, L.S.; Baldisserotto, B. Analgesic and anti-inflammatory properties of Plantago australis hydroalcoholic extract. Acta Farm. Bonaerense 2002, 21, 89-92.

200. Guillen, M.E.N.; Emim, J.A.S.; Souccar, C.; Lapa, A.J. Analgesic and antiinflammatory activities of the aqueous extract of Plantago major L. Int. J. Pharmacog. 1997, 35, 99-104.

201. Oliveira-Simoes, C.M.; Ribeiro-Do-Vale, R.M.; Poli, A.; Nicolau, M.; Zanin, M. Pharmacological investigation on Polygonum punctatum Elliot (P.Acre H.B.K) estracts. J. Pharm. Belg. 1989, 44, 275-284.

202. Erazo, S.; Garcia, R.; Bakchouse, N.; Lemus, I.; Delporte, I.C.; Andrade, C. Phytochemical and biological study of radal Lomatia hirsuta (Proteacea). J. Ethnopharmacol. 1997, 57, 81-83.

203. Delporte, C.L.; Bakchouse, C.N.; Erazo, S.; Negrete, R.E.; Silva, C.; Hess, A.; Munoz, O.; Garcia-Gravalos, M.D.; Feliciano, A.S. Biological activities and metabolites from Trevoa trinervis Miers. Phytother. Res. 1997, 11, 504-507.

204. Backhouse, N.; Delporte, C.; Negrete, R.; Suarez, S.; Cassels, B.K.; Breitmaier, E.; Schneider, C. Antiinflammatory and antipyretic metabolites of Acaena splendens. Int. J. Pharmacog. 1997, 35, 49-54.

205. Delporte, C.; Munoz, O.; Rojas, J.; Ferrandiz, M.; Paya, M.; Erazo, S.; Negrete, R.; Maldonado, S.; Feliciano, A.S.; Backhouse, N. Pharmaco-toxicological study of Kageneckia olblonga, Rosaceae. Z. Naturforsch. 2002, 57c, 100-108.

206. de Almeida, E.R.; de Santana, C.F.; de Mello, J.F. Anti-inflammatory activity of Coutarea hexandra. Fitoterapia 1991, 62, 447-448.

207. Piscoya, J.; Rodriguesz, Z.; Bustamante, S.A.; Okuhama, N.N.; Miller, M.J.S.; Sandoval, M. Efficacy and safety of freeze-dried cat's claw in osteoarthritis of the knee: mechanisms of action of the species Uncaria guianensis. Inflamm. Res. 2001, 50, 442-448.

208. Aguilar, J.L.; Rojas, P.; Marcelo, A.; Plaza, A.; Bauer, R.; Reininger, E.; Klass, C.A.; Merfort, I. Anti-inflammatory activity of two different extracts of Uncaria tomentosa (Rubiaceae). J. Ethnopharmacol. 2002, 81, 271-276.

209. Herrera, H.; Jorge, E. Procesamiento de la Uncaria tomentosa (willd.) Dc. Una de gato en imet-ipss. Biodivers. Salud 1998, 1, 32-37.

210. Sandoval-Chacon, M.; Thompson, J.H.; Zhang, X.J.; Liu, X.; Mannick, E.E.; Sadowska-Krowicka, H.; Charbonnet, R.M.; Clark, D.A.; Miller, M.S.J. Antiinflammatory actions of cat's claw: the role of nf-kb. Aliment. Pharmacol. Ther. 1998, 12, 1279-1289.

211. Centi, R.; Esquivel, C.; Pino, A. Fractionation of the methanolic extract of Uncaria tomentosa Willd D.C. And its relation with the anti-inflamamtory effect. Phytomedicine 2000, 7, 90.

212. Mur, E.; Hartig, F.; Eibl, G.; Schirmer, M. Randomized double blind trial of an extract from the pentacyclic alkaloid-chemotype of Uncaria tomentosa for the treatment of rheumatoid arthritis. J. Rheumatol. 2002, 29, 678-681.

213. Senatore, A.; Cataldo, A.; Iaccarino, F.P.; Elberti, M.G. Phytochemical and biological reserach on Uncaria tomentosa. Boll. Soc. Ital. Biol. Sper. 1989, 65, 517-520. 
214. Keplinger, K.; Laurs, G.; Wurm, M.; Dierich, M.P.; Teppner, H. Uncaria tomentosa (Willd.) D.C.-ethnomedicinal use and new pharmacological, toxicological and botanical results. J. Ethnopharmacol. 1999, 64, 23-34.

215. Miller, M.; Mehta, K.; Kunte, S.; Raut, V.; Gala, J.; Dhumale, R.; Shukla, A.; Tupalli, H.; Parikh, H.; Bobrowski, P.; Chadhary, J. Early relief of osteoarthritis symptoms with a natural mineral supplement and a herbomineral combination: A randomized controlled trial. J. Inflamm. 2005, 2, 14.

216. Villalba, M.A.; Carmo, M.I.; Leite, M.N.; Sousa, O.V. Pharmacological activities of Zanthoxylum chiloperone (Rutaceae) extracts. Rev. Bras. Farmacogn. 2007, 17, 236-241.

217. Khalil, N.M.; Sperotto, J.S.; Manfron, M.P. Antiinflammatory activity and acute toxicity of Dodonaea viscose. Fitoterapia 2006, 77, 478-480.

218. Almeida, R.N.; Barbosa Filho, J.M.; Naik, S.R. Chemistry and pharmacology of an ethanol extract of Bumelia sartorum. J. Ethnopharmacol. 1985, 14, 173-185.

219. Freire, S.M.D.F.; Emim, J.A.D.S.; Torres, L.M.B. Analgesic and antiinflammatory properties of Scoparia dulcis L. extracts and glutinol in rodents. Phytother. Res. 1993, 7, 408-414.

220. Hammarlund, E.R. Occurrence of a weak anti-inflammatory substance in Simaba cedroon seed. J. Pharm. Sci. 1963, 52, 204.

221. Iyer, R.P.; Brown, J.K.; Chaubal, M.G.; Malone, M.H. Brunfelsia hopeana I: Hippocratic screening and antiinflammatory evaluation. Lloydia 1977, 40, 356-360.

222. Iyer, R.P.; Chaubal, M.G. Brunfelsia hopeana-pharmacologic screening: Isolation and characterization of hoppeanine. Diss. Abstr. Int. B 1978, 39, 761.

223. Delporte, C.; Backhouse, N.; Negrete, R.; Salinas, P.; Rivas, F.; Cassels, B.K.; San Feliciano, A. Antipyretic, hypothermic and antiinflammatory activities and metabolites from Solanum ligustrinum Lood. Phytother. Res. 1998, 12, 118-122.

224. Vieira, J.R.G.; Ferreira, P.M.; Matos, L.G.; Ferreira, E.C.; Rodovalho, W.; Ferri, P.H. Anti-inflammatory effect of Solanum lycocarpum fruits. Phytother. Res. 2003, 17, 892-896.

225. Antonio, M.A.; Souza Brito, A.R.M. Oral anti-flammatory and anti-ulcerogenic activities of a hydroalcoholic extract and partitioned fractions of Turnera ulmifolia (Turneraceae). J. Ethnopharmacol. 1998, 61, 215-228.

226. Costa, V.B.; Coube, C.S.; Marinho, B.G.; Matheus, M.E.; Leitão, S.G.; Fernandes, P.D. Anti-inflammatory and analgesic activity of Bouchea fluminensis. Fitoterapia 2003, 74, 364-371.

227. Schapoval, E.E.S.; de Vargas, M.R.W.; Chaves, C.G.; Bridi, R.; Zuanazzi, J.A.; Henriques, A.T. Antiinflammatory and antinociceptive activities of extracts and isolated compounds from Stachytarpheta cayennensis. J. Ethnopharmacol. 1998, 60, 53-59.

228. Mesia-Vela, S.; Souccar, C.; Lima-Landman, M.T.R.; Lapa, A.J. Pharmacological study of Stachytarpheta cayennensis Vahl in rodents. Phytomedicine 2004, 11, 616-624.

229. Tratsk, K.S.; Campos, M.M.; Vaz, Z.R.; Filho, V.C.; Schlemper, V.; Yunes, R.A.; Calixto, J.B. Anti-allergic effects and oedema inhibition caused by the extract of Drymis Winteri. Inflamm. Res. 1997, 46, 509-514. 
230. Penna, S.C.; Medeiros, M.V.; Aimbire, F.S.C.; Faria-Neto, H.C.C.; Sertie, J.A.A.; Lopes-Martins, R.A.B. Anti-inflammatory effect of the hydralcoholic extract of Zingiber officinale rhizomes on rat paw and skin edema. Phytomedicine 2003, 10, 381-385.

231. Pedernera, A.M.; Guardia, T.; Calgeron, C.G.; Rotelli, A.E.; de la Rocha, N.E.; di Genaro, S.; Pelzer, L.E. Anti-ulcerogenic and anti-inflammatory activity of the methanolic extract of Larrea divaricata Cav. in rat. J. Ethnopharmacol. 2006, 105, 415-420.

232. Martino, R.F.; Davicino, R.C.; Mattar, M.A.; Casali, Y.A.; Correa, S.G.; Anesini, C. Micalizzi, B. In vitro immunomodulatory effects of fractions obtained from aqueous extraxts of Larrea divaricata Cav (Jarilla) on mouse peritoneal macrophages. Immunopharmacol. Immunotoxicol. 2010, 32, 125-132.

(C) 2011 by the authors; licensee MDPI, Basel, Switzerland. This article is an open access article distributed under the terms and conditions of the Creative Commons Attribution license (http://creativecommons.org/licenses/by/3.0/). 